\title{
A Review on the Synthesis and Functionalization of Gold Nanoparticles as a Drug Delivery Vehicle
}

This article was published in the following Dove Press journal:

International Journal of Nanomedicine

\section{Sundus Jabeen Amina' Bin Guo (iD) ${ }^{2}$}

\author{
'Atta-ur-Rahman School of Applied \\ Biosciences (ASAB), National University \\ of Sciences and Technology (NUST), \\ Islamabad, Pakistan; ${ }^{2}$ Department of \\ Pharmacological \& Pharmaceutical \\ Sciences, University of Houston, \\ Houston, TX 77204, USA
}

\begin{abstract}
Metal nanoparticles are being extensively used in biomedical fields due to their small size-to-volume ratio and extensive thermal stability. Gold nanoparticles (AuNPs) are an obvious choice for biomedical applications due to their amenability of synthesis, stabilization, and functionalization, low toxicity, and ease of detection. In the past few decades, various chemical methods have been used for the synthesis of AuNPs, but recently, newer environment friendly green approaches for the synthesis of AuNPs have gained attention. AuNPs can be conjugated with a number of functionalizing moieties including ligands, therapeutic agents, DNA, amino acids, proteins, peptides, and oligonucleotides. Recently, studies have shown that gold nanoparticles not only infiltrate the blood vessels to reach the site of tumor but also enter inside the organelles, suggesting that they can be employed as effective drug carriers. Moreover, after reaching their target site, gold nanoparticles can release their payload upon an external or internal stimulus. This review focuses on recent advances in various methods of synthesis of AuNPs. In addition, strategies of functionalization and mechanisms of application of AuNPs in drug and bio-macromolecule delivery and release of payloads at target site are comprehensively discussed.
\end{abstract}

Keywords: gold nanoparticles, drug delivery, biological synthesis, functionalization, drug release

\section{Introduction}

Nanotechnology is referred to the designing and application of components which occur at the nano-scale: up to $10-1,000 \mathrm{~nm}$ in size. ${ }^{1}$ Nanotechnology encompasses the study of structural properties of nano-structures at the molecular and submolecular level along with their electrical, optical, and magnetic attributes. At present, nanotechnology is an interdisciplinary field which takes engineering, biomedicine, chemistry, and physics under one umbrella. ${ }^{2}$ The application of nanomaterials in different fields ranging from oil and gas and cosmetics to nanomedicine has taken this world to the new era, which is the era of nanotechnology. ${ }^{3,4}$ The best investigated nanostructures include carbon nanotubes, gold nanoparticles, liposomes, and paramagnetic nanostructures. ${ }^{5-8}$ Gold colloids are now increasingly utilized in different fields like chemistry, biology, engineering, and medicine. In the biomedical field they have vast applications in diagnostics, therapy, and immunology. ${ }^{9}$

Gold nanoparticles provide an outstanding material for study due to the fact that they are one of the most stable, non-toxic, and easy to synthesize nanoparticles and exhibit various fascinating properties like assembly of various types and quantum size
Correspondence: Bin Guo; Sundus Jabeen Amina

Email bguo@central.uh.edu; sundus.jabeenamina@gmail.com
International Journal of Nanomedicine 2020:15 9823-9857

9823

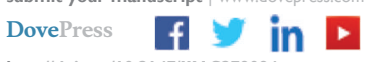

http://doi.org/| $0.2147 / \mid I N$.S279094 
effect. ${ }^{6}$ The optical behavior of gold nanoparticles is dependent on their surface plasmon resonance (SPR), located in a wide region ranging from visible to the infrared region of the spectrum, which is determined by collective oscillation of conducting electrons. The range of the spectrum depends on various features of gold nanoparticles, including size and shape. ${ }^{9}$ Methods have been developed to synthesize these materials reproducibly, which can further be modified using countless chemical functional groups. Many new sensitive and specific assays are based on the gold nanoconjugates.

Gold nanoparticles have emerged as an excellent candidate for the application in delivery of various payloads to the target site. ${ }^{10,11}$ These payloads range from small drug molecules including drugs to large biomolecules like DNA, RNA, and proteins. Some drugs molecules do not require modification of a monolayer of gold nanoparticles for their delivery and can be directly conjugated with gold nanoparticles through physical absorption and ionic or covalent bonding. ${ }^{12}$ Whereas for the delivery of other payloads, gold nanoparticles require functionalization like PEGlyation, ${ }^{13}$ peptide and amino acid conjugation, ${ }^{14,15}$ or functionalization with oligonucleotides. ${ }^{16}$ Apart from that, another prerequisite for the efficient delivery of therapeutic agents is their release. Various internal stimuli (glutathione, $\mathrm{pH}$ and enzymes) ${ }^{17-19}$ and external stimuli (light, etc. $)^{20}$ have been investigated for the efficient release of these payloads from gold nanoparticles.

Due to the vast amount of information available and the level at which it is being renewed we have chosen the generalized data from the past few years to present this review encompassing the most promising application of gold nanoparticles in drug delivery.

\section{Synthesis of AuNPs}

For the synthesis of AuNPs, there are two basic strategies that are used, which are "Top-Down" and "Bottom-Up" approaches. The top-down approach involves the synthesis of AuNPs starting from bulk material and cracking it into nanoparticles using different methods. In contrast, the bottom-up approach synthesizes nanoparticles starting from atomic level. Figure 1 shows the basic steps that are involved in the top-down and bottom-up approaches. Synthesis methods that involve the top-down approach include laser ablation, ${ }^{21}$ ion sputtering, ${ }^{22} \mathrm{UV}$ and IR irradiation, ${ }^{23,24}$ and aerosol technology, ${ }^{25}$ whereas the reduction of $\mathrm{Au}^{3+}$ to $\mathrm{Au}^{0}$ is the bottom-up approach.

The formulation of AuNPs involves two main stages:
In the first stage the gold precursor, which is usually an aqueous gold salt solution, is reduced to gold nanoparticles using a specific reducing agent like citrate.

In the second stage the stabilization of gold nanoparticles is done by a specific capping agent. The capping agents hinder the agglomeration of metallic nanoparticles.

\section{Chemical Synthesis}

\section{Turkevich Method}

This method for the synthesis of AuNPs was first reported in 1951. It is one of the most commonly used techniques for formulation of spherical AuNPs. AuNPs prepared using this method have the size in the range of 1-2 $\mathrm{nm} .{ }^{26}$ The basic principle of this technique involves the reduction of gold ions $\left(\mathrm{Au}^{3+}\right)$ to produce gold atoms $\left(\mathrm{Au}^{0}\right)$ by using some reducing agents like amino acids, ${ }^{27}$ ascorbic acid, ${ }^{28}$ UV light, or citrate. ${ }^{29,30}$ Stabilization of AuNPs is carried out by using different capping/stabilizing agents. At the beginning, the applications of Turkevich method were finite because of the limited range of AuNPs that could be synthesized by this technique. With the passage of time several advancements in the basic method have enabled researchers to extend the size range of particles synthesized using this method. In 1973, it was established that by varying the ratio of reducing as well as stabilizing agents, AuNPs of particular size with the range from 16-147 nm can be produced. ${ }^{31-33}$ Figure 2A shows the basic method involved in the Turkevich method.

\section{The Brust Method}

This method was first reported in 1994 and involves a twophase reaction to synthesize AuNPs with the size range of $1.5-5.2 \mathrm{~nm}$ by using organic solvents. ${ }^{34}$ The method encompasses the use of a phase transfer such as tetraoctylammonium bromide to carry out transferring of gold salt to organic solvent from its aqueous solution (eg, toluene). The gold is then reduced by the use of a reducing agent such as sodium borohydride along with an alkanethiol. The alkanethiol carries out the stabilization of AuNPs. ${ }^{35}$ As a result of this reaction the color changes from orange to brown. ${ }^{34,36}$ Figure 2B shows the schematic illustration of main steps involved in Brust method.

\section{Seed-Mediated Growth}

The previous two methods can synthesize only spherical AuNPs; however, they can also be formulated in a number of geometries and shape such as rods. ${ }^{37,38}$ The most commonly used technique to synthesize rod shaped AuNPs is 


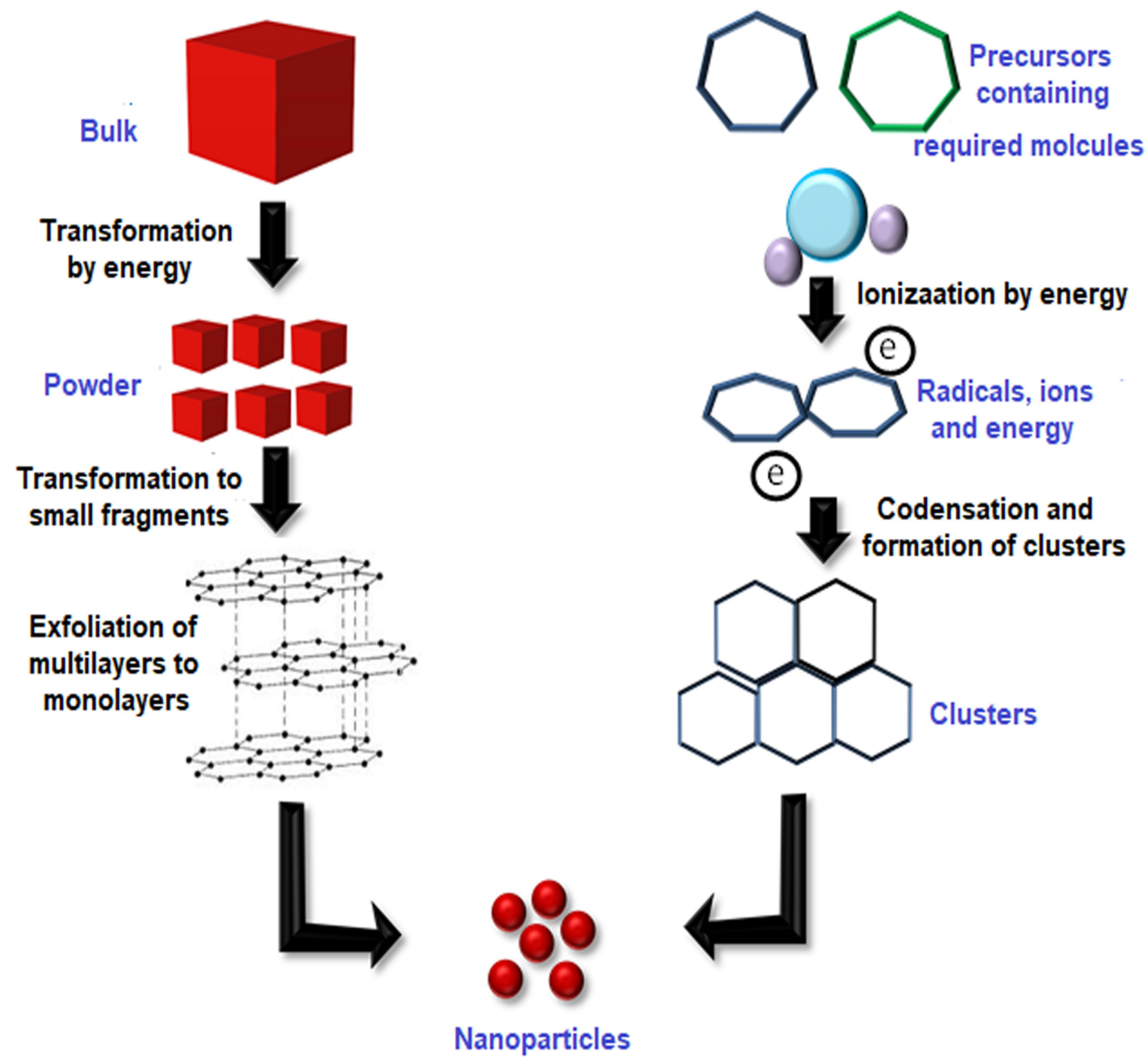

Figure I Top-down and bottom-up approaches for the synthesis of NPs. The top-down approach involves the transformation of bulk material by using energy to produce the powder form which is then transformed into smaller fragments with multiple layers and then to the monolayers leading to the formation of nanoparticles. On the other hand, the bottom-up approach uses the precursor molecules which are then ionized by using energy. Radicals, ions, and electrons thus produced are condensed to form clusters which are then transformed to nanoparticles.
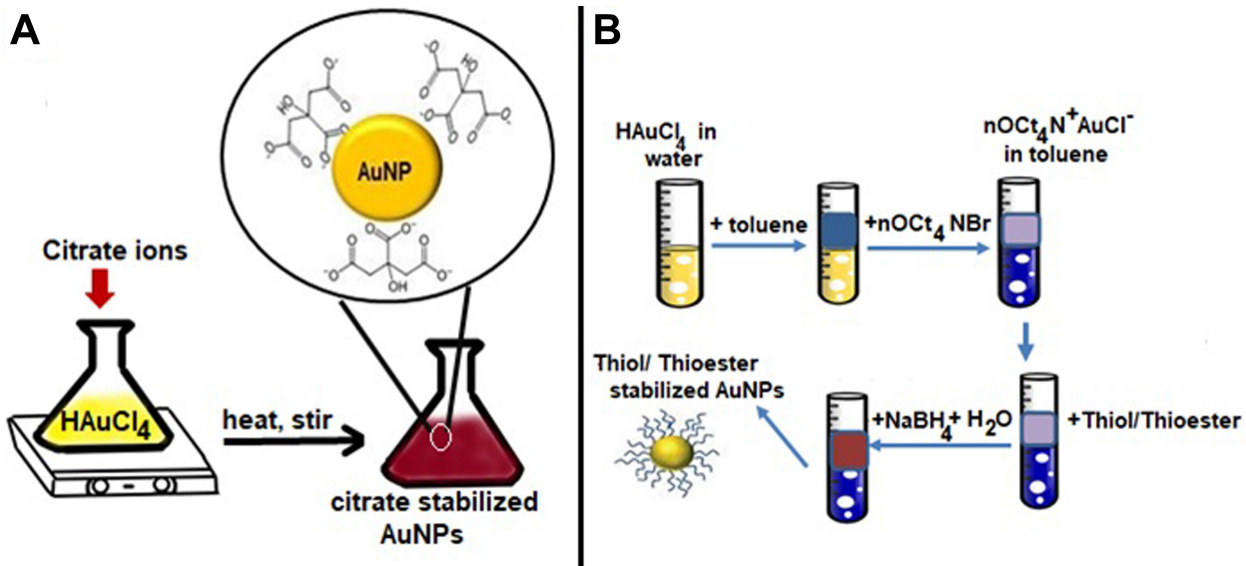

Figure 2 (A) Turkevich method for the synthesis of AuNPs. (B) Series of steps involved in the Burst method for the synthesis of AuNPs.

seed-mediated growth. This method is based on the fundamental principle which involves first synthesizing seed particles by reducing gold salts. This reaction is done in the presence of reducing agents like $\mathrm{NaBH}_{4}$. The next step involves the transferring of the seed particles to a metal salt and a weak reducing agent like ascorbic acid which prevents further nucleation and speeds up the synthesis of AuNPs of rod shape. Shape and geometry of gold 
nanoparticles depends on the concentration of reducing agents and seeds. Figure $3 \mathrm{~A}$ shows schematic illustration of seed-mediated growth of short and long gold nanorods as reported by a study. ${ }^{39}$

\section{Digestive Ripening}

Digestive ripening is considered to be a convenient method to prepare monodispersed gold nanoparticles in the presence of excessive ligands (digestive ripening agents). The basic process comprises heating a colloidal suspension at high temperatures $\left(\sim 138^{\circ} \mathrm{C}\right)$ for 2 minutes and then heating at $110^{\circ} \mathrm{C}$ for 5 hours by using alkanethiol, as shown in Figure 3B. Temperature is the major factor for determining the size distribution of the gold colloids. ${ }^{40}$

In addition to these methods, other methods involve the use of ultrasonic waves for the synthesis of AuNPs. ${ }^{41,42}$

\section{Advantages and Limitations of the Methods}

Turkevich method is a fairly uncomplicated and reproducible procedure for the formulation of spherical particles with the size range $10-30 \mathrm{~nm}$. But, as the size of particles increases above $30 \mathrm{~nm}$, they become less spherical in shape with broader size distribution. Moreover, this reaction gives low yield and involves the use of only water as a solvent. ${ }^{43}$ Brust method, on the other hand, involves an easy strategy for the formulation of thermal and air-stable AuNPs having controlled size and less dispersity. One possible limitation of Brust method is synthesis of AuNPs which are less dispersed and used of organic solvents immiscible with water, therefore, limiting their biological applications. ${ }^{44}$ Seed-mediated growth is a reliable method for the synthesis of rod-shaped AuNPs, but various factors affect the size of rod and so must be carefully controlled. In a study when higher concentrations of $\mathrm{HAuCl}_{4}$ were used it produced bigger seed rods with smaller aspect ratios. Temperature also plays a significant role in the synthesis of rods and at higher temperatures rods with lower aspect ratio were produced. Also, the number of seeds added to the reaction mixture must be critically considered to stimulate the growth of rods. ${ }^{45}$ The digestive ripening method is also an easy and valuable
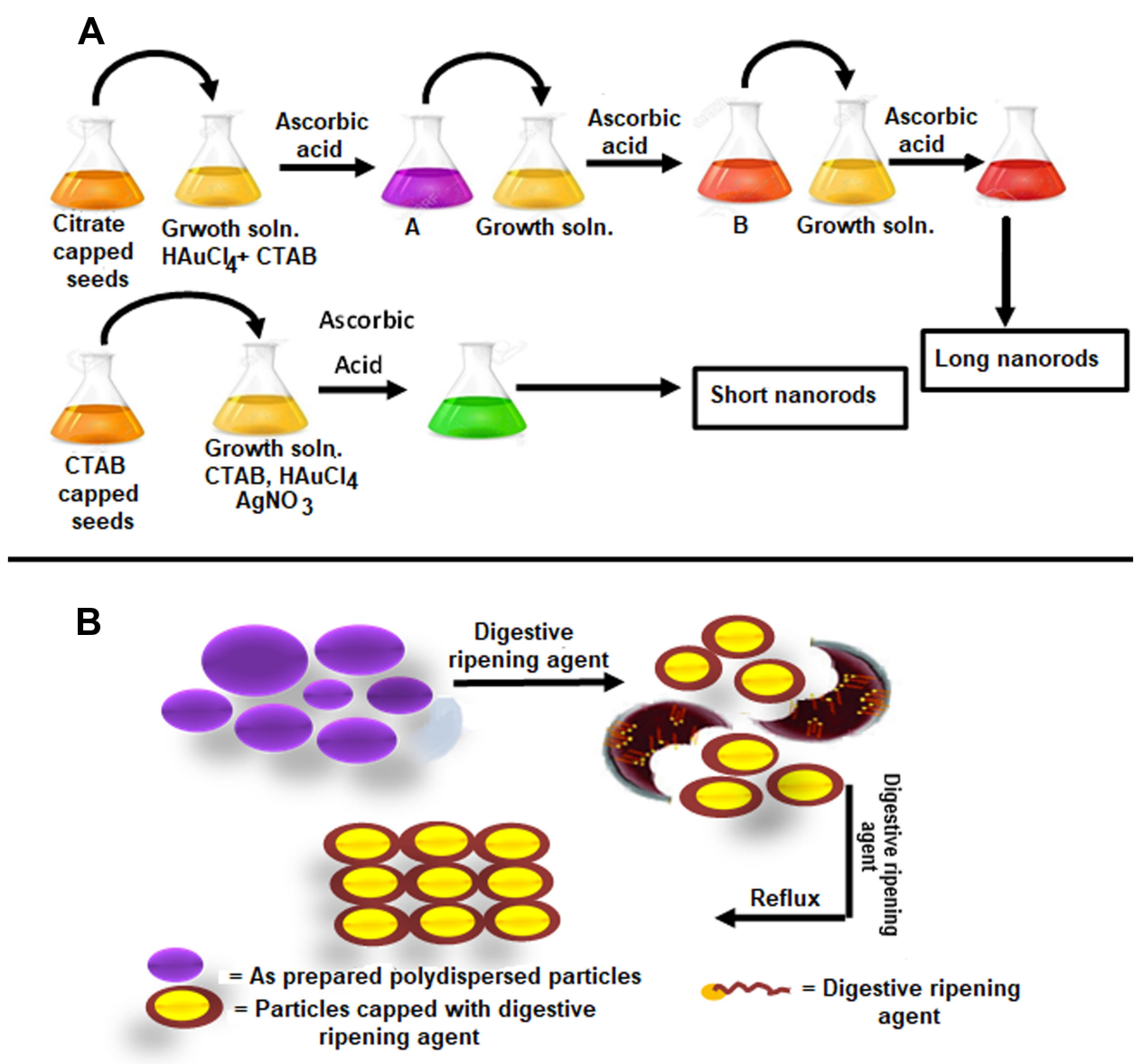

Figure 3 Series of steps involved in the synthesis of AuNPs. (A) Seed-mediated method. (B) Digestive ripening method. 
chemical technique to produce monodispersed nanoparticles. Another benefit of this strategy is the high yield of nanoparticles. ${ }^{46}$ A possible disadvantage of the digestive ripening method is that controlling the shape of nanoparticles via the digestive ripening process is difficult as it involves very high temperatures. ${ }^{47}$

In addition, chemical methods are inherited with their own limitations which include environmental and biocompatibility concerns. Some of the chemicals that are used in the synthesis of gold nanoparticles during chemical synthesis can affect our environment and are the cause of risks for administering them into the living organisms, thus limiting the biological applications of such NPs. ${ }^{48}$ Therefore, various biological methods have been devised for the synthesis of AuNPs to limit these concerns.

\section{Biological Synthesis}

Recently, efforts have been made for biological synthesis of AuNPs, which is a clean, dependable, and bio-friendly alternative to harsh chemicals used in chemical synthesis reactions. The biological resources used in synthesis of nanoparticle range from simple bacterial cells to complex eukaryotes. Interestingly, the capability of organisms in synthesis of metal nanoparticles has given rise to a new thrilling approach toward the development of these biological nano-factories. ${ }^{49}$ A plethora of organisms have been reported to carry out successful synthesis of AuNPs, ranging from bacteria to plants, algae, and fungi.

\section{Bacteria}

Microorganisms have been reported to be an excellent candidate for the synthesis of both intracellular and extracellular AuNPs. ${ }^{50-52}$ The negatively charged cell wall of bacteria can electrostatically interact with positively charged $\mathrm{Au}(\mathrm{III})$ ions. During the intracellular synthesis, gold ions are transported inside the cell where enzymes and biomolecules carry out the synthesis of AuNPs. On the other hand, during extracellular synthesis the gold ions are trapped on the cell membrane by membrane enzymes. These enzymes on the membrane or reductase enzymes secreted out by the microbial cell can carry out the synthesis process outside the bacterial cell. ${ }^{53}$ Extracellular synthesis, however, is more fascinating as it does not require extra downstream processing steps which are required for the separation of nanoparticles from the intracellular matrix. A study has shown that, during the extracellular synthesis reaction NADPH-dependent enzymes are secreted by bacteria which can reduce $\mathrm{Au}$ (III) ions to
$\mathrm{Au}^{0}$ such as nitrate reductase secrete by Pseudomonas denitrificans. The results showed that the action reductase enzyme diminished once AuNPs had been synthesized. ${ }^{54}$ Shah et $\mathrm{al}^{55}$ reported that both NADH and NADHdependent enzymes function as a scaffold or nucleating agent for the synthesis reaction. Singh et al reported that Rhodopseudomonas capsulate secreted NADH and NADH-dependent enzymes during extracellular synthesis of AuNPs. The transfer of electrons from NADH carried by NADH-dependent enzyme causes the reduction of $\mathrm{Au}(\mathrm{III})$ to $\mathrm{Au}^{0}$, resulting in the synthesis of AuNPs. ${ }^{51}$ Thermomonospora sp. (Order: Actinomycetes) was reported to carry out intracellular enzymes mediated synthesis of AuNPs by achieving the reduction of $\mathrm{Au}$ (III) ions at the surface of membrane and mycelia. ${ }^{56}$ Similarly, Shewanella algae efficiently carried out enzymes mediated bioreduction of $\mathrm{AuCl}^{4-}$ ions to AuNPs which were found to be dispersed in periplasmic membrane of bacterium. ${ }^{57}$ Certain materials produced by microbial cells like proteins, enzymes, and organic substances can act as capping agents to stabilize nanoparticles and, hence, prevent their agglomeration. ${ }^{58}$ Micro-organisms possess certain reductase enzymes which can reduce metal salts to metal nanoparticles with narrow size distributions and monodispersity. By altering the essential growth parameters, the shape and size of AuNPs can be controlled. Synthesis of AuNPs using bacteria is a tedious reaction and requires additional precautionary measures while handling bacteria, and also takes hours and days as bacterial cultural is a time consuming process. These drawbacks have limited the use of bacteria for the synthesis of AuNPs. ${ }^{59}$

\section{Fungi}

Fungi have also been used as a biological source for the synthesis of AuNPs. Fungi secrete a number of biomolecules, including metabolites and extracellular enzymes, such as hemicellulose, acetyl xylem esterase, 3-glucanase, cell wall lytic enzyme $\beta-1$, etc., which have been reported to play a role during the synthesis of metallic nanoparticles. ${ }^{60}$ Numerous studies have reported the synthesis of gold nanoparticles using unicellular and multicellular fungi. ${ }^{61,62}$ A fungal species Fusarium oxysporum was used in a study for the extracellular synthesis of AuAg alloy NPs by the reduction action of nitrate-dependent enzyme and shuttle quinone. ${ }^{63}$ A fungal species Verticillium has also been reported to carry out intracellular synthesis of AuNPs. AuNPs were found to be trapped 
in the cell membrane and the cell wall of fungi, indicating that $\mathrm{Au}^{3+}$ ions were bio-reduced by the reduction action of reductase enzymes in fungi. ${ }^{64} \mathrm{~A}$ study on the biosynthesis of AuNPs from Phanerochaete chrysosporium proved that laccase was the enzyme secreted by the fungi for extracellular synthesis of AuNPs and, for intracellular synthesis, ligninase was found to be responsible. ${ }^{65}$

\section{Plants}

Phytonanotechnology has gained attention with time as it comprises an eco-friendly, cheap, and rapid process for the synthesis of nanoparticles. A number of studies have reported biosynthesis of AuNPs using different plants or plant extracts involving the use of harmless biocomponents from plants to carry out the reduction and capping of AuNPs, reducing the waste generation and limiting the requirement for additional purification steps. Numerous bio-components present in plants such as flavonoids, phytosterols, quinones, etc., play a role in the synthesis of AuNPs because of the functional groups which speed up the reduction and stabilization of AuNPs. ${ }^{66}$ Although nearly every part of plants has been reported to successfully carry out the synthesis of AuNPs, leaves are most commonly used. The difference in the level of various compounds present in different plants and even in different parts of a plant affects the synthesis of AuNPs. For example, a study has reported the effect of difference in level of phenolic contents present in leaves and fruit of Garcinia mangostana plant on the synthesis of AuNPs. As the leaves are rich in phenolic content so the rate of synthesis of AuNPs was faster in the presence of leaves than fruit. ${ }^{67,68}$ Moreover, recently the synthesis of gold nanoparticles using medicinal plant Acorus calamus and Cassia auriculate has been reported. ${ }^{69,70}$

Reactive compounds; Lignans [(+)-pinoresinol, $(+)-$ medioresinol], alkaloids, flavonoids, steroids (sitosterol3-0-glucoside), and terpenoids present in the leaves of Justicia glauca have been reported to complete the synthesis reaction of AuNPs in 1 hour. AuNPs had spherical and hexagonal morphology and were $32 \mathrm{~nm}$ in size. ${ }^{71}$ Leaves of the Terminalia arjuna plant also carried out the synthesis of AuNPs within 15 minutes. AuNPs synthesized in this study were $20-50 \mathrm{~nm}$ in size and had spherical morphology. The author claimed that the reactive compounds Arjunetin, leucoanthoc-yanidins and hydrolysable tannins present in leaves of Terminalia arjuna contributed to the synthesis of AuNPs. ${ }^{72}$ Similarly, the leaves of olive plant and Cassia auriculata were shown to complete the synthesis reaction of AuNPs in 20 minutes and 10 minutes, respectively. The active metabolites and biomolecules in the leaves of the olive plant are proteins, oleuropein, apigenin-7-glucoside, and luteolin-7-glucoside, which resulted in the formation of spherical and anisotropic AuNPs with the size range of $50-100 \mathrm{~nm}^{73}$ Polysaccharides and flavonoids are the major active substances in the leaves of Cassia auriculata and AuNPs synthesized from leaves of this plant were $15-25 \mathrm{~nm}$ in size and had spherical and anisotropic morphology. ${ }^{70}$ Mangifera indica leaves used by Philip ${ }^{74}$ synthesized spherical AuNPs within 2 minutes of reaction time. The size of AuNPs was found to be in the range of 17-20 nm. Terpenoids, flavonoids, and thiamine are the active compounds present in mango fruit, which might have contributed to the synthesis of AuNPs.

Apart from leaves, various other parts of plants, including fruits, roots, stems, etc., have been used for the synthesis of AuNPs. The fruit of Citrus maxima was used in one study and synthesized spherical AuNPs with the size range of 15-35 nm within 5 minutes of reaction time. Proteins, terpenes, and ascorbic acid were the major compounds that were claimed to act as reducing agents during reaction. ${ }^{75}$ The high phenolic content of Sambucus nigra (elderberry) was the major factor in the synthesis of AuNPs. ${ }^{76}$ Apart from that, flowers of Lonicera Japonica contain amino acids as active compounds and successfully synthesized AuNPs of triangular and tetrahedral morphology with the size range of $8 \mathrm{~nm}$ in the reaction time of 1 hour. ${ }^{77}$ Similarly flowers of the Moringa oleifera plant synthesized AuNPs of size 3-5 nm. This plant was reported to contain a high content of flavonoids, carotenoids, phenols, sterols, and amino acids, which were claimed to be responsible for carrying out the reduction reaction during the synthesis process. $^{78}$ Various types of roses have been demonstrated to possess the reducing ability for the synthesis of AuNPs. ${ }^{79,80}$ Similarly, banana and mango peels can synthesize AuNPs with the sizes $50 \mathrm{~nm}$ and $6.03 \pm 2.77$ to $18.01 \pm 3.67 \mathrm{~nm}$, respectively. Banana peels synthesized spherical shaped AuNPs and mango peel synthesized quasi-spherical shaped AuNPs. The reaction time for both processes was 20 and 25 minutes, respectively. ${ }^{81,82}$ Apart from the above-mentioned parts of plants, rhizomes of turmeric, ${ }^{83}$ yam beans, ${ }^{84}$ ginger, ${ }^{85}$ and seeds of cocoa, ${ }^{86}$ pulp of green pepper, ${ }^{87}$ bark of bay cedar, ${ }^{88}$ galls of zebra wood, ${ }^{89}$ latex of Hevea brasiliensis, ${ }^{90}$ nuts of Areca catechu, ${ }^{91}$ and effluent from palm oil mill ${ }^{92}$ were found to carry out the synthesis of AuNPs. 


\section{Algae}

There are a few studies which have demonstrated the synthesis of gold NPs using algae. A few species of both marine and fresh algae were used in these studies. Among the marine red algae, Gracilaria corticata, ${ }^{93}$ Acanthophora spicifera, ${ }^{94}$ and Galaxaura elongata, ${ }^{95}$ and marine brown algae, Stoechospermum marginatum, ${ }^{96}$ Ecklonia cava, ${ }^{97}$ Sargassum wightii, ${ }^{98}$ Cystoseira baccata, ${ }^{99}$ Laminaria japonica, ${ }^{100}$ and Turbinaria conoides ${ }^{101}$ have been previously reported to carry out the synthesis of AuNPs. On the other hand, biomass from freshwater algae including Prasiola crispa,${ }^{102}$ Lemanea fluviatilis, ${ }^{103}$ and Chlorella pyrenoidusa $^{104}$ can also synthesize AuNPs. Previous studies have shown that hydroxyl and carbonyl groups present in algal biomass can act as reducing agents for carrying out the synthesis of AuNPs. It has also been shown that these group can also act as the capping agent for gold nanoparticles. ${ }^{105-107}$ Table 1 shows the list of various organisms that have been reported to carry out successful synthesis of AuNPs.

\section{Biomolecules}

Molecules synthesized by living organisms to speed up their biological processes of the body are known as biomolecules and these include macromolecules such as amino acids, nucleic acids, carbohydrates, and lipids. Previous studies have reported the synthesis of gold nanoparticles using chitosan which does not only act as a reducing agent but also as a stabilizing agent during synthesis reaction. ${ }^{108}$ Apart from that, starch is another polysaccharide used for the synthesis of AuNPs. In an alkaline environment starch can be degraded into short chains having carboxyl groups and the $-\mathrm{OH}$ group of carboxylic acid can reduce $\mathrm{Au}^{3+}$ ions to gold nanoparticles. ${ }^{109}$ Among proteins, consensus sequence tetratricopeptide repeat proteins and corn protein, $\alpha$-zein can be used to carry out the synthesis reaction of AuNPs. ${ }^{110,111}$ The biological method of synthesis of AuNPs can conveniently overcome the complications of biosafety of the chemicals used for the generation of AuNPs.

\section{Advantages and Limitations of Biological Synthesis}

Synthesis of AuNPs using biomass from bacteria is an advantageous process as some species of bacteria are not affected by the presence of heavy metals. Also, the extracellular synthesis approach produces pure nanoparticles as compared to the intracellular synthesis process which requires additional purification steps. Conversely, culturing of bacteria is a slow and tedious process so the
Table I Various Types of Living Organisms That Can Carry Either Intracellular or Extracellular Synthesis of AuNPs

\begin{tabular}{|c|c|c|c|}
\hline Name of Organism & $\begin{array}{l}\text { Intra/ } \\
\text { Extracellular }\end{array}$ & $\begin{array}{l}\text { Reaction } \\
\text { Type }\end{array}$ & References \\
\hline \multicolumn{4}{|l|}{ Bacteria } \\
\hline $\begin{array}{l}\text { Deinococcus } \\
\text { radiodurans }\end{array}$ & Extra/intra & Reduction & {$[311]$} \\
\hline Bacillus cereus & Extra & Reduction & [50] \\
\hline $\begin{array}{l}\text { Pseudomonas } \\
\text { aeruginosa }\end{array}$ & Extra & Reduction & {$[3 \mid 2]$} \\
\hline $\begin{array}{l}\text { Rhodopseudomonas } \\
\text { capsulate }\end{array}$ & Extra & Reduction & [5। $]$ \\
\hline Rhodococcus & Intra & Reduction & {$[3 \mid 3]$} \\
\hline Marinobacter pelagius & Extra & Reduction & [52] \\
\hline Bacillus megaterium & Extra & Reduction & {$[112]$} \\
\hline \multicolumn{4}{|l|}{ Fungi } \\
\hline Neurospora crassa & Intra & Reduction & [61] \\
\hline Trichothecium sp. & Extra/Intra & Reduction & {$[3 \mid 4]$} \\
\hline Candida albicans & Extra & Reduction & {$[315]$} \\
\hline $\begin{array}{l}\text { Penicillium } \\
\text { brevicompactum }\end{array}$ & Extra/Intra & Reduction & {$[316]$} \\
\hline \multicolumn{4}{|l|}{ Algae } \\
\hline Rhizoclonium fontinale & Intra & Reduction & {$[3 \mid 7]$} \\
\hline Sargassum wightii & Extra & Reduction & [98] \\
\hline Tetraselmis kochinensis & Intra & Reduction & {$[3 \mid 8]$} \\
\hline Prasiola crispa & Extra & Reduction & [102] \\
\hline Shewanella & Extra & Reduction & [319] \\
\hline \multicolumn{4}{|l|}{ Plants } \\
\hline Magnolia kobus & Extra & Reduction & [320] \\
\hline Sesbania drummondii & Intra & Reduction & {$[321]$} \\
\hline Coriandrum sativum & Extra & Reduction & [322] \\
\hline Tanacetum vulgare & Extra & Reduction & [323] \\
\hline Abelmoschus esculentus & Extra & Reduction & [324] \\
\hline
\end{tabular}

synthesis reaction of AuNPs can take a long time comprising hours and even days. On the other hand, fungi produce a large quantity of proteins and reactive compounds. Therefore, the reaction process can be easily scaled up. ${ }^{112-114}$ Moreover, as compared to bacteria it is easier to culture and grow fungi. But preparing biomass from fungi for the synthesis reaction requires careful steps as it 
is complicated to separate mycelia from culture filtrates. Manipulation of the genetic makeup of eukaryotes to produce desired proteins is also challenging. Also, some species of fungi are pathogenic. ${ }^{115-117}$ Synthesis of AuNPs using plants based material is a facile and uncomplicated process. Various attributes of AuNPs such as shape and size can be regulated by controlling the reaction parameters. Additionally, the reaction process is fast and economical. The disadvantage of using plants for the synthesis of AuNPs is that the identification of reactive components is difficult as plant biomass comprises a large number of organic components. ${ }^{118-120}$ Synthesis of AuNPs from algal biomass is also easy and simple, but algae take a lot of time to grow so the overall process can become tedious and time consuming. Biomolecules on the other hand contains various functional groups which can aid in the synthesis of AuNPs. Contrarily, as different biomaterials show different reducing ability it is imperative to first determine their reducing ability before using them in the synthesis reaction. ${ }^{110,111,121,122}$

\section{Stabilization of AuNPs}

Nanoparticles can be stabilized using a stabilizing agent which basically assists in maintaining repulsive forces to overcome Wan der Vaal forces in the solution of nanoparticles to avoid agglomeration. ${ }^{123}$ During the chemical synthesis of AuNPs sodium borohydride or sodium hydride, sodium citrate or ascorbic acid may act as capping and stabilizing agents for AuNPs. However, during the biological synthesis of AuNPs, stabilization of nanoparticles can be successfully achieved by using the bio-material rich in antioxidant properties. The large variety of reactive compounds present in the biomass can take part in the synthesis and stabilizing process. Various studies have reported the synthesis of highly stable AuNPs via green approach. AuNPs synthesized from Actinidia deliciosa showed a zeta potential value of $-22.3 \mathrm{mV},{ }^{124}$ whereas two different types of AuNPs synthesized from Cannabis sativa showed zeta potential values of $-12.3 \mathrm{mV}$ and $-20.6 \mathrm{mV}$. $^{125}$ The high values of zeta potential mean that AuNPs are highly stable due to the presence of high surface charge which prevents agglomeration. Various studies have reported that phenolic compounds, ${ }^{126}$ terpenoids, ${ }^{127,128}$ proteins, ${ }^{129}$ and nicotinamide adenine dinucleotide ${ }^{54}$ might act as stabilizing and capping agents during the biological synthesis of AuNPs.

Moreover, changing the concentration of gold salt used for the synthesis reaction, $\mathrm{pH}$, and temperature can also provide control over the size and geometry of AuNPs. Derjaguin Landau VerweyOverbeek theory (DLVO) explains the whole process for stabilization of metallic nanoparticles. ${ }^{130,131}$ The stabilization of NPs done by using various capping agents can be divided into three different categories, including steric, electrostatic, and unification of steric and electrostatic stabilization. ${ }^{132}$

\section{Electrostatic Stabilization}

Ionic groups present in the liquid dispersion media can attach to the surface of a colloidal nanoparticle giving rise to a charged layer. As a result, an equal number of oppositely charged ions will border the colloidal nanoparticles giving rise to overall electro-neutral double layers.

This stabilization which involves an electric double layer originating from the presence of both repulsive as well as attractive forces between the nanoparticles as a result of the action of some ionic composites is shown in Figure 4A. These ions include polyoxyanions, carboxylates, as well as fluorides. This type of stabilization involving electrostatic repulsions inhibits the agglomeration of nanoparticles in the solution phase. Electrostatic stabilization is regulated by controlling certain significant variables including $\mathrm{pH}$, concentration, and temperature. ${ }^{133}$

\section{Steric Stabilization}

Steric stabilization hinders the free movement of metal nanoparticles during synthesis reactions. Stabilizing agents used in this type of stabilization include various functional groups such as hydroxyl groups, surfactants, and different oligomers/polymers. This results in the generation of a protective layer by the assimilation of the stabilizing agent at the outer surface of nanoparticles which plays an important role in the stability of metallic nanoparticles. ${ }^{134}$ The mechanism of steric stabilization is shown in Figure 4B.

\section{Electrosteric Stabilization of AuNPs}

The stability of metallic nanoparticles in solution phase can also be maintained by another type of stabilization which involves unification of electrostatic and steric stabilization. A polyelectrolyte employed as a polymeric surfactant gives combined effects of electrostatic and steric stabilization in one molecule. A double electric layer around the nanoparticle is generated by an ionic surfactant possessing extended end chains and polar head group which offers steric repulsion within the nanoparticles, thus preventing the agglomeration and giving rise to 


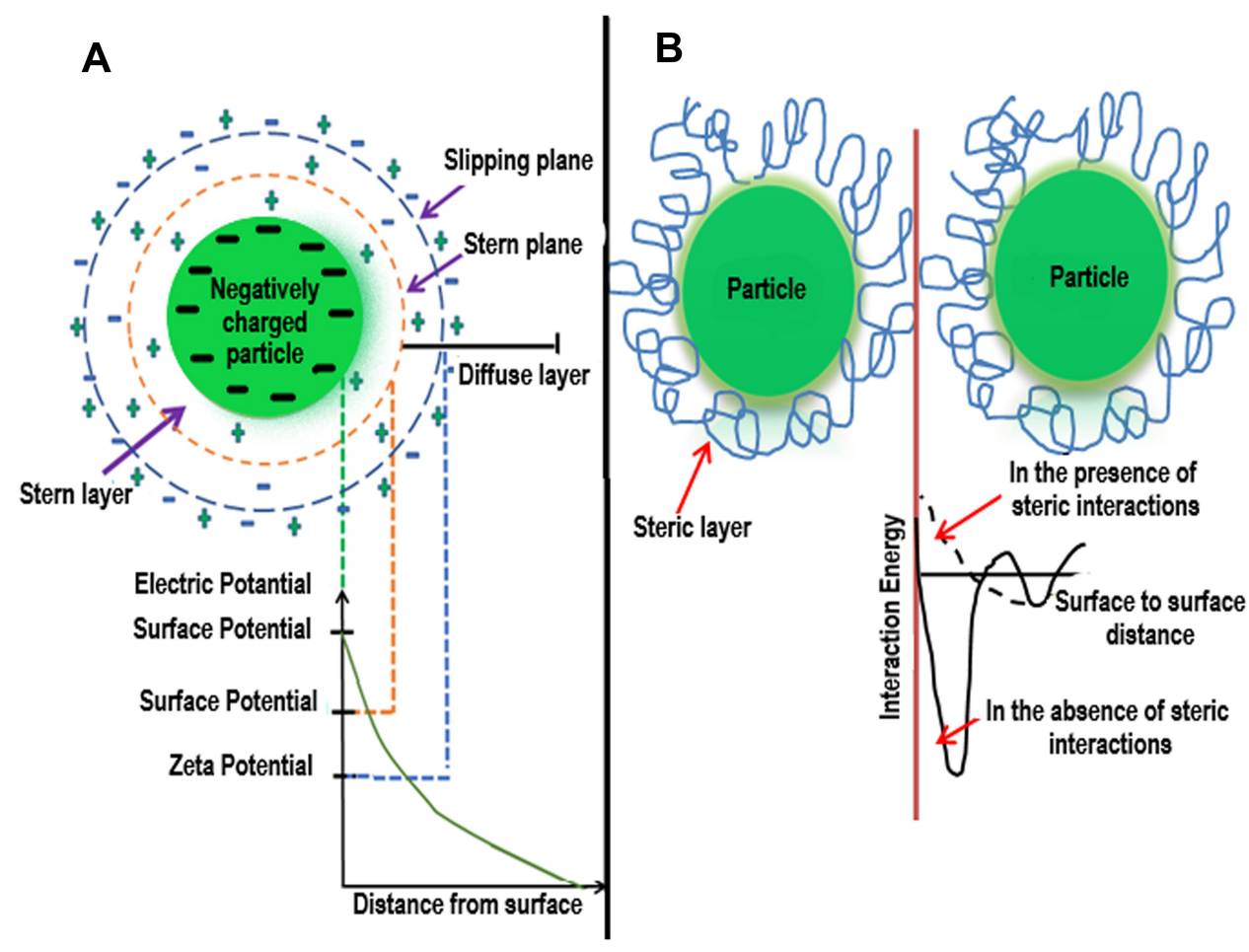

Figure 4 (A) Electrostatic stabilization of gold nanoparticles. (B) Steric stabilization of gold nanoparticles.

a mutual stabilization system. ${ }^{135}$ Figure 5 shows the stabilization of AuNPs by the unification of steric and electrostatic interactions.

\section{Advantages and Disadvantages of Stabilization Methods}

Although electrostatic stabilization is easier to maintain in colloidal media, there are certain limitations to it. Firstly, electrostatic stabilization cannot be achieved in electrolyte sensitive media. Additionally, due to strong forces of interactions between oppositely charged ions it is impossible to separate agglomerated particles. Moreover, it cannot be applied to multiple phase systems as different solids establish distinct surface charge and surface potential. As compared to the electrostatic stabilization, which is a kinetic stabilization method, steric stabilization is a thermodynamic stabilization method; therefore, particles can be redispersed. It is also not sensitive to electrolytes and can be applied to multiple phase systems.

\section{Properties of AuNPs}

AuNPs exhibit properties which are different from those shown by bulk material. These properties of AuNPs depend on their size and shape. Gold nanoparticles exhibit a wide variety of colors which include brown, purple, blue, orange, and red in the solution form, and the color also depends on the size of the particles. Gold nanoparticles exhibit the SPR band in the range of 500-550 nm, which also depends on the size of nanoparticles. ${ }^{136-138}$ The SPR band arises due to the collective oscillations of conduction electrons caused by the incident photon. Such a band is absent in AuNPs of very small size, particularly those which have a diameter $<2 \mathrm{~nm}$ as well as in the bulk materials. ${ }^{139,140}$ Apart from the size of the particles, the shape of nanoparticles, ligands, temperature and charge also influence SPR of AuNPs. ${ }^{141,142}$ If the gold nanoparticles exist in the form of aggregates there is a red shift in SPR which results in the broadening of SPB resulting in the change of color of particles from red to blue. ${ }^{143}$

AuNPs also exhibit the property of quenching florescence of proximate fluorophore by inducing the deactivation pathway. This is done by generation of an excellent overlap between the SPB of AuNPs and emission spectra of fluorophores. ${ }^{144,145}$ This phenomenon is called fluorescent resonance energy transfer (FRET) and has been observed in AuNPs as small as $1 \mathrm{~nm}$ in size. ${ }^{146^{\circ}}$ AuNPs can also cause quenching by another process called photoinduced electron transfer (PET) during which AuNPs accept the photon and cause the quenching of fluorescence. ${ }^{147}$ 

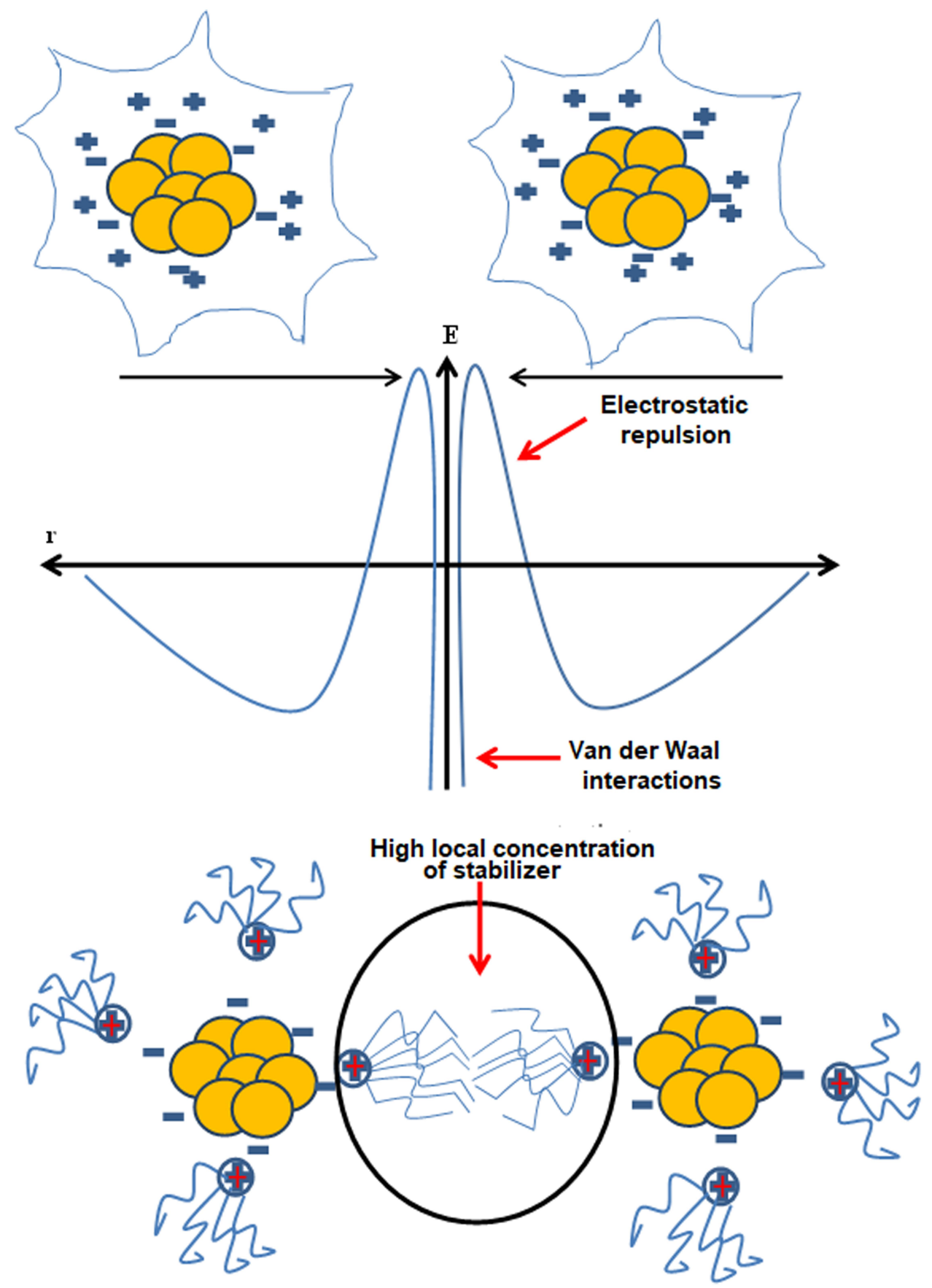

Figure 5 Unification of electrostatic and steric stabilization. Gold nanoparticles surround the ionic surfactants having polar ends and extended side chains. The area with high local concentration of stabilizer hinders the agglomeration of AuNPs.

AuNPs have been widely applied as surface enhanced Raman scattering (SERS) substrate for the detection of various elements in living cells. The basic mechanism of SERS is caused by two major amplifications that result in the increase in the cross-section of Raman scattering; first being the electromagnetic enhancement. The resonance of applied light field along with the collective oscillations of electrons of nanostructures cause amplification in the local electric field at nanoparticle surface. Second is the short range chemical enhancement caused by the alteration in polarizability of molecules due to its charge-transfer interaction with the surface of nanoparticles. ${ }^{148}$

The oxidation reduction reactions of AuNPs make them efficient tools for applications in electrochemical sensing $1^{149,150}$ and electronic devices. ${ }^{151,152}$ On the other hand, the applications of AuNPs in the field of 
imaging $^{153,154}$ and sensing ${ }^{155,156}$ can be attributed to their surface enhanced raman scattering (SERS). Studies show that AuNPs can be used for calorimetric sensing ${ }^{157,158}$ and laser ablation ${ }^{159,160}$ because of their SPR, whereas florescence quenching properties of AuNPs make them well suited for the applications in the field of material engineering $^{161,162}$ and sensors development. ${ }^{163,164}$

Melting point of gold nanoparticles changes with the change in the size of particles. Gold nanoparticles are shown to have a lower melting point as compared to the bulk materials. This decrease in the melting point is because of the fact that the attractive forces of interaction of core get weaker due to a decrease in the number of neighboring atoms. As a result of this, the interaction between inner and surface atoms is reduced and surface atoms get higher surface energy. This leads to the decrease in the melting points. ${ }^{165,166}$ Electrical properties of AuNPs are also reported to be different from that of bulk material. As the particle size decreases the surface area is increased which causes a decrease in electrical conductivity. ${ }^{167}$ However, different materials can be used in combination to enhance their electrical and optical properties. For example, AuNPs can be used to enhance electrical and optical properties of zinc oxide nanoparticles. ${ }^{168}$

\section{Anisotropic AuNPs}

The physical and chemical properties of AuNPs greatly depend on the shape and size of AuNPs. AuNPs of spherical shape can be synthesized by isotropic growth on gold nuclei. On the other hand, gold nanoparticles of different shapes can be synthesized by anisotropic growth on gold nuclei. As described above in the synthesis methods for AuNPs, the synthesis of anisotropic gold nanoparticles can be carried out by a two-step process, ie, seed-mediated growth. In the first step, spherical gold seeds are synthesized which have uniform size. In the second step, the reaction conditions are changed including the addition of more gold ions, along with a capping agent and reductant. The gold seeds produced in the first step act as a template on which newly reduced AuNPs deposit and form AuNPs of larger size with varied shapes. The reducing agent used in the second step is a weak reducing agent and $\mathrm{Au}^{3+}$ can be converted to $\mathrm{Au}^{0}$ only in the presence of seeds which act as a catalyst for the reaction. Because of the use of weak reducing agent, the second step is a slower process than the first step. ${ }^{169}$ Various studies have reported synthesis of AuNPs of different shapes including gold nanorods, ${ }^{170,171}$ nanocages, ${ }^{172}$ nanowires, ${ }^{173,174}$ nanoplates, ${ }^{175,176}$ polyhedral, ${ }^{177,178}$ flower shaped, ${ }^{179,180}$ and star shaped. ${ }^{181,182}$
A study which involved the use of cell free extract from a fungus Rhizopus oryzae showed that different factors such as protein concentration, $\mathrm{pH}$ of solution, and time of the reaction contribute to the synthesis of AuNPs of varied shapes. When proteins got deposited at 111 plane of nuclei it resulted in the formation of nanoplates which were either triangular, pentagonal, hexagonal, or star shaped. Similarly, isotropic deposition of proteins on all planes resulted in the formation of nanospheres, and orientated attachment under the limited supply of cell free extract caused the spherical gold nanoparticles to give rise to urchin shaped nanoparticles. For the formation of 2D nanowires, first the spherical agglomerates formed followed by the deposition of protein molecules on the concave surfaces of two particles which joined together finally resulting in the formation of long wires. When these wires underwent the process of Oswald ripening it resulted in the formation of nanorods. ${ }^{183}$ The schematic illustration of the study is shown in Figure 6.

\section{Properties of Anisotropic AuNPs}

The shape of nanoparticles has an effect on their optical $^{184,185}$ and catalytic properties. ${ }^{186,187}$ Nanoparticles having different shapes have the atoms of different faces which have different electronic distribution and are thus used to catalyze different types of chemical reactions. Anisotropic nanoparticles can show various plasmon resonances other than dipole resonance which can be attributed to their higher order modes. These additional resonances include quadruple and octopole resonances. ${ }^{188,189}$ AuNPs show their typical LSPR with the maximum absorption observed at around $520 \mathrm{~nm}$, but as the symmetry of AuNPs changes to gold nanorods (AuNRs) two different LSPRs can be observed, with one being at the short axis, which is transverse LSPR, and the other one being along the long axis, which is longitudinal LSPR. There is a red shift in longitudinal LSPR of the peak with the increase in the aspect ratio. ${ }^{190}$ The studies have demonstrated that a peak shift and aspect ratio of anisotropic AuNRs have a linear relationship. ${ }^{136}$ AuNRs have diverse applications in the field of biology. When AuNRs are exposed to laser light, they absorb the portion of that resonant light with their surface plasmon oscillations. The light that they absorb is quickly converted to heat and if the rate of heat absorption is higher than the rate of heat loss it results in the accumulation of heat inside the lattice and sometimes this heat is enough to cause the conformational change in these AuNRs, changing them to spherical AuNPs. ${ }^{191,192}$ 


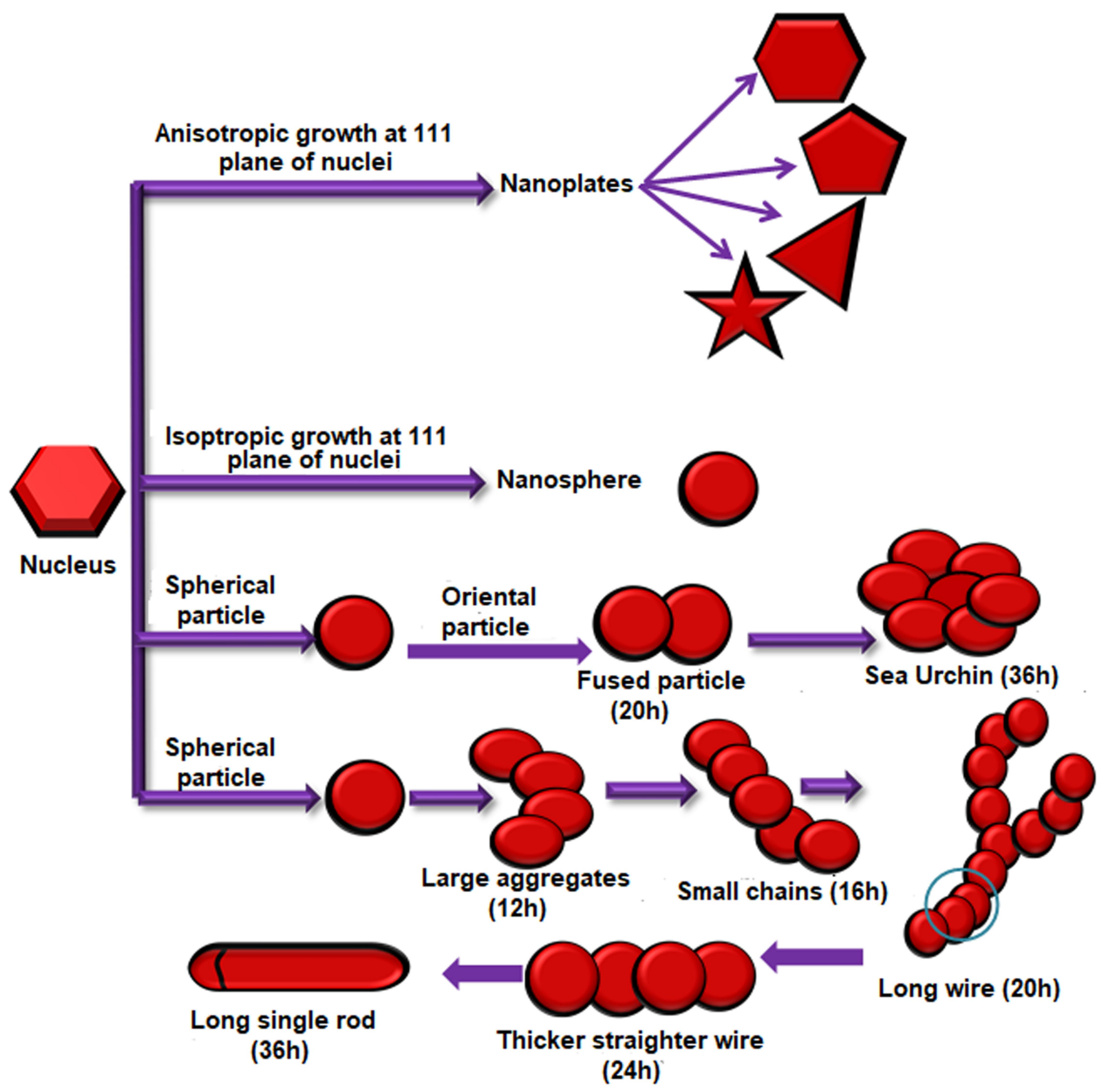

Figure 6 Synthesis of AuNPs of various shapes under different conditions due to different type of growths on the gold nuclei.

The aspect ratio of AuNRs is an important factor in determining the applications of AuNRs. For example, AuNRs that have higher a aspect ratio respond effectively to NIR light and therefore have application in the field of Photothermal therapy. However, larger sized AuNRs having fixed and larger aspect ratios can scatter the light effectively and thus can be used for optical imaging. Higher absorption efficiency can be attributed to smaller AuNRs which make them an efficient tool for photothermal therapy. ${ }^{193}$ The surface plasmon resonance of gold nanostructures having other shapes has also been studied. Gold nano-stars exhibit various surface plasmon resonances which result from hybridization of resonances related to their core and tips. ${ }^{194}$

\section{Functionalization of AuNPs}

AuNPs can be functionalized in a number of ways which generate the possibilities for a variety of approaches for their use in designing various drug delivery systems
(DDS). When non-covalent interactions are used for the loading of drugs on nanoparticles, no specific bond cleavage is required to carry out the efficient drug release and only alterations in native physical forces are needed. ${ }^{17}$ For example, the release of hydrophobic drugs can be carried out by inducing changes in local hydrophobicity. Similarly, AuNPs can be covalently bonded to the drug through cleavable bonds forming a prodrug which can be delivered to the cell liberating the drug from AuNPs using either external or internal stimuli. ${ }^{195,196}$ Irrespective of the method used for the drug delivery, the modification of the monolayer of AuNPs is very important for the extracellular or intracellular discharge mechanisms.

Various mechanisms for the synthesis of AuNPs containing functional moieties are being developed in order to increase their bonding with biological molecules and to make them better drug-carriers with improved specificity. Current methods for the functionalization of AuNPs involve the use of either one or a combination of the 
functional groups including oligo or polyethylene glycol (PEG), bovine serum albumin (BSA), amino acids and polypeptides, oligonucleotides, antibodies, receptors, and diverse similar particles. Table 2 shows various functional groups, their ligand moieties, and key features which make them suitable for their biological application.

\section{PEGlyation of AuNPs}

During the PEGlyation, AuNPs are conjugated with PEG alone or in the presence of some other molecule in order to make the cellular uptake of AuNPs efficient. These molecules include biotin, peptides, and oligonucleotides. These functionalized AuNPs can be used for targeted drug delivery owing to their binding ability with cell membranes. Studies have been reported for the synthesis of AuNPs functionalized with lectin, lactose, and biotin along-with PEG. ${ }^{197-199}$ Such functionalized AuNPs cannot only be used for cellular internalization but for intracellular internalization as well. PEGlyated gold nanoparticles can also be conjugated with thiol having florescent dye coumarin attached on one side. These fAuNPs work as hetero-bifunctional moieties and can make their way into the cells and be tracked simultaneously because of dye molecule attached at one end. ${ }^{200}$ The study which involved the internalization of such fAuNPs for application in tumor ablation in mice has been reported. The result of this study showed that the internalization of AuNPs into cells was also affected by factors such as size of AuNP, $M_{r}$ of PEG, the ligand conjugated with PEG, and physiochemical properties. $^{201}$

\section{Peptides and Amino Acid Conjugation}

Nanoparticles have also been conjugated with peptide/ amino acid in order to produce effective and targeted delivery systems. Synthesis of AuNPs conjugated with aspartic acid, ${ }^{14}$ glutamic acid, phenylalanine and tryptophan, ${ }^{202}$ L-cysteine, ${ }^{203}$ lysine,${ }^{204}$ and peptides ${ }^{15,205}$ has been reported. Amino acids and peptides bind with negatively charged AuNPs through amine groups, whereas the negatively charged carboxylic groups extend outwards to stabilize AuNPs. Some amino acids including lysine, poly-lysine, and glycine exhibit higher efficacy to conjugate with DNA and can be used for DNA or gene delivery

Table 2 List of Various Functional Groups, Their Ligands, and Key Features Which Make Them Suitable for Biological Applications

\begin{tabular}{|c|c|c|c|c|c|}
\hline S. No. & $\begin{array}{l}\text { Functional } \\
\text { Groups }\end{array}$ & Ligands & Key Feature & Application & Ref. \\
\hline 1 & $\begin{array}{l}\text { Polyethylene } \\
\text { Glycol (PEG) }\end{array}$ & Thiol (-SH) group & $\begin{array}{l}\text { Adhesion with plasma } \\
\text { membrane }\end{array}$ & $\begin{array}{l}\text { Cell targeting, intracellular } \\
\text { targeting, biodistribution analysis }\end{array}$ & {$[197,199,325-327]$} \\
\hline 2 & Peptides & $\begin{array}{l}\text { Cell surface receptors, amyloid } \\
\text { inhibitory peptide }+ \text { sweet } \\
\text { arrow peptide, antibody, } \\
\text { octreotide peptide }\end{array}$ & $\begin{array}{l}\text { Cytoplasmic and nuclear } \\
\text { translocation, adjuvant, } \\
\text { targeting carcinoma cells } \\
\text { analog of somatostatin }\end{array}$ & $\begin{array}{l}\text { Cellular and intracellular } \\
\text { targeting, macrophage and } \\
\text { proinflammatory cytokine } \\
\text { elicitation bioimaging imaging of } \\
\text { cancer cells }\end{array}$ & {$[209,328-331]$} \\
\hline 3 & $\begin{array}{l}\text { Carboxyl } \\
\text { group }\end{array}$ & Amino acids & Delivery of various agents & $\begin{array}{l}\text { Various applications which } \\
\text { depend on the amino acid used }\end{array}$ & [27] \\
\hline 4 & $\begin{array}{l}\text { Amine } \\
\text { Group }\end{array}$ & PEG & siRNA delivery & RNA technology & [207] \\
\hline 5 & DNA & $\begin{array}{l}\text { Aptamer, PEGylated gold poly } \\
\text { ( } \beta \text {-amino ester), Thiolated } \\
\text { ssDNA of RNA I gene, } \\
\text { antisense DNA } \\
\text { oligonucleotides }\end{array}$ & $\begin{array}{l}\text { Targeting Prostate cancer } \\
\text { cells, siRNA carrier, binds } \\
\text { to antisense RNA of p53 }\end{array}$ & $\begin{array}{l}\text { Bioimaging, gene delivery RNAi- } \\
\text { regulation of transgene } \\
\text { expression, detection of specific } \\
\text { genes, eg, for microbial detection }\end{array}$ & {$[220,332-335]$} \\
\hline 6 & RNA & $\begin{array}{l}\text { Polyvalent RNA-gold } \\
\text { nanoconjugates }\end{array}$ & RNA delivery & RNA technology & [336] \\
\hline 7 & Folate & Folate & $\begin{array}{l}\text { Targets cancer cells that } \\
\text { are folate receptor } \\
\text { positive }\end{array}$ & Cancer targeting & [337] \\
\hline
\end{tabular}


without inducing any cytotoxicity. Anionic DNA shows higher binding capacity with the positively charged ammonium ions present on amino acids. One possible method could be the use of AuNPs having thiol end which can then be conjugated with amino acids to give out positive amino groups. These amino groups will bind with DNA through ion pairing. A study which reported the similar mechanism for the synthesis of lysine and poly-lysine conjugated AuNPs expression for gene delivery found that lysine dendrons were better at expressing reporter $\beta$ galactosidase gene as compared to polylysine. ${ }^{206}$ Similarly another study has reported that AuNPs functionalized with positively charged amine groups were able to effectively conjugate with negatively charged PEGlyated siRNA. When these fAuNPs were tested against prostate cancer cell lines they efficiently inhibited cancer genes. Also, specific cancer genes were efficiently inhibited using these amine functionalized AuNPs carrying siRNA-PEG conjugates when used against human prostate cancer cells. ${ }^{207}$ Later a study reported triethylenetetramine (TETA) functionalized gold cores of size $2 \mathrm{~nm}$ which featured biodegradable glutamic acid scaffolds and showed that positively charged amino groups of TETA moieties interact electrostatically with anionic siRNA. These dendronized AuNPs were very effective at suppressing expression of $\beta$-gal $(-50 \%)$ with the least toxicity. ${ }^{208}$ Proteins can also be conjugated with AuNPs via glutamic acid which conjugates with AuNPs through their amino groups and their carboxyl groups extending outwards bind with amino groups of proteins. On the other hand, the attachment of protein with glutamic acid can induce certain conformational changes in proteins. ${ }^{27}$ Lysine conjugated AuNPs were first synthesized and then conjugated with doxorubicin and the results showed that most of the drug was released within 12 hours. $^{204}$

Gold nanoparticles functionalized with peptides have also been reported for the application in targeted drug delivery. Peptide-drug conjugates (PDC) are an efficient and effective tool for delivering drugs to cancer cells. Phage Peptide P4 conjugated with 2-chlorotrityl resin was tested against A20 leukemic-like cell line. The results showed that chlorambucil which previously was less effective as compared to bendamustine was equally as effective as bendamustine when used in conjugation with peptides fAuNPs. ${ }^{15}$ Phospho-peptides have also been investigated for application in drug delivery. The results have shown that phospho-tyrosine modified AuNPs when used as a delivery vehicle for doxorubicin were more effective at killing SGC-7901 cells. ${ }^{205}$
Another study reports the conjugation of peptide CALNN and its derivative CALNNR8 with AuNPs for targeting components present inside the cell. AuNPs with the size of $30 \mathrm{~nm}$ could cross the cell membrane more easily through the processes of endocytosis and micropinocytosis. Both of these functionalized nanostructure types demonstrated higher binding capacity for DNA, RNA as well as for the organelles like endoplasmic reticulum. Upon testing CALNN and CALNNR8 together for internalization in cells it was found that both of them could enter in the nucleus but the most of the CALNNR8 was still bound with endoplasmic reticulum as ER has a high binding affinity for signal peptides rich in arginine. ${ }^{209}$

\section{Oligonucleotide Functionalized Nanoparticles}

Synthesis of DNA functionalized inorganic nanoparticles is an area of fascination for researchers because of their definite structures and functions, ${ }^{210-212}$ and possesses a programmable assembly process as far as the sequence, length, and structure of DNA is concerned. ${ }^{213,214}$ Similarly, the synthesis process can be controlled either to form oligomers or large agglomerations. Moreover, it is even possible to control the separation distance between the assemblies of nanoparticle to produce crystals of nanoparticles. ${ }^{215-217}$ DNA functionalized nanoparticles can be synthesized under specific conditions. DNA can be used as in the form of a single strand capped with thiol as well as by saturation of the AuNPs' surface with single stranded DNA molecules. ${ }^{218}$ Studies carried out on kinetics and thermodynamics of DNA conjugated with AuNPs have demonstrated that ssDNA first attach to AuNPs and then gradually spread on their surface. ${ }^{219}$ Another study has shown that conjugation of aptamers through hybridization reactions on oligonucleotide functionalized gold nanoparticles is a better approach than carrying out the direct conjugation of aptamers with AuNPs. The first advantage is that the integrity of aptamers remains intact and a smaller amount of aptamers is required to carry out the conjugation process. This technique was employed for the detection of prostate cancer cells. $^{220}$

\section{Other Common Functionalization Methods}

Several molecules other than proteins, amino acids, and nucleic acids have also been used for the functionalization of AuNPs for diverse applications. One study has reported 
the functionalization of AuNPs with anti-human IgG to develop a technique for the detection of human IgG in blood serum samples and the results were found to be consistent with enzyme-linked immunosorbent assay (ELISA). ${ }^{221}$ Apart from that studies have been carried out for functionalization of AuNPs with antibodies for application in the detection of E. coli. Antibody conjugated AuNPs interacted with E. coli O157:H7 through EDC coupling chemistry. ${ }^{22}$ In addition to that, in a study the enzyme glucose oxidase was attached on chitosan conjugated AuNPs for the detection of glucose. The results showed that the method was effective for the enzyme to retain its enzymatic activity, even at extreme conditions, including higher temperature. ${ }^{223}$ Another study has reported the application of AuNPs in the detection of 5-fluorouracil; an anti-cancer drug, as AuNPs show a quenching effect against the fluorescence produced by 5-fluorouracil. Along with the detection of 5-fluorouracil, this conjugate was also shown to have antifungal and antibacterial properties. ${ }^{224}$ Depending on the application of AuNPs, there are many studies which have used the combination of proteins, oligonucleotides, and antibodies for the functionalization of AuNPs. This type of functionalization of AuNPs is increasing now and has diverse applications in the field of biomedical sciences.

\section{Advantages and Limitations of Functionalization Methods}

Functionalization allows us to impart AuNPs with multimodal features. ${ }^{225}$ Physical aspects of AuNPs can be modified through functionalization, making them efficient for clearance. AuNPs when layered with small molecule or polymers such as poly(ethylene glycol) (PEG), the resultant nanostructure displays improved blood circulation with better biodistribution and active cellular uptake. PEG also reduces the degree of attractive forces between AuNPs by expanding the steric gap between the particles and developing hydrophilicity through hydrogen bonds with solvent. ${ }^{226}$ PEGylation can also result in the alteration of the size of the particle. The rate of renal filtration of particles with the size $>10 \mathrm{~nm}$ reduces $t_{1} / 2$; though a bigger size $(>100 \mathrm{~nm})$ enhances their uptake by liver and reduces EPR extravasation. ${ }^{227}$ PEG also alters the flexibility of NP which can become "softer" due to PEGylation, thus effecting extravasation. Though the toxicity caused by PEG is little but is inversely proportional to the molecular weight, mainly after oral consumption. NPs and not the PEG corona are the cause of toxicity caused after intravenous injection. ${ }^{228}$ Though the hindrance of PEG to the degradation by serum is advantageous from a stability perspective, functionalized AuNPs which are harmlessly biodegraded in-vivo after a certain time period are desired. An ultimate challenge of PEG coating is its fragmentation by light, heat, or stress, resulting in the diminishing of its coating ability. $^{229}$

Similarly, functionalization of gold nanoparticles with some amino acids can cause the aggregation of nanoparticles. Thiol chemistry can be used to our advantage, but the thiol groups can be replaced by other thiol groups present in the high concentration in living organisms. ${ }^{230}$ The other challenge is formulation-function challenge which is to determine the exact sequence of peptides to be used to obtain the desired function. The results of another study which involved the synthesis of L-Arginine (Arg) functionalized AuNPs showed that Arg and nanoparticles interact through covalent or coordination-like bond, and the resultant steric limitation on binding of gold nanoparticles to Arg results in reducing the coverage of Arg. ${ }^{231}$ On the other hand, the potential of oligonucleotides functionalized AuNPs has been generally shown using in-vitro analysis; but, there are questions to be addressed before conjugates of AuNPs and oligonucleotides can be moved to clinical applications. First of all, diminishing short- and long-term cytotoxic effects of AuNPs is indispensable. Various investigations have reported the biocompatibility of such therapeutic AuNPs through uncomplicated cytotoxicity studies, though comprehensive toxicological assessment needs to be appropriately carried out. Secondly, delivery of these carriers to targeted organs and tissues is essential to lessen side-effects. Coating AuNPs surface with precise antibodies destined to the damaged cells and decorating them with functional groups like polyethylene glycol and zwitterionic moieties to avoid adsorption of plasma protein, bettering the pharmacokinetics and escaping immune system can be done to achieve the desired drug targeting. Lastly, immunological problems are required to be entirely researched prior to the clinical application of any novel material. $^{232}$

\section{Applications of AuNPs in Drug Delivery}

Gold nanoparticles have lately been exploited as an excellent applicant for delivering numerous drugs to their target sites. ${ }^{10,11}$ These payloads range from small drug molecules to bigger biomolecules such as RNA, DNA, and proteins. 
Effective discharge of these payloads is an essential factor to be considered for efficient therapy. The release of therapeutic agent from gold nanoparticles can be achieved by using internal stimuli such as glutathione, ${ }^{233} \mathrm{pH}$ etc., ${ }^{234}$ and as well as external stimuli such as light. ${ }^{235}$ Drug targeting can be generally categorized into passive or active targeting. In the "passive targeting," drug or nanoparticle is built-up at the targeted site by using their physiochemical properties like weight and size, extravasation, and pharmacological aspects. ${ }^{236}$ However, during the "active target", the drug molecule or nanoparticle are modified by attaching them with a definite active molecule for targeting particular cells. For instance, studies have reported the targeting of nanoparticles to specific phagocytic cells $^{237}$ and to tumor cells. ${ }^{238}$ But the major factor that plays a significant role in such targeting is surface modification and functionalization.

\section{Direct Conjugation of AuNPs with Drug}

AuNPs can be conjugated directly with drug molecules or antibiotics with the help of physical absorption, covalent, or ionic bonding. One example is methotrexate (MTX); a folic acid analog that was conjugated to $13 \mathrm{~nm}$ colloidal gold nanoparticles to disrupt the folate metabolism in the cancer cells and has mainly been used as a cytotoxic anticancer drug. After the overnight incubation, carboxylic groups on the molecule of methotrexate had the ability to bind with the surface of gold nanoparticles and as reported the tumor cells had higher concentration of AuNP conjugated methotrexate as compared to that of free methotrexate. Also, the conjugated form exhibited a 7-times higher cytotoxic effect in Lewis lung carcinoma mouse models as compared to free methotrexate. ${ }^{12}$ The schematic illustration of mechanism used for the synthesis of MTX conjugated AuNPs is shown in Figure 7A. Saha et al, ${ }^{239}$ in another example, directly conjugated non-functionalized spherical gold nanoparticles of about $14 \mathrm{~nm}$ diameter to several different antibiotics such as streptomycin, ampicillin, and kanamycin by physical means. As a result, conjugated antibiotics showed more stability and higher inhibition of bacterial growth than their free forms.

\section{Alterations in AuNPs' Surface for Drug Conjugation}

During the conjugation process of nanoparticles and biomolecules, the surface chemistry of a nanomaterial plays the vital role. For the drug delivery system there are four main reasons to define why the modifications in the surface of AuNP could be worthy. The primary reason is slowing or preventing the removal of conjugate by reticulo-endothelial system (RES) and to increase the conjugate's lifetime of circulation. The second reason is the proper attachment of therapeutic molecules and desired targeting. Another reason is preventing the aggregation of nanoparticles and improving their stability. Lastly, surface modification can solve the problem of cytotoxicity in gold nanoparticles due to original capping ligands. There are many studies on the methodology to improve the bio-stability, biocompatibility, and water-solubility of gold-bioconjugates. A number of studies have highlighted the properties of polymer-modified gold nanoparticles. Farooq et $\mathrm{al}^{240}$ showed the synthesis of doxorubicin (DOX) conjugated PEGlyated AuNPs, bleomycin (BLM) conjugated PEGlyated AuNPs, as well as both DOX and BLM conjugated PEGlyated AuNPs. The results provided evidence that nanohybrid drug carriers significantly resulted in the decrease of half-maximal drug concentration to be effective. The mechanism for the synthesis of nanohybrid drug carrier is shown in Figure 7B. Studies have shown that PEG inhibits the agglomeration of gold nanoparticles in an environment with high concentration of ions and favors a longer particle circulation in the vivo systems. ${ }^{200,241}$ In a different study carried out in mice, the biological distribution of PEG modified AuNRs was compared with nonmodified AuNRs and results showed that when PEGmodified gold nanorods were injected in mice $54 \%$ of the gold nanorods were found in blood at 0.5 hours after injection while, at 72 hours, $35 \%$ of AuNRs were found accumulated in the liver. On the other hand, at 0.5 hours the gold nanorods without modification were already $30 \%$ accumulated in the liver. ${ }^{242}$ In a different study, coumarin dye was conjugated with one end of PEG spacer and then AuNPs were conjugated with coumarin-PEG-thiol and the results showed that these particles were not toxic and can enter into the cells after 1 hour of incubation and were found localized in the peri-nuclear region. These particles internalized into cells by non-specific endocytosis. ${ }^{200}$ The PEG-modified gold nanorods can be used as a contrast agent for in vivo screening of organs using the light in the near-infrared region. ${ }^{242,243}$ Bhattacharya et $\mathrm{al}^{244}$ reported that gold nanoparticles functionalized with PEG-amines and folic acid via non-covalent interactions target the cancerous cells which have folate receptors. Takahashi et $\mathrm{al}^{245}$ used the technique "layer-by-layer" surface modification to modify phosphatidylcholine-gold nanorods (PC-NR) with polyethylenimine (PEI) and bovine serum albumin (BSA) which showed 

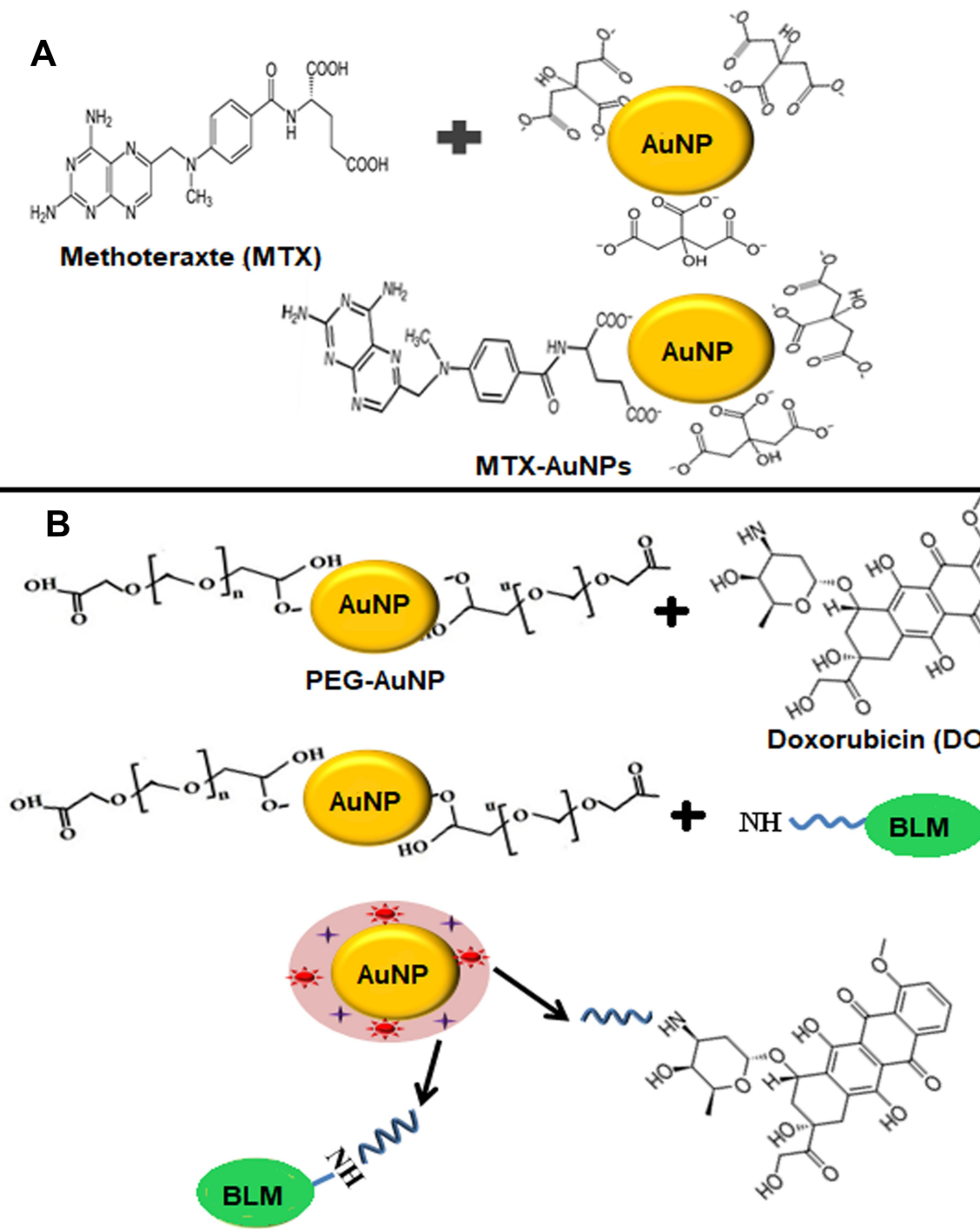

Figure 7 (A) Direct conjugation of AuNPs with methotrexate drug (MTX). Methotrexate molecule possesses two amine and carboxylic groups and exchanges citrate ions present on the surface of citrate capped AuNPs to form MXT-AuNPs. (B) Surface modification of AuNPs with PEG for conjugation of Doxorubicin (DOX) and Bleomycin (BLM). During the conjugation reaction, carboxylic groups on PEG forms amide bonds with amino groups present on BLM and DOX.

greater stability in electrolyte buffer solution and as a result prevented their aggregation under physiological conditions and caused increased uptake of the nanoparticles and cellular binding. Recently, Gu et $\mathrm{al}^{246}$ exhibited another type of surface-functionalized gold nanoparticle that had the ability to focus a payload to the core of the cell. The surface of the circular gold nanoparticles with a diameter of $3.7 \mathrm{~nm}$ was altered with 3-mercaptopropionic acid (MPA) to frame a self-assembled monolayer. The carboxylic end groups on the particles were then conjugated with amine endgroups on the $\mathrm{NH}_{2}-\mathrm{PEG}-\mathrm{NH}_{2}$. This conjugation brought great stability and high proficiency of intracellular vehicles for the targeted delivery to the nucleus. The schematic representation of this study is shown in Figure 8. Gold nanoparticles functionalized with paclitaxel are another example of a nano-sized drug delivery framework. The C-7 position of paclitaxel was bonded with hexa-ethylene glycol (carboxyl-terminated linker) which was then directly conjugated to 4-mercaptophenol-coated gold nanoparticles of diameter $2 \mathrm{~nm}$. The results showed that approximately 70 molecules of paclitaxel were conjugated per nanoparticle. ${ }^{247}$ As illustrated above, there are diverse ways of surface modification of gold nanoparticles. Among covalent and non-covalent reaction based modifications, the covalent interactions are stronger but the interesting assemblies are provided by non-covalent interactions of NPs with the biomolecules. ${ }^{248}$ Due to the stable covalent interaction the problem of effective release of the drug 


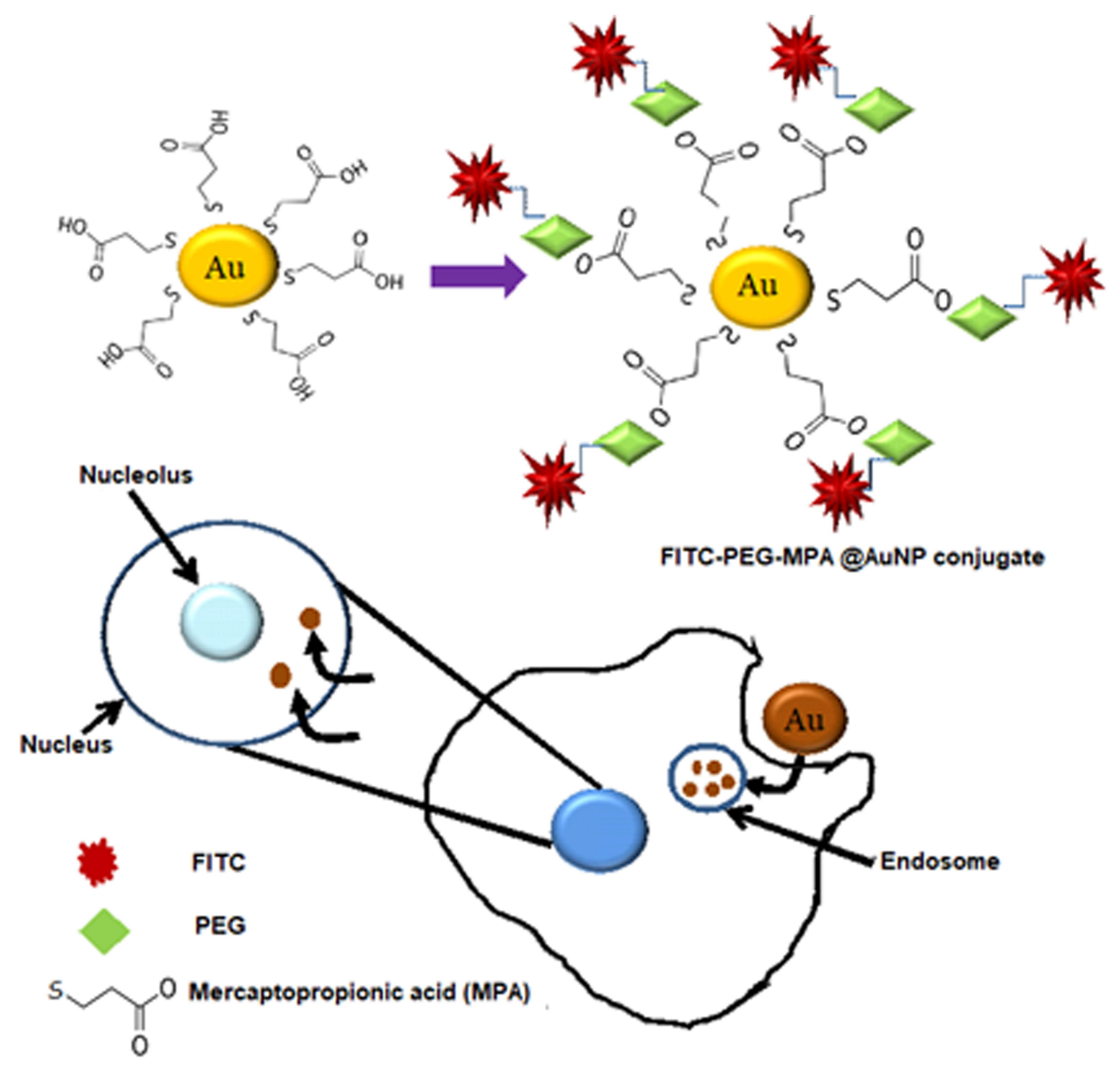

Figure 8 Surface modification of AuNPs with mercaptopropionic acid. These fAuNPs were conjugated with PEG- FITC (fluorescein isothiocyanate). These AuNPs entered the cell through endocytosis and were found localized in the endosomes and nucleus.

payload on the target site needs to be addressed. To solve this problem, surface modification with functional ligands having acid sensitive or amine groups can act as a site for non-covalent binding of drug molecules. ${ }^{249}$ Surface coating with polyelectrolytes such as poly(diallydimethyl ammonium chloride; PDADMAC), poly(sodium-4-stryrenesulfonate; PSS), and poly(allylamine hydrochloride; PAH) has already been used. ${ }^{250,251}$ So, to avoid any agglomeration, a careful surface modification strategy is needed to deliver the payload.

\section{Limitations of AuNPs in Drug Delivery}

Although gold nanoparticles show a promising future in the field of drug delivery, the other side of the coin is imperative to be considered, ie, their potential side-effects. Although most of the concerns related to biological applications of gold nanoparticles have been addressed in various studies, their results seem to contradict each other, and final answers to all the questions related to biocompatibility, biodistribution, cytotoxicity, retention, and clearance time are still required. One major limitation of gold nanoparticles in drug delivery is their non-specific targeting and the capability of stimulating the host's immune system. These problems have been addressed by modifying the surface of AuNPs with PEG, thereby masking their surface and leaving them inactive regarding protein adhesion on the surface, thus minimizing the likelihood of immune system stimulation. Unexpectedly, such perfect coating not only causes nanoparticles to become "invisible" to the immune system but it also makes them lose their capability to adhere to definite receptors. To overcome such in vivo obstacles, gold nanoconjugates are additionally altered using targeting ligands. But this detailed alteration of the surface may give rise to undesirable toxic effects. Considering the mechanism by which conjugated ligands may result in the alteration of the pharmacokinetics, biodistribution, and ultimate potential side-effects is also very crucial. Some toxicity can be 
attributed to specific type of ligands. For instance, in-vitro toxicity has been reported only for cationic ligands. ${ }^{252}$ Moreover, as a result of chemoresistance and the diversity of genetic makeup of cancer cells, not all the therapeutics may be effective for every patient. The efficacy of nano cancer drug carriers can be increased by decorating nanoparticles with stromal antagonists. However, to facilitate the specific targeting of nanotherapeutics, additional studies are imperative to discover new molecular targets expressed only in the cancer microenvironment. One possible way to solve the problem of cancer heterogeneity is to possibly target stromal cells. Other important candidates for active drug targeting are cancer stem cells (CSC). Potential solution for eradicating chemoresistance of cancer cells is by eliminating chemoresistance of CSCs. ${ }^{253}$ Consequently, there several serious concerns that require serious attention, for instance, dependable formulation assays, deep rooted side effects, and cellular and immune reactions. This calls for continued research in the development of the techniques described above, particularly with respect to active targeting. ${ }^{254}$

\section{Delivery of Large Biomolecules Using AuNPs}

The capability of gold nanoparticles in delivering large biomolecules, such as peptides, nucleic acids, and proteins, has also gained success. Various biomolecules including genes, oligonucleotides, proteins, and peptides are various types of biomolecules which have been delivered to target cells using AuNPs as delivery vehicles.

\section{Nanoparticle-Based Genetic Therapy}

The ideal approach to treat genetically acquired disease is via Gene therapy. ${ }^{255}$ Viruses also provide a vehicle for highly efficient gene therapy, ${ }^{256}$ but they have raised safety concerns which arise due to immune response and random cytotoxicity. ${ }^{257}$ Conversely, at present less efficiency has been reported via non-viral gene delivery systems. ${ }^{258}$ An effective delivery vehicle should provide efficient entry into the cell, protection of nucleic acid against degradation by nucleases, and release of the nucleic acid in functional form in the nucleus. ${ }^{259}$ Nanoparticles, on the other hand, have outstanding therapeutic effects and are capable to deliver all kinds of oligonucleotides such as single stranded DNA (ssDNA), double stranded DNA (dsDNA), plasmids, and single stranded RNA (ssRNA). Gold nanoparticles such as nanorods and nanospheres give protection to nucleic acid and prevent their degradation by nuclease. Oligonucleotide and siRNA-modified AuNPs conjugates are used in gene delivery and gene therapy as intracellular gene regulatory agents which are able to activate immune-related genes. ${ }^{260}$

AuNPs can be conjugated with oligonucleotides using both covalent and non-covalent interactions. Nucleic acid strands can be modified with thiols (-SH) for covalently grafting them onto nanoparticles. In one study, citratecapped AuNPs were functionalized with antisense oligonucleotides using cyclic disulphides (DTPA) anchoring group and alkyl-thiol anchoring groups to produce tetrathionate particles and mono-thiolated particles. The particles complexes were found to possess high affinity constant for the complementary nucleotide sequence and showed 99\% higher cellular internalization without causing any cytotoxicity. When treated with DNAse, AuNPs bound antisense oligonucleotides degraded at a much slower rate than the free antisense oligonucleotide duplexes. ${ }^{261}$ The basic mechanism of the study is shown in Figure 9A. A group has reported the synthesis of polyvalent nucleic acid and AuNPs conjugates by covalently bonding AuNPs with thiol modified nucleic acids. The resultant conjugate was resistant to any degradation by enzymes and showed high cellular internalization. ${ }^{262}$ In another study, the same group has applied their "antisense particles" for tumor suppressing. They used mimics of tumor suppressive miRNA-miR-205 for functionalization of AuNPs and sense strand was linked to AuNPs through absorption of alkyl thiol linkage. These conjugates of miR205 down-regulated the expression of miRNA target protein and successfully inhibited cancer cell proliferation as compared to non-targeted AuNPs. ${ }^{263}$

Nucleic acids can be conjugated with AuNPs via noncovalent interactions as well. Strongly anionic nucleic acids can interact with cationic AuNPs through electrostatic interactions. Gold clusters protected with mixed monolayer functionalized with quaternary ammonium salts were tested for their ability to transfect plasmid DNA. The results showed that various factors contribute to the successful transfection assemblies which include DNA:AuNPs and hydrophobicity. ${ }^{264}$ Zhao et al $^{265}$ developed gold nanoparticle-based nano-carriers with polyallylamine hydrochloride (PAH) and poly-sodium 4-styrenesulfonate (PSS), and they were able to deliver a small interfering RNA (siRNA) targeting LSD1 gene to induce the differentiation of human mesenchymal stem cells (MSCs). The results of this research may contribute to 

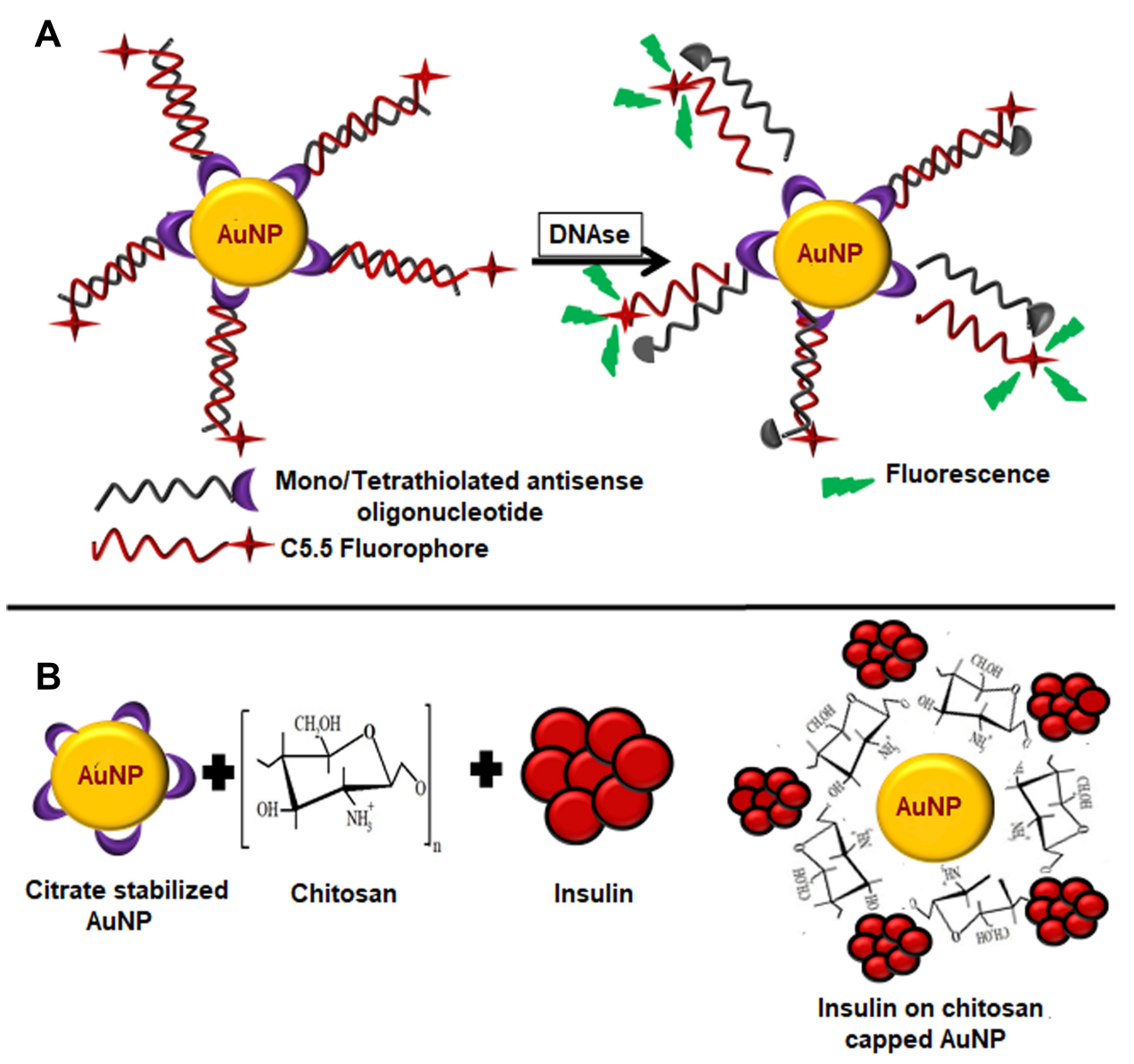

Figure 9 (A) Citrate capped AuNPs conjugated with mono/tetrathiol modified antisense oligonucleotides treated with DNAse. (B) Schematic illustration of preparation of insulin loaded AuNPs. Chitosan acts as a reducing and stabilizing agent during the formation of AuNPs. Insulin reacts with chitosan capped AuNPs through hydrogen bonding.

tissue regeneration therapy by delivering siRNA. An effective scaffold for binding of gold colloids with DNA can be produced by functionalizing AuNPs with amino acids. AuNPs functionalized with lysine dendron have been reported to be 28 -fold more efficient in gene expression as compared to polylysine. ${ }^{206}$

\section{Nanocarriers for the Delivery of Protein}

Gold nanoparticles can act as nanocarriers of proteins and peptides of interest. Verma et $\mathrm{al}^{266}$ reported that cationic tetraalkyl ammonium functionalized gold nanoparticles identify the surface of an anionic protein $\beta$ galactosidase via complementary electrostatic interaction and restrain its activity which can be reversed by cellular concentrations of glutathione. The study showed that glutathione-mediated discharge of enzyme $\beta$ galactosidase from AuNPs, which depends on the chain length of monolayer, makes it a potential transporter of the protein. In an earlier study, gold nanoparticles functionalized by chitosan have been used to deliver insulin. Chitosan is a non-toxic biopolymer used to synthesize and stabilize the nanoparticles. Chitosan functionalized insulin loaded AuNPs were found to lower the blood glucose level to $30.41 \%$ after 2 hours of oral administration. ${ }^{267}$ The schematic illustration of this study is shown in Figure 9B. AuNPs conjugated with cell penetrating peptides and lysosomes sorting peptides were tested for their targeted localization into lysosomes. The results showed that these functionalized AuNPs can be efficiently delivered into lysosomes while causing minimum cytotoxicity. Schäffler et $\mathrm{al}^{268}$ used gold nanoparticles for conjugation with human serum albumin (alb-AuNP) or apolipoprotein E prior to their intravenous injection. The outcome of the study demonstrated that protein conjugation extremely reduced the liver retention of AuNPs. This study suggests that the stable conjugation enhances the efficiency and specificity of nanoparticles in the target organ, therefore signifying a potential application in nanopharmacology and nanomedicine. 


\section{Limitations of Delivery of Large Biomolecules Using AuNPs}

The delivery of large biomolecules to the cells not only requires targeting to a site but also cellular internalization and sometimes intracellular release of the cargo. Therefore, various factors are to be considered before using gold nanoparticles in biomolecule delivery. As the size and shape of nanoparticles influence their cellular uptake, fabrication of gold nanoparticles of desired shape and size is critical. For the targeted drug delivery, the decoration of surface of AuNPs with specific ligands is very important. Moreover, lack of investigation on biodistribution and retention of these gene carriers is a major problem. In vivo investigations are needed to determine the response of living systems to these nanocarriers.

\section{Drug Release from AuNPs $\mathrm{pH}-$ Mediated Drug Release}

One of the most appropriate conditions for the release of drug at site of the target over the surrounding tissues is $\mathrm{pH}^{269}$ The acidic environment with the $\mathrm{pH}$ range from 5.7-7.8 is present in human cancer cells or inside the cell organelles including endosomes and vesicles. ${ }^{270,271}$ These specific $\mathrm{pH}$ conditions lead to the cleavage of acid sensitive bond and charge switching due to protonation and morphological alterations of carriers. For example, the acidic conditions ( $\mathrm{pH}$ 5.0) in lysosomes or endosomes or both can cause the cleavage of the hydrazone bond which is an acid-sensitive bond. ${ }^{272}$ This property of hydrazone bond has widely been used in the preparation of $\mathrm{pH}$ responsive supramolecular fabrications for intracellular drug release. A study has reported the AuNPs modified with methyl thioglycolate (MTG) and thiolated methoxy polyethylene glycol (HS-mPEG) having a molar ratio of 1:1. When doxorubicin (DOX) was conjugated with MTG through hydrazine bond the resultant DOX-AuNPs conjugates showed higher $\mathrm{pH}$-sensitive drug release under the $\mathrm{pH} 5.3$ as compared to the normal $\mathrm{pH}$ 7. The results showed that after 28 hours of incubation the released DOX drug can be located in the perinuclear region and the nuclei of $4 \mathrm{~T} 1$ cancer cells. ${ }^{273}$ The schematic illustration of this study is presented in Figure 10A. A study has also shown the synthesis of AuNPs functionalized with PEG ligands terminated with DOX having hydrazone bond between PEG and DOX for the release of therapeutics under low $\mathrm{pH}$. These particles were found to enter the cells through endocytosis. Apart from that, DOX-AuNPs having hydrazone bond as compared to the free doxorubicin showed higher drug built-up and retention in MCF-7/ ADR cancer cells which are multidrug resistant cells. ${ }^{274}$

\section{Glutathione (GSH)-Mediated Drug Release}

Glutathione-mediated drug release characterizes an alternate non-enzymatic approach for the activation of prodrugs in the intracellular environment. The basic principle of this approach is based on the difference in the concentration of GSH in the intracellular environment $(1-10 \mathrm{mM})^{275,276}$ as compared to that in the extracellular conditions ${ }^{277}$ and the major thiols present in the blood plasma are cysteine $(8 \mu \mathrm{M})$ and glutathione $(2 \mu \mathrm{M}) .{ }^{278}$ Previous approaches are based on the disulfide bond between the drugs and drug carriers. ${ }^{279,280}$ Although this approach can be efficacious, modification of the reactivity of the disulfide bond is relatively difficult. Another limitation is that the thiol-disulfide exchange can take place in the presence of cysteines located on the surface of the blood proteins, thus giving rise to a protein-carrier conjugate with different bioaccumulation and pharmacokinetic profiles. In a recent study, hydrophobic dye was used as a model for demonstrating glutathionemediated hydrophobic drug release using functionalized gold nanoparticles. A monolayer composed of PEGlyated cationic ligands (TTMA) and thiolated bodipy fluorogenic ligands (HSBDP) was presented on the particles. The presence of cationic ligand enables the passage through the plasma membrane barrier. The release of BODIPY which was not observed when tripeptide was used instead of glutathione indicated that thiol linkage (present in GSH and absent in tripeptide) was required for the release of payload. When AuNPs are conjugated with the dye, BODIPY fluorescence does not occur because the gold core quenches fluorescence through energy and/or electron transfer mechanisms. The fluorescence is produced when AuNPs are triggered with glutathione in cuvette, or cellular thiols present in HepG2 human liver cells. The dye liberation from AuNPs could be controlled by treating embryonic fibroblast cells from mouse with various concentrations of glutathione monoester. ${ }^{196}$ Figure 10B shows the schematic illustration of glutathione-mediated drug release from AuNPs.

\section{Light-Mediated Drug Release}

Studies have shown that gold nanoparticles having diverse shapes can exhibit very strong surface plasmon resonance 


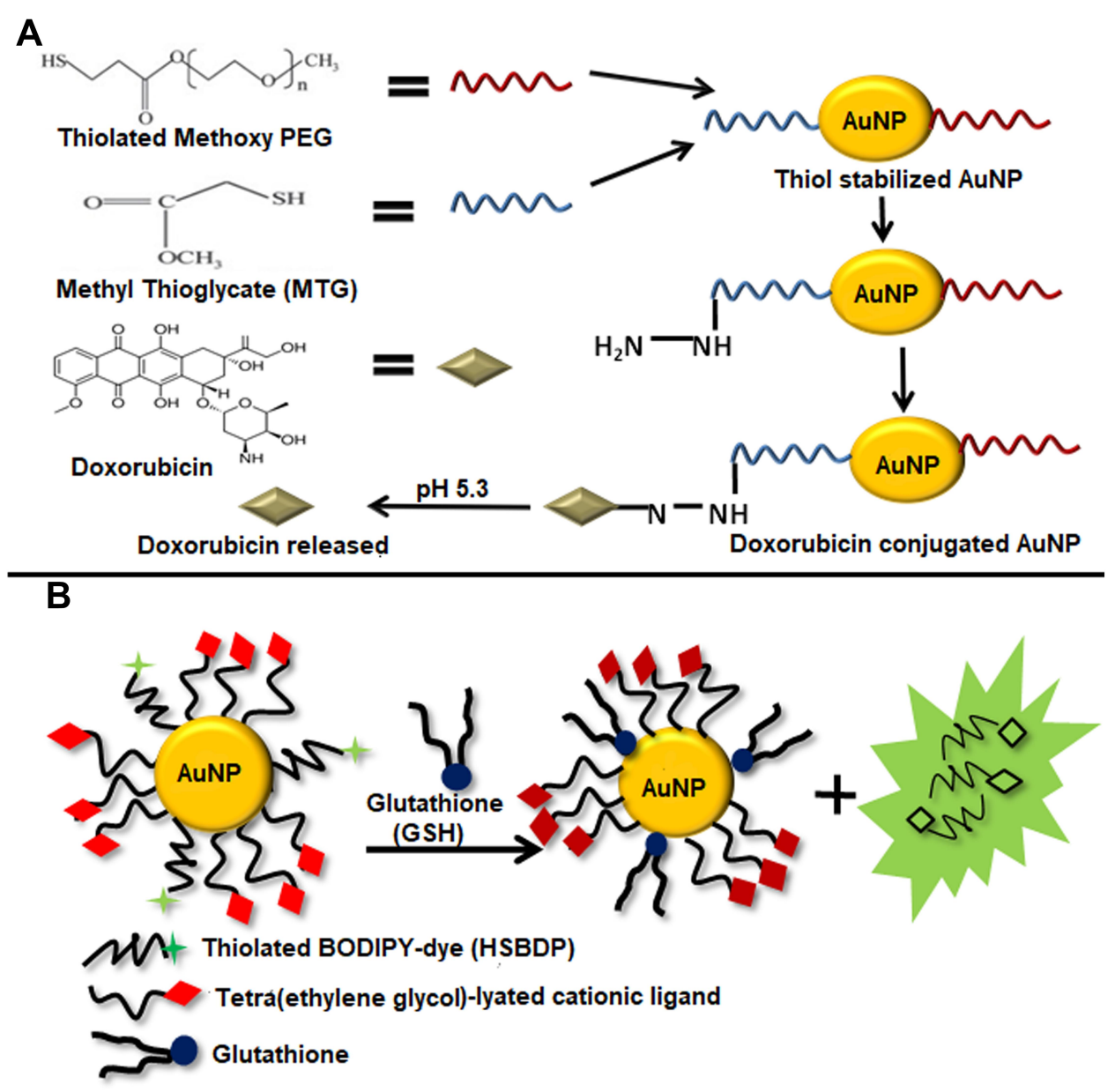

Figure 10 (A) Schematic Illustration of $\mathrm{pH}$-mediated release of Doxorubicin from Doxorubicin conjugated AuNPs. First thiol stabilized AuNPs were prepared using Thiolated Methoxy PEG and Methyl Thioglycate (MTG). Doxorubicin was conjugated to AuNPs through hydrazone bond. The acidic conditions ( $\mathrm{PH}$ 5.4) in the tumor cells cause the breaking of hydrazone bond releasing doxorubicin. (B) Glutathione-mediated release of a drug analog (HSBDP) from AuNPs. TTMA and HSBDP functionalized AuNPs when treated with glutathione at $37^{\circ} \mathrm{C}$ cause the release of HSBDP which can be detected by the fluorescence it produces in the free form which was quenched when conjugated with AuNPs.

in the presence of light. ${ }^{281}$ Due to this reason gold nanoparticles have been used for photothermal ablation and have been tested on various target cells including cancerous and bacterial cells. ${ }^{282-285}$ Gold nanoparticles have also been used for photodynamic therapy during which light triggers the production of oxygen at the site of target. The heating of gold nanoparticles using light may also be used for releasing therapeutic drug attached to gold nanoparticles. This plasmon induced heating of gold nanoparticles has application in the delivery of therapeutics into the cells as well as into the nucleus of target cells. Drug release from gold nanoparticles using this property was first reported in $2000 .{ }^{286}$ Similarly, later in time, Sreejivungsa et $\mathrm{al}^{287}$ showed that AuNPs exhibiting a novel monolayer can be used for controlled discharge of a model drug by using the light. Hydrophobic parts of the drug are trapped in the portions of monolayers of AuNPs through non- covalent linkages. When the light was irradiated it resulted in the cleavage of dinitrobenzyl linker causing the release of model drug entrapped in the compartments of monolayer of AuNPs. The results showed that more drug was released upon irradiation with UV light as compared to when no light was irradiated. Agasti et $\mathrm{al}^{288}$ demonstrated light-mediated release of anticancer drug; 5-fluorouracil (5-FU) from gold nanoparticles. Zwitterionic ligand was used for enhanced solubility and controlled cellular internalization. The irradiation with light $(365 \mathrm{~nm})$ causes the cleavage of orthonitrobenzyl group releasing 5-FU from the conjugate. Figure 11A shows the schematic illustration of this study. In another study, Wang et $\mathrm{al}^{289}$ used an amalgamation of chemotherapy and photothermal ablation to treat metastatic breast cancer using DNA-wrapped AuNRs loaded with DOX (GNR@DOX). Spherical gold nanoparticles display plasmon resonance in the central 

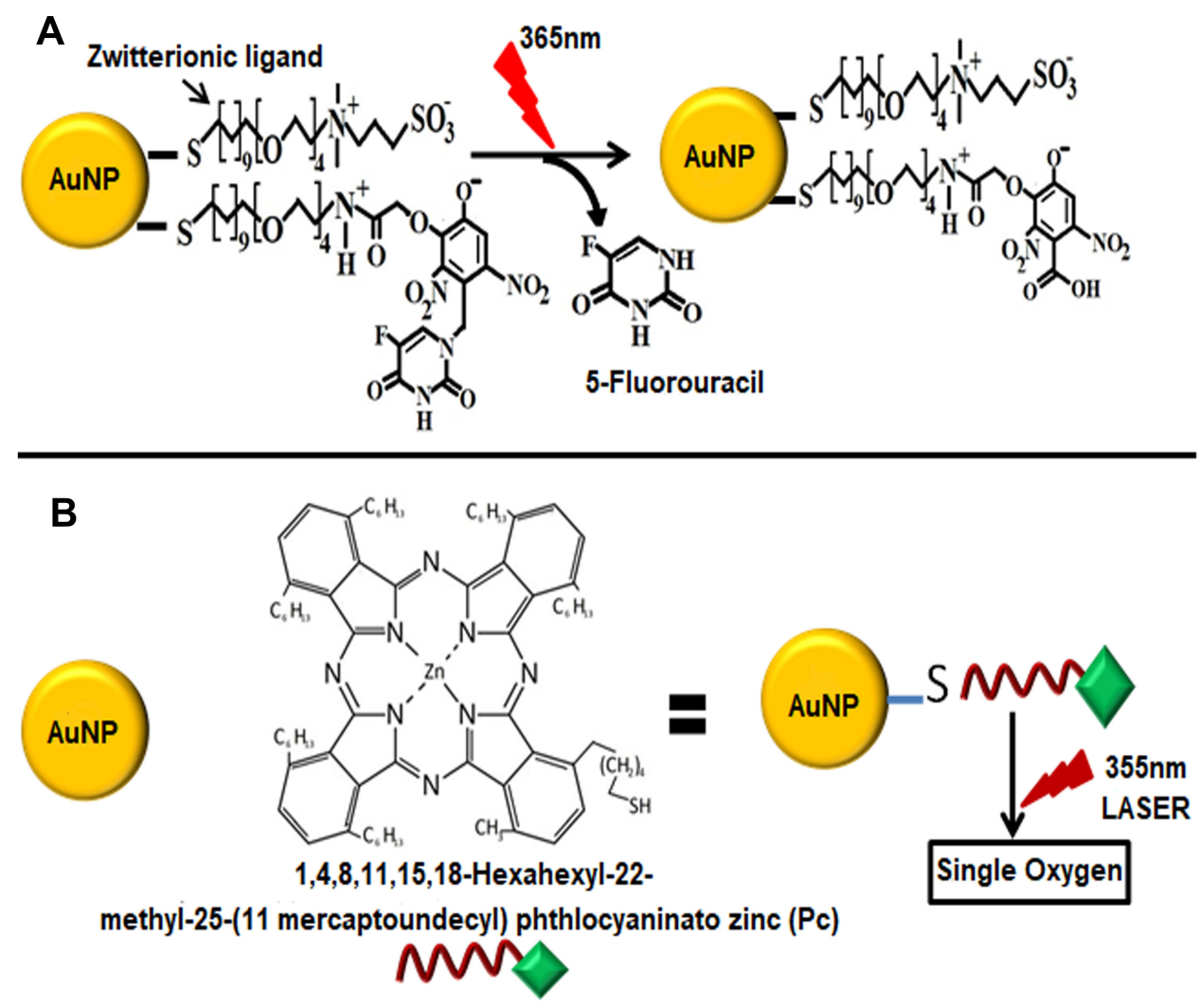

Figure II (A) Light-mediated drug release from AuNPs. Zwitterionic ligand integrates 5-fluorouracil (5-FU) to AuNPs through the Orthonitrobenzyl group which when irradiated with UV light with $365 \mathrm{~nm}$ wavelength undergoes photolytic cleavage of bond liberating 5-FU. (B) Release of singlet oxygen from phthalocyanines (Pc) conjugated AuNPs. When these conjugates were irradiated at $355 \mathrm{~nm}$ using a Q-switched Nd:YAG laser they generated singlet oxygen.

region of visible light, yet this resonance peak can be shifted to wavelength range of $\sim 800-1,200 \mathrm{~nm}$ in the infrared region when nanoparticles having complex shapes like rods and shells are used. As the body tissues are more transparent to NIR wavelength of light, nanoparticles with complex shapes can be used for in vivo therapy. ${ }^{290,291}$ Another study has also reported the synthesis of hydrogel poly (Nisopropylacryamide) (PNIPAM) coated gold nanorods. When the NIR laser was irradiated onto these gold nanorods it resulted in the shrinkage of the hydrogels, thus causing the drug release. ${ }^{292,293}$ As an extension of this basic principle, the surface of AuNPs was attached with light sensitive chemical species, spiropyran. Spiropyran can make complex structures in conjugation with amino acids which are sensitive to light. It can also reverse its conformational changes upon further irradiation with light. The complexes that spiropyran makes with amino acids in open form are destroyed upon irradiation with light and its conformation can be reversed to closed form thus causing the release of the amino acids. ${ }^{294}$ These conjugates have a potential application as a basis for efficient light- dependent controlled drug discharge systems for treatment of various conditions.

\section{Release of Atomic Oxygen or Nitric Oxide}

Atomic oxygen $\left(1 / 2 \mathrm{O}_{2}\right)$ exhibit cytotoxic properties and can be used for photodynamic therapy of cancer. ${ }^{295}$ AuNPs can act as delivery vehicles for the transport of such therapeutics as atomic oxygen, or nitric oxide. In an investigation, phthalocyanines (PCs) were attached on the surface of thiol-protected AuNPs, also called as monolayer protected clusters (MPCs), for the generation of atomic oxygen with good quantum yield. ${ }^{296}$ The results indicated that as compared to the free PCs quantum yield was augmented by almost 50\% when conjugated with MPCs. In addition to that, upon conjugation hydrophobic PCs became soluble in polar solvents such as ethanol and toluene. Figure 11B shows schematic illustration of this study for the release of singlet oxygen. On the other hand, nitric oxide (NO), controls numerous cellular processes including angiogenesis, vasodilation, as well as the immune response. ${ }^{297}$ Controlled release of NO can prove 
to be an efficient treatment strategy for hypoxic respiratory failure. Polizzi et al $^{298}$ reported that NO can be proficiently stored via covalent bonding with polyamine stabilized MPCs through the development of $\mathrm{pH}$-sensitive $\mathrm{N}$-diazeniumdiolate. The results showed that at a low $\mathrm{pH}$ of 3 there was an efficient liberation of NO from the nanocontainers. As the tumor and inflammatory tissues, endosomes etc. have mild acidic conditions these $\mathrm{pH}$-sensitive materials can be efficiently used for drug delivery to these entities. $^{299-301}$

\section{Enzyme-Mediated Drug Release}

Enzymes which are biological catalysts are responsible to sustain life as they catalyze millions of chemical reactions taking place in the living organism. They are substrate specific and not only increase the speed of chemical reactions but also control specificity of metabolic processes. ${ }^{302}$ The characteristic degradation by enzyme can be employed for the selective and controlled release of therapeutics from gold nano-conjugates through enhanced permeability and retention effect (EPR). ${ }^{303}$ In a study, Hwu et $\mathrm{al}^{304}$ reported AuNPs and $\mathrm{Fe}_{3} \mathrm{O}_{4}$ nanoparticles conjugated with Paclitaxel (PTX) through a phosphodiester bond between thiol-terminated tetraethylene glycol and the $\mathrm{C}-2^{\prime}$ position of PTX. The phosphodiesterase enzyme present in cancer cells resulted in the cleavage of the phosphodiester linkage. The schematic illustration of this study is presented in Figure 12. Similarly, another method employed for the designing of prodrugs is esterification and acylation. Enzymes esterases and amidases present in living cells can break the bonds between drugs and nanostructures resulting in liberation of drugs from their prodrugs. ${ }^{19}$ Gibson et al, ${ }^{247}$ in order to accurately measure the quantity of drug loading through thermogravimetric analysis efficaciously linked gold nanocrystals terminated with phenol to a linear derivative of paclitaxel. The mild esterification conditions were used for this reaction and resulted in the high yield of PTX payload.

\section{Advantages and Limitations in Drug Release Methods}

The low $\mathrm{pH}$ value of cancer microenvironments can be used for effective drug release from nanocarrier by cleaving an acid sensitive bond between drug and nanoparticle. But with the evidence from new investigation which reported that cancer cells not only have acidic environment but also alkaline has limited the applications of $\mathrm{pH}$ sensitive nano drug carriers. $^{305,306}$ Moreover, the cleavage of $\mathrm{pH}$ responsive bond is not a rapid process making drug release timeconsuming. ${ }^{307}$ Light-mediated drug release is relatively new and an auspicious strategy to regulate the liberation of drugs and fluorescent dyes during in vitro and in vivo analysis. Even though initially this strategy has been very successful, the conventional mechanism which involves the use of light with short wavelength, ie, UV light and visible light has its inherited drawbacks. These drawbacks include inadequate tissue penetration, undesirable absorption, or scattering of light and possible phototoxicity to normal cells, etc. One possible solution is irradiation with NIR light which has

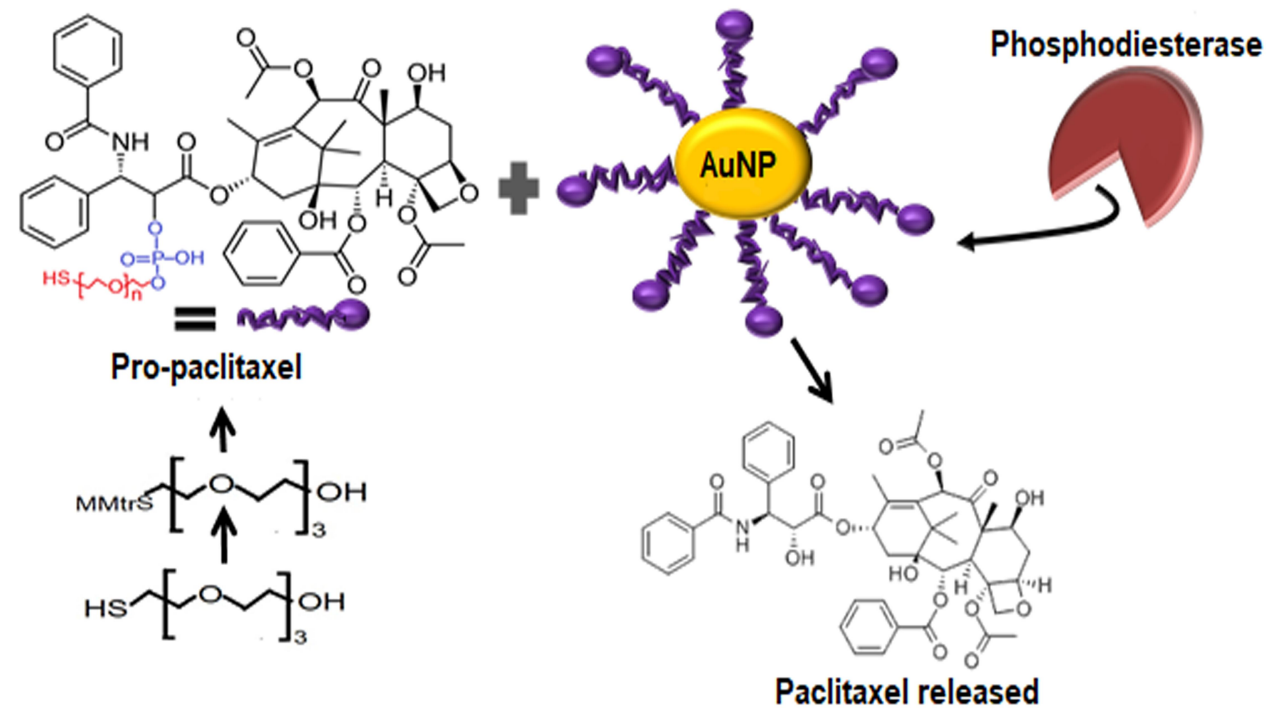

Figure 12 Enzyme-mediated drug release from AuNPs. Pro-paclitaxel was produced by first protecting the thiol group of tetraethylene glycol using (mono-4-methoxy) trityl chloride $(\mathrm{MMTrCl})$ and then reacting it with paclitaxel. The thiol terminal of pro-paclitaxel incorporated it onto AuNPs. When treated with enzyme Phosphodiesterase, the Phosphodiester moieties were hydrolyzed causing the liberation of free paclitaxel. 
longer wavelength (700-1,000 nm) and demonstrates appropriate penetration of tissues and exhibits reduced phototoxicity in living systems. Although various NIR-sensitive compounds are being tested for clinical applications, several associated shortcomings include complex synthetic methodologies, low water solubility, and the capability of imperfectly aggregating in targeted areas which greatly hinders their applications in drug delivery to deep tissues. ${ }^{308}$ Glutathione is considered as efficient stimuli for carrying out successful release of drug in vivo systems, yet there are certain limitations associated with this approach, as described in section 10.2. First, the modification of reactivity of disulphide bond is difficult and undesirable thiol-disulfide exchange reactions can take place with cysteines present on other proteins. Moreover, their instability in-vivo systems, challenges in the modifications of surface of AuNPs for multifunctioning and less blood circulation time period of gold nanoparticles protected with monolayer makes them unsuitable for applications in drug delivery. ${ }^{309}$ In contrast, enzyme-responsive drug delivery structures are considered as a promising strategy to attain effective intracellular drug release, ${ }^{303,310}$ since there are a plethora of enzymes comprising proteases, matrix metalloproteinases, and hyaluronidases located inside the lysosomes. ${ }^{307}$ Complex formulation strategies of enzymes-responsive AuNP-drug carriers and severe conditions inside lysosomal environment causing the drug to degrade and reduce its practicability are major challenges of enzymes mediated drug release. It is anticipated that with the unceasing progress in formulation of materials science and cancer treatment, the difficulties cited above can be successfully resolved by the designing "smart" drug release systems.

\section{Conclusion}

In this review article, we have discussed the approaches for the synthesis of gold nanoparticles, functionalization, and application in drug and biomolecule delivery. Due to their exclusive properties like tunable size and shape, ease of functionalization and fabrication, monodispersity, and low toxicity, AuNPs are considered as exceptionally suitable agents for drug delivery. Green synthesis of gold nanoparticle is rather an effortless and ecofriendly method which ousts the concerns associated with biomedical applications of chemically formulated gold nanoparticles. There are wide varieties of biological systems which have been tested for their potential to operate as reducing agents during synthesis reaction. Plants are contemplated to be the most dependable resource for this purpose. Not only do parts of plants (leaves, stems and roots) have reducing abilities, but also the waste produced by plants, such as fruit peels etc. exhibit the same properties. Moreover, the process is quite simple and rapid. There are numerous possibilities for tuning the surface of AuNPs using different moieties, including PEG, amino acids and peptides, oligonucleotides, and antibodies to facilities the loading of the drug and biomolecules. PEGlyation of AuNPs is considered as the most suitable choice of functionalization for in vivo delivery of therapeutic agents as it is biocompatible and facilitates nano drug carriers to evade the body's immune system. Limitations associated with PEGlyation such as loss of ability of AuNPs to bind with the target receptor can be addressed by decorating the surface of AuNPs with target specific ligands. Delivery of large biomolecules using AuNPs as a delivery vehicle is an innovative and interesting field and has received a lot of consideration over the past few years, but more investigations are still required to design structures capable of intracellular and intranuclear delivery of conjugates with minimal side effects. Another challenge related to the application of AuNPs in drug delivery is effective and efficient release of payloads at the target site. Various stimuli (both external and internal) have been reported to perform this function. Although each of these drug release strategies has its own limitations, designing a novel gold nano drug delivery system capable of flawlessly carrying and discharging payload at the target site is the subject of future research. Conclusively, gold nanoparticles offer a promising strategy, but in vivo delivery efficacy and clinical studies are critically needed.

\section{Disclosure}

The authors report no conflicts of interest for this work.

\section{References}

1. Ealias AM, Saravanakumar MP. A review on the classification, characterisation, synthesis of nanoparticles and their application. IOP Conf Ser Mater Sci Eng. 2017;263:3. doi:10.1088/1757-899X/263/3/032019

2. Cai W, Gao T, Hao Hong JS. Applications of gold nanoparticles in cancer nanotechnology. Nanotechnol Sci Appl. 2008;1:17-32. doi:10.2147/NSA.S3788

3. Mokhatab S, Fresky MA, Islam MR. Applications of nanotechnology in oil and gas E\&P. J Pet Technol. 2006;58(04):48-51. doi:10.2118/ 0406-0048-jpt

4. Mu L, Sprando RL. Application of nanotechnology in cosmetics. Pharm Res. 2010;27(8):1746-1749. doi:10.1007/s11095-010-0139-1

5. Liu Z, Cai W, He L, et al. In vivo biodistribution and highly efficient tumour targeting of carbon nanotubes in mice. Nat Nanotechnol. 2007;2(1):47-52. doi:10.1038/nnano.2006.170

6. Daniel M-C, Astruc D. Gold nanoparticles: assembly, supramolecular chemistry, quantum-size-related properties, and applications toward biology, catalysis, and nanotechnology. Chem Rev. 2004;104 (1):293-346. 
7. Park JW, Benz CC, Martin FJ. Future directions of liposome- and immunoliposome-based cancer therapeutics. Semin Oncol. 2004;31 (SUPPL. 13):196-205. doi:10.1053/j.seminoncol.2004.08.009

8. Jurgons R, Seliger C, Hilpert A, Trahms L, Odenbach S, Alexiou C. Drug loaded magnetic nanoparticles for cancer therapy. J Phys Condens Matter. 2006;18(38):38. doi:10.1088/ 0953-8984/18/38/S24

9. Dykman L, Khlebtsov N. Gold nanoparticles in biomedical applications: recent advances and perspectives. Chem Soc Rev. 2012;41(6):2256-2282. doi:10.1039/c1cs15166e

10. Paciotti GF, Kingston DGI, Tamarkin L. Colloidal gold nanoparticles: a novel nanoparticle platform for developing multifunctional tumor-targeted drug delivery vectors. Drug Dev Res. 2006;67(1):47-54. doi:10.1002/ddr.20066

11. Paciotti GF, Myer L, Weinreich D, et al. Colloidal gold: a novel nanoparticle vector for tumor directed drug delivery. Drug Deliv J Deliv Target Ther Agents. 2004;11(3):169-183. doi:10.1080/ 10717540490433895

12. Chen YH, Tsai CY, Huang PY, et al. Methotrexate conjugated to gold nanoparticles inhibits tumor growth in a syngeneic lung tumor model. Mol Pharm. 2007;4(5):713-722. doi:10.1021/ mp060132k

13. Prabaharan M, Grailer JJ, Pilla S, Steeber DA, Gong S. Gold nanoparticles with a monolayer of doxorubicin-conjugated amphiphilic block copolymer for tumor-targeted drug delivery. Biomaterials. 2009;30(30):6065-6075. doi:10.1016/j.biomaterials.2009.07.048

14. Zarabi MF, Farhangi A, Mazdeh SK, et al. Synthesis of gold nanoparticles coated with aspartic acid and their conjugation with FVIII protein and FVIII antibody. Indian J Clin Biochem. 2014;29(2):154-160. doi:10.1007/s12291-013-0323-2

15. Kalimuthu K, Lubin BC, Bazylevich A, et al. Gold nanoparticles stabilize peptide-drug-conjugates for sustained targeted drug delivery to cancer cells. J Nanobiotechnology. 2018;16(1). doi:10.1186/s12951-018-0362-1

16. Storhoff JJ, Mirkin CA. Programmed materials synthesis with DNA. Chem Rev. 1999;99(7):1849-1862. doi:10.1021/cr970071p

17. Park C, Youn H, Kim H, et al. Cyclodextrin-covered gold nanoparticles for targeted delivery of an anti-cancer drug. $J$ Mater Chem. 2009;19(16):2310-2315. doi:10.1039/b816209c

18. Joshi P, Chakraborti S, Ramirez-Vick JE, et al. The anticancer activity of chloroquine-gold nanoparticles against MCF-7 breast cancer cells. Colloids Surf B Biointerfaces. 2012;95:195-200. doi:10.1016/j.colsurfb.2012.02.039

19. Schwert GW, Eisenberg MA. The kinetics of the amidase and esterase activities of trypsin. J Biol Chem. 1949;179(5):665-72.

20. Han K, Zhu JY, Wang SB, Li ZH, Cheng SX, Zhang XZ. Tumor targeted gold nanoparticles for FRET-based tumor imaging and light responsive on-demand drug release. J Mater Chem B. 2015;3(41):8065-8069. doi:10.1039/c5tb01659b

21. Tangeysh B, Tibbetts KM, Odhner JH, Wayland BB, Levis RJ. Gold nanoparticle synthesis using spatially and temporally shaped femtosecond laser pulses: post-irradiation auto-reduction of aqueous [AuCl4]. J Phys Chem C. 2013;117(36):18719-18727. doi:10.1021/jp4056494

22. Birtcher RC, Kirk MA, Furuya K, Lumpkin GR. In situ transmission electron microscopy investigation of radiation effects. J Mater Res. 2005;20(7):1654-1683. doi:10.1557/ JMR.2005.0242

23. Sakamoto M, Fujistuka M, Majima T. Light as a construction tool of metal nanoparticles: synthesis and mechanism. J Photochem Photobiol C. 2009;10(1):33-56. doi:10.1016/j. jphotochemrev.2008.11.002

24. Zhou Y, Wang CY, Zhu YR, Chen ZY. A novel ultraviolet irradiation technique for shape-controlled synthesis of gold nanoparticles at room temperature. Chem Mater. 1999;11(9):2310-2312. doi:10.1021/cm990315h
25. Krinke TJ, Deppert K, Magnusson MH, Schmidt F, Fissan H. Microscopic aspects of the deposition of nanoparticles from the gas phase. J Aerosol Sci. 2002;33(10):1341-1359. doi:10.1016/ S0021-8502(02)00074-5

26. Turkevich J, Cooper PHJ. A study of the nucleation and growth process in the synthesis of colloidal gold. Discuss Faraday Soc. 1951;55(c):55-75. doi:10.1039/df9511100055

27. Wangoo N, Bhasin KK, Mehta SK, Suri CR. Synthesis and capping of water-dispersed gold nanoparticles by an amino acid: bioconjugation and binding studies. J Colloid Interface Sci. 2008;323(2):247-254. doi:10.1016/j.jcis.2008.04.043

28. Niidome Y, Nishioka K, Kawasaki H, Yamada S. Rapid synthesis of gold nanorods by the combination of chemical reduction and photoirradiation processes; morphological changes depending on the growing processes. ChemComm. 2003;18(18):2376-2377. doi:10.1039/ b307836a

29. Pal A, Esumi K, Pal T. Preparation of nanosized gold particles in a biopolymer using UV photoactivation. J Colloid Interface Sci. 2005;288(2):396-401. doi:10.1016/j.jcis.2005.03.048

30. Kumar S, Gandhi KS, Kumar R. Modeling of formation of gold nanoparticles by citrate method. Ind Eng Chem Res. 2007;46 (10):3128-3136. doi:10.1021/ie060672j

31. Frens G. Controlled nucleation for the regulation of the particle size in monodisperse gold suspensions. Nat Phys Sci. 1973;241 (105):20-22. doi:10.1038/physci241020a0

32. Yonezawa $\mathrm{T}$, Kunitake $\mathrm{T}$. Practical preparation of anionic mercapto ligand-stabilized gold nanoparticles and their immobilization. Colloids Surf a Physicochem Eng Asp. 1999;149(1-3):193-199. doi:10.1016/S0927-7757(98)00309-4

33. Watson KJ, Zhu J, Nguyen ST, Mirkin C. Hybrid nanoparticles with block copolymer shell structures. J Am Chem Soc. 1998;121 (2):462-463. doi:10.1021/ja9831731

34. Brust M, Walker M, Bethell D, Schiffrin DJ, Whyman R. Synthesis of thiol-derivatised gold nanoparticles in a two-phase liquid-liquid system. J Chem Soc Chem Commun. 1994;7:5-7.

35. Giersig M, Mulvaney P. Preparation of ordered colloid monolayers by electrophoretic deposition. Langmuir. 1993;9 (12):3408-3413. doi:10.1021/la00036a014

36. Faraday M. The bakerian lecture: experimental relations of gold (and other metals) to light. Philos Trans $R$ Soc. 1857;147:145-181. doi:10.1098/rstl.1857.0011

37. Sau TK, Murphy CJ. Room temperature, high-yield synthesis of multiple shapes of gold nanoparticles in aqueous solution. $J \mathrm{Am}$ Chem Soc. 2004;126(28):9-10. doi:10.1021/ja047846d

38. Chen Y, Gu X, Nie C-G, Jiang Z-Y, Xie Z-X, Lin C-J. Shape controlled growth of gold nanoparticles by a solution synthesis. ChemComm. 2005;1(33):4181. doi:10.1039/b504911c

39. Hinman JG, Stork AJ, Varnell JA, Gewirth AA, Murphy CJ. Seed mediated growth of gold nanorods: towards nanorod matryoshkas 1. Introduction: a brief review of anisotropy on the nanoscale. Faraday Discuss. 2016;191:9-33. doi:10.1039/C6FD00145A

40. Sahu P, Prasad BLV. Time and temperature effects on the digestive ripening of gold nanoparticles: is there a crossover from digestive ripening to ostwald ripening? Langmuir. 2014;30 (34):10143-10150. doi:10.1021/la500914j

41. Kundu S, Peng L, Liang H. A new route to obtain high-yield multiple-shaped gold nanoparticles in aqueous solution using microwave irradiation. Inorg Chem. 2008;47(14):6344-6352. doi: $10.1021 /$ ic 8004135

42. Lee JH, Choi SUS, Jang SP, Lee SY. Production of aqueous spherical gold nanoparticles using conventional ultrasonic bath. Nanoscale Res Lett. 2012;7(1):1-7. doi:10.1186/1556-276X-7-420

43. Dong J, Carpinone PL, Pyrgiotakis G, Demokritou P, Moudgil BM. Synthesis of precision gold nanoparticles using turkevich method. KONA Powder Part J. 2020;37:224-232. doi:10.14356/kona.2020011 
44. Herizchi R, Abbasi E, Milani M, Akbarzadeh A. Current methods for synthesis of gold nanoparticles. Artif Cells Nanomed Biotechnol. 2016;44(2):596-602. doi:10.3109/21691401.2014.971807

45. Ward CJ, Tronndorf R, Eustes AS, Auad ML, Davis EW. Seedmediated growth of gold nanorods: limits of length to diameter ratio control. J Nanomater. 2014;2014:1-7. doi:10.1155/2014/765618

46. Sidhaye DS, Prasad BLV. Many manifestations of digestive ripening: monodispersity, superlattices and nanomachining. New $J$ Chem. 2011;35(4):755-763. doi:10.1039/c0nj00359j

47. Shimpi JR, Sidhaye DS, Prasad BLV. Digestive ripening: a fine chemical machining process on the nanoscale. Langmuir. 2017;33 (38):9491-9507. doi:10.1021/acs.langmuir.7b00193

48. Chen YS, Hung YC, Liau I, Huang GS. Assessment of the in vivo toxicity of gold nanoparticles. Nanoscale Res Lett. 2009;4 (8):858-864. doi:10.1007/s11671-009-9334-6

49. Korbekandi H, Iravani S, Abbasi S. Production of nanoparticles using organisms. Crit Rev Biotechnol. 2009;29(4):279-306 doi:10.3109/07388550903062462

50. Pourali P, Badiee SH, Manafi S, Noorani T, Rezaei A, Yahyaei B. Biosynthesis of gold nanoparticles by two bacterial and fungal strains, bacillus cereus and fusarium oxysporum, and assessment and comparison of their nanotoxicity in vitro by direct and indirect assays. Electron J Biotechnol. 2017;29:86-93. doi:10.1016/j.ejbt.2017.07.005

51. Singh PK, Kundu S. Biosynthesis of gold nanoparticles using bacteria. Proc Natl Acad Sci India Sect B Biol Sci. 2014;84 (2):331-336. doi:10.1007/s40011-013-0230-6

52. Sharma N, Pinnaka AK, Raje M, Fnu A, Bhattacharyya MS, Choudhury AR. Exploitation of marine bacteria for production of gold nanoparticles. Microb Cell Fact. 2012;11(1):1-6. doi: 10.1186/1475-2859-11-86

53. Li X, Xu H, Chen Z-S, Chen G. Biosynthesis of nanoparticles by microorganisms and their applications. Liang XJ, ed. J Nanomater. 2011;2011:270974. doi:10.1155/2011/270974

54. Mewada A, Oza G, Pandey S, Sharon M, Ambernath W. Extracellular biosynthesis of gold nanoparticles using pseudomonas denitiricans and comprehending its stability. J Microbiol Biotechnol Res. 2012;2(4):493-499.

55. Shah R, Oza G, Pandey S, Sharon M. Biogenic fabrication of gold nanoparticles using halomonas salina. J Microbiol Biotechnol Res. 2012;2(4):485-492.

56. Ahmad A, Senapati S, Khan MI, Kumar R, Sastry M. Extracellular biosynthesis of monodisperse gold nanoparticles by a novel extremophilic actinomycete, thermomonospora sp. Langmuir. 2003;19(8):3550-3553. doi:10.1021/la0267721

57. Konishi Y, Tsukiyama T, Tachimi T, Saitoh N, Nomura T, Nagamine S. Microbial deposition of gold nanoparticles by the metal-reducing bacterium shewanella algae. Electrochim Acta. 2007;53(1):186-192. doi:10.1016/j.electacta.2007.02.073

58. Zhang X, He X, Wang K, Yang X. Different active biomolecules involved in biosynthesis of gold nanoparticles by three fungus species. J Biomed Nanotechnol. 2011;7(2):245-254. doi:10.1166/ jbn.2011.1285

59. Medina Cruz D, Mi G, Webster TJ. Synthesis and characterization of biogenic selenium nanoparticles with antimicrobial properties made by Staphylococcus aureus, methicillin-resistant Staphylococcus aureus (MRSA), Escherichia coli, and Pseudomonas aeruginosa. J Biomed Mater Res Part A. 2018;106 (5):1400-1412. doi:10.1002/jbm.a.36347

60. Ovais M, Khalil AT, Islam NU, et al. Role of plant phytochemicals and microbial enzymes in biosynthesis of metallic nanoparticles. Appl Microbiol Biotechnol. 2018;102 (16):6799-6814. doi:10.1007/s00253-018-9146-7

61. Castro-Longoria E, Vilchis-Nestor AR, Avalos-Borja M. Biosynthesis of silver, gold and bimetallic nanoparticles using the filamentous fungus neurospora crassa. Colloids Surf B Biointerfaces. 2011;83(1):42-48. doi:10.1016/j.colsurfb.2010.10.035
62. Agnihotri M, Joshi S, Kumar AR, Zinjarde S, Kulkarni S. Biosynthesis of gold nanoparticles by the tropical marine yeast yarrowia lipolytica NCIM 3589. Mater Lett. 2009;63 (15):1231-1234. doi:10.1016/j.matlet.2009.02.042

63. Senapati S, Ahmad A, Khan MI, Sastry M, Kumar R. Extracellular biosynthesis of bimetallic au-ag alloy nanoparticles. Small. 2005;1(5):517-520. doi:10.1002/smll.200400053

64. Mukherjee P, Ahmad A, Mandal D, et al. Bioreduction of AuCl (4)(-) ions by the fungus, verticillium sp. and surface trapping of the gold nanoparticles formed D.M. and S.S. thank the council of scientific and industrial research (CSIR), Government of India, for financial assistance. Angew Chem Int Ed Engl. 2001;40(19). doi:10.1002/1521-3773(20011001)40:19<3585::AIDANIE3585>3.0.CO;2-K

65. Sanghi R, Verma P, Puri S. Enzymatic formation of gold nanoparticles using phanerochaete chrysosporium. Adv Chem Eng Sci. 2011;01(03):154-162. doi:10.4236/aces.2011.13023

66. Lee KX, Shameli K, Yew YP, et al. Recent developments in the facile bio-synthesis of gold nanoparticles (AuNPs) and their biomedical applications. Int $J$ Nanomedicine. 2020;15:275-300. doi:10.2147/IJN.S233789

67. Zadernowski R, Czaplicki S, Naczk M. Phenolic acid profiles of mangosteen fruits (Garcinia mangostana). Food Chem. 2009;112 (3):685-689. doi:10.1016/j.foodchem.2008.06.030

68. Lee KX, Shameli K, Miyake M, et al. Gold nanoparticles biosynthesis: a simple route for control size using waste peel extract. IEEE Trans Nanotechnol. 2017;16(6):954-957. doi:10.1109/ TNANO.2017.2728600

69. Ganesan R, Gurumallesh Prabu H. Synthesis of gold nanoparticles using herbal Acorus calamus rhizome extract and coating on cotton fabric for antibacterial and UV blocking applications. Arab J Chem. 2015. doi:10.1016/j.arabjc.2014.12.017

70. Ganesh Kumar V, Dinesh Gokavarapu S, Rajeswari A, et al. Facile green synthesis of gold nanoparticles using leaf extract of antidiabetic potent Cassia auriculata. Colloids Surf $B$ Biointerfaces. 2011;87(1):159-163. doi:10.1016/j. colsurfb.2011.05.016

71. Karuppiah C, Palanisamy S, Chen S-M, Emmanuel R, Muthupandi K, Prakash P. Green synthesis of gold nanoparticles and its application for the trace level determination of painter's colic. RSC Adv. 2015;5(21):16284-16291. doi:10.1039/ C4RA14988B

72. Gopinath K, Venkatesh KS, Ilangovan R, Sankaranarayanan K, Arumugam A. Green synthesis of gold nanoparticles from leaf extract of terminalia arjuna, for the enhanced mitotic cell division and pollen germination activity. Ind Crops Prod. 2013;50:737-742. doi:10.1016/j.indcrop.2013.08.060

73. Khalil MMH, Ismail EH, El-Magdoub F. Biosynthesis of Au nanoparticles using olive leaf extract: 1st nano updates. Arab J Chem. 2012;5(4):431-437. doi:10.1016/j.arabjc.2010.11.011

74. Philip D. Rapid green synthesis of spherical gold nanoparticles using mangifera indica leaf. Spectrochim Acta A Mol Biomol Spectrosc. 2010;77(4):807-810. doi:10.1016/j. saa.2010.08.008

75. Yu J, Xu D, Guan HN, Wang C, Huang LK, Chi DF. Facile one-step green synthesis of gold nanoparticles using Citrus maxima aqueous extracts and its catalytic activity. Mater Lett. 2016;166:110-112. doi:10.1016/j.matlet.2015.12.031

76. Opris R, Tatomir C, Olteanu D, et al. The effect of Sambucus nigra L. extract and photosynthesized gold nanoparticles on diabetic rats. Colloids Surf B Biointerfaces. 2017;150:192-200. doi:10.1016/j.colsurfb.2016.11.033

77. Lee S-E, Lee KD, An M, Lee K-D. Green synthesis of silver and gold nanoparticles using lonicera japonica flower extract. Bull Korean Chem Soc. 2012;33(8):2609-2612. doi:10.5012/ BKCS.2012.33.8.2609 
78. Anand K, Gengan RM, Phulukdaree A, Chuturgoon A. Agroforestry waste moringa oleifera petals mediated green synthesis of gold nanoparticles and their anti-cancer and catalytic activity. J Ind Eng Chem. 2015;21:1105-1111. doi:10.1016/j. jiec.2014.05.021

79. Ghoreishi SM, Behpour M, Khayatkashani M. Green synthesis of silver and gold nanoparticles using rosa damascena and its primary application in electrochemistry. Physica E Low Dimens Syst Nanostruct. 2011;44(1):97-104. doi:10.1016/j.physe.2011.07.008

80. Noruzi M, Zare D, Khoshnevisan K, Davoodi D. Rapid green synthesis of gold nanoparticles using rosa hybrida petal extract at room temperature. Spectrochim Acta A Mol Biomol Spectrosc. 2011;79(5):1461-1465. doi:10.1016/j.saa.2011.05.001

81. Vijayakumar S, Vaseeharan B, Malaikozhundan B, et al. Therapeutic effects of gold nanoparticles synthesized using Musa paradisiaca peel extract against multiple antibiotic resistant Enterococcus faecalis biofilms and human lung cancer cells (A549). Microb Pathog. 2017;102:173-183. doi:10.1016/j. micpath.2016.11.029

82. Yang N, WeiHong L, Hao L. Biosynthesis of Au nanoparticles using agricultural waste mango peel extract and its in vitro cytotoxic effect on two normal cells. Mater Lett. 2014;134:67-70. doi:10.1016/j.matlet.2014.07.025

83. Nadagouda MN, Iyanna N, Lalley J, Han C, Dionysiou DD, Varma RS. Synthesis of silver and gold nanoparticles using antioxidants from blackberry, blueberry, pomegranate, and turmeric extracts. ACS Sustain Chem Eng. 2014;2(7):1717-1723. doi:10.1021/sc500237k

84. Lv J, Yi Y, Wu G, Liu W. Gold nanotriangles: green synthesis and PDT \& PTT effect. Mater Lett. 2017;187:148-150. doi:10.1016/j. matlet.2016.10.087

85. Velmurugan P, Anbalagan K, Manosathyadevan M, et al. Green synthesis of silver and gold nanoparticles using zingiber officinale root extract and antibacterial activity of silver nanoparticles against food pathogens. Bioprocess Biosyst Eng. 2014;37 (10):1935-1943. doi:10.1007/s00449-014-1169-6

86. Fazal S, Jayasree A, Sasidharan S, Koyakutty M, S V N, Menon D. Green synthesis of anisotropic gold nanoparticles for photothermal therapy of cancer. ACS Appl Mater Interfaces. 2014;6(11):8080-8089. doi:10.1021/am500302t

87. Yuan C-G, Huo C, Yu S, Gui B. Biosynthesis of gold nanoparticles using capsicum annuum var. grossum pulp extract and its catalytic activity. Physica E Low Dimens Syst Nanostruct. 2017;85:19-26. doi:10.1016/j.physe.2016.08.010

88. Karthika V, Arumugam A, Gopinath K, et al. Guazuma ulmifolia bark-synthesized $\mathrm{Ag}$, $\mathrm{Au}$ and $\mathrm{Ag} / \mathrm{Au}$ alloy nanoparticles: photocatalytic potential, DNA/protein interactions, anticancer activity and toxicity against 14 species of microbial pathogens. J Photochem Photobiol B Biol. 2017;167:189-199. doi:10.1016/ j.jphotobiol.2017.01.008

89. Islam NU, Jalil K, Shahid M, Muhammad N, Rauf A. Pistacia integerrima gall extract mediated green synthesis of gold nanoparticles and their biological activities. Arab J Chem. 2019;12 (8):2310-2319. doi:10.1016/j.arabjc.2015.02.014

90. Cabrera FC, Mohan H, Dos Santos RJ, et al. Green synthesis of gold nanoparticles with self-sustained natural rubber membranes. Gu HC, ed. J Nanomater. 2013;2013:710902. doi:10.1155/2013/ 710902

91. Rajan A, Vilas V, Philip D. Studies on catalytic, antioxidant, antibacterial and anticancer activities of biogenic gold nanoparticles. J Mol Liq. 2015;212:331-339. doi:10.1016/j. molliq.2015.09.013

92. Gan PP, Ng SH, Huang Y, Li SFY. Green synthesis of gold nanoparticles using palm oil mill effluent (POME): a low-cost and eco-friendly viable approach. Bioresour Technol. 2012;113:132-135. doi:10.1016/j.biortech.2012.01.015
93. Naveena BE, Prakash S. Biological synthesis of gold nanoparticles using marine algae gracilaria corticata and its application as a potent antimicrobial and antioxidant agent. Asian J Pharm Clin Res. 2013;6(2):179-182.

94. Swaminathan S, Subbiah M, Damodarkumar S, Dhamotharan R, Bhuvaneshwari S. Synthesis and characterization of gold nanoparticles from alga acanthophora specifera (VAHL) boergesen. Int J Nano Sci Nanotech. 2011;2:85-94.

95. Abdel-Raouf N, Al-Enazi NM, Ibraheem IBM. Green biosynthesis of gold nanoparticles using galaxaura elongata and characterization of their antibacterial activity. Arab J Chem. 2017;10: S3029-S3039. doi:10.1016/j.arabjc.2013.11.044

96. Arockiya Aarthi Rajathi F, Parthiban C, Ganesh Kumar V, Anantharaman P. Biosynthesis of antibacterial gold nanoparticles using brown alga, stoechospermum marginatum (kützing). Spectrochim Acta A Mol Biomol Spectrosc. 2012;99:166-173. doi:10.1016/j.saa.2012.08.081

97. Venkatesan J, Manivasagan P, Kim SK, Kirthi AV, Marimuthu S, Rahuman AA. Marine algae-mediated synthesis of gold nanoparticles using a novel ecklonia cava. Bioprocess Biosyst Eng. 2014;37(8):1591-1597. doi:10.1007/s00449-014-1131-7

98. Singaravelu G, Arockiamary JS, Kumar VG, Govindaraju K. A novel extracellular synthesis of monodisperse gold nanoparticles using marine alga, sargassum wightii greville. Colloids Surf B Biointerfaces. 2007;57(1):97-101. doi:10.1016/j.colsurfb.2007.01.010

99. González-Ballesteros N, Prado-López S, Rodríguez-González JB, Lastra M, Rodríguez-Argüelles MC. Green synthesis of gold nanoparticles using brown algae cystoseira baccata: its activity in colon cancer cells. Colloids Surf $B$ Biointerfaces. 2017;153:190-198. doi:10.1016/j.colsurfb.2017.02.020

100. Ghodake G, Lee DS. Biological synthesis of gold nanoparticles using the aqueous extract of the brown algae laminaria japonica. J Nanoelectron Optoelectron. 2011;6.(3):268-271. doi:10.1166/ jno.2011.1166

101. Rajeshkumar S, Malarkodi C, Gnanajobitha G, et al. Seaweedmediated synthesis of gold nanoparticles using turbinaria conoides and its characterization. J Nanostructure Chem. 2013;3 (1):44. doi:10.1186/2193-8865-3-44

102. Sharma B, Dhar D, Hazra S, Gogoi L. Biosynthesis of gold nanoparticles using a freshwater green alga, prasiola crispa. Mater Lett. 2014;116:94-97. doi:10.1016/j.matlet.2013.10.107

103. Sharma B, Purkayastha DD, Hazra S, et al. Biosynthesis of fluorescent gold nanoparticles using an edible freshwater red alga, Lemanea fluviatilis (L.) C.Ag. and antioxidant activity of biomatrix loaded nanoparticles. Bioprocess Biosyst Eng. 2014;37 (12):2559-2565. doi:10.1007/s00449-014-1233-2

104. Oza G, Pandey S, Mewada A, Kalita G, Sharon M. Facile biosynthesis of gold nanoparticles exploiting optimum $\mathrm{pH}$ and temperature of fresh water algae chlorella pyrenoidusa. Available from: www.pelagiaresearchlibrary.com. Accessed July 21, 2020.

105. Santhoshkumar J, Rajeshkumar S, Venkat Kumar S. Phytoassisted synthesis, characterization and applications of gold nanoparticles - a review. Biochem Biophys Rep. 2017;11:46-57. doi:10.1016/j.bbrep.2017.06.004

106. Mohamad NAN, Arham NA, Jai J, Hadi A. Plant extract as reducing agent in synthesis of metallic nanoparticles: a review. Adv Mater Res. 2013;832:350-355. doi:10.4028/www.scientific. net/AMR.832.350

107. Mahdavi M, Ahmad MB, Haron MJ, et al. Synthesis, surface modification and characterisation of biocompatible magnetic iron oxide nanoparticles for biomedical applications. Molecules. 2013;18(7):7533-7548. doi:10.3390/molecules 18077533

108. Esther J, Sridevi V. Synthesis and characterization of chitosan-stabilized gold nanoparticles through a facile and green approach. Gold Bull. 2017;50(1):1-5. doi:10.1007/s13404-0160189-1 
109. Pienpinijtham P, Thammacharoen C, Ekgasit S. Green synthesis of size controllable and uniform gold nanospheres using alkaline degradation intermediates of soluble starch as reducing agent and stabilizer. Macromol Res. 2012;20(12):1281-1288. doi:10.1007/ s13233-012-0162-7

110. Geng X, Grove TZ. Repeat protein mediated synthesis of gold nanoparticles: effect of protein shape on the morphological and optical properties. RSC Adv. 2015;5(3):2062-2069. doi:10.1039/ C4RA12014K

111. Chen Y, Wu X, Lv L, et al. Enhancing reducing ability of $\alpha$-zein by fibrillation for synthesis of $\mathrm{Au}$ nanocrystals with continuous flow catalysis. $J$ Colloid Interface Sci. 2017;491:37-43. doi:10.1016/j.jcis.2016.09.081

112. Sathiyanarayanan G, Vignesh V, Saibaba G, et al. Synthesis of carbohydrate polymer encrusted gold nanoparticles using bacterial exopolysaccharide: a novel and greener approach. RSC Adv. 2014;4(43):22817-22827. doi:10.1039/c4ra01428f

113. Ganesh Kumar C, Poornachandra Y, Mamidyala SK. Green synthesis of bacterial gold nanoparticles conjugated to resveratrol as delivery vehicles. Colloids Surf $B$ Biointerfaces. 2014;123:311-317. doi:10.1016/j.colsurfb.2014.09.032

114. Ganaie SU, Abbasi T, Anuradha J, Abbasi SA. Biomimetic synthesis of silver nanoparticles using the amphibious weed ipomoea and their application in pollution control. J King Saud Univ Sci. 2014;26(3):222-229. doi:10.1016/j.jksus.2014.02.004

115. Manjunath HM, Joshi CG, Raju NG. Biofabrication of gold nanoparticles using marine endophytic fungus - penicillium citrinum. IET Nanobiotechnol. 2017;11(1):40-44. doi:10.1049/ietnbt.2016.0065

116. Qu Y, Pei X, Shen W, et al. Biosynthesis of gold nanoparticles by aspergillum sp. WL-Au for degradation of aromatic pollutants. Physica E Low Dimens Syst Nanostruct. 2017;88:133-141. doi:10.1016/j.physe.2017.01.010

117. Lee KD, Nagajyothi PC, Sreekanth TVM, Park S. Eco-friendly synthesis of gold nanoparticles (AuNPs) using inonotus obliquus and their antibacterial, antioxidant and cytotoxic activities. $J$ Ind Eng Chem. 2015;26:67-72. doi:10.1016/j.jiec.2014.11.016

118. Mofrad R, Hadi R, Tahmasebi B, Farhoudian S, Mehravar M, Nasiri R. Green synthesis of gold nanoparticles using plant extract: mini-review. Nanochem Res. 2017;2(1):8-19. doi:10.22036/ncr.2017.01.002

119. Bogireddy NKR, Pal U, Gomez LM, Agarwal V. Size controlled green synthesis of gold nanoparticles using coffea arabica seed extract and their catalytic performance in 4-nitrophenol reduction. RSC Adv. 2018;8(44):24819-24826. doi:10.1039/ c8ra04332a

120. Siddiqi KS, Husen A. Recent advances in plant-mediated engineered gold nanoparticles and their application in biological system. J Trace Elem Med Biol. 2017;40:10-23. doi:10.1016/j. jtemb.2016.11.012

121. Lee J, Kim HY, Zhou H, et al. Green synthesis of phytochemical-stabilized $\mathrm{Au}$ nanoparticles under ambient conditions and their biocompatibility and antioxidative activity. $J$ Mater Chem. 2011;21(35):13316-13326. doi:10.1039/ cljm $11592 \mathrm{~h}$

122. Saha SK, Roy P, Mondal MK, et al. Development of chitosan based gold nanomaterial as an efficient antifilarial agent: a mechanistic approach. Carbohydr Polym. 2017;157:1666-1676. doi:10.1016/j.carbpol.2016.11.047

123. Astruc D. Nanoparticles and Catalysis. Wiley-VCH; 2008. doi:10.1002/9783527621323

124. Naraginti S, Li Y. Preliminary investigation of catalytic, antioxidant, anticancer and bactericidal activity of green synthesized silver and gold nanoparticles using actinidia deliciosa. J Photochem Photobiol B Biol. 2017;170:225-234. doi:10.1016/ j.jphotobiol.2017.03.023
125. Singh P, Pandit S, Garnæs J, et al. Green synthesis of gold and silver nanoparticles from cannabis sativa (industrial hemp) and their capacity for biofilm inhibition. Int $J$ Nanomedicine. 2018;13:3571-3591. doi:10.2147/IJN.S157958

126. Emmanuel R, Karuppiah C, Chen S-M, Palanisamy S, Padmavathy S, Prakash P. Green synthesis of gold nanoparticles for trace level detection of a hazardous pollutant (nitrobenzene) causing methemoglobinaemia. $J$ Hazard Mater. 2014;279:117-124. doi:10.1016/j.jhazmat.2014.06.066

127. Song JY, Jang H-K, Kim BS. Biological synthesis of gold nanoparticles using magnolia kobus and diopyros kaki leaf extracts. Process Biochem. 2009;44(10):1133-1138. doi:10.1016/j. procbio.2009.06.005

128. Elavazhagan T, Arunachalam KD. Memecylon edule leaf extract mediated green synthesis of silver and gold nanoparticles. Int $J$ Nanomedicine. 2011;6:1265-1278. doi:10.2147/IJN.S18347

129. Mukherjee S, Sushma V, Patra S, et al. Green chemistry approach for the synthesis and stabilization of biocompatible gold nanoparticles and their potential applications in cancer therapy. Nanotechnology. 2012;23(45):455103. doi:10.1088/0957-4484/ 23/45/455103

130. Derjagiun B, Landau L. The theory of stability of highly charged lyophobic sols and coalescence of highly charged particles in electrolyte solutions. Acta Physicochim URSS. 1941;14 (58):633-652.

131. Verwey EJ, Overbeek JT. Theory of the stability of lyophobic colloids: the interaction of sol particles having an electric double layer; 1948. Available from: https://trove.nla.gov.au/work/ 15258113. Accessed December 24, 2019.

132. Pugh RJ, Matsunaga T, Fowkes FM. The dispersibility and stability of carbon black in media of low dielectric constant. 1. Electrostatic and steric contributions to colloidal stability. Colloids Surf. 1983;7(3):183-207. doi:10.1016/0166-6622(83) 80046-8

133. Raveendran P, Fu J, Wallen SL. Completely "green" synthesis and stabilization of metal nanoparticles. J Am Chem Soc. 2003;125 (46):13940-13941. doi:10.1021/ja029267j

134. Lourenco C, Teixeira M, Simões S, Gaspar R. Steric stabilization of nanoparticles: size and surface properties. Int $J$ Pharm. 1996;138(1):1-12. doi:10.1016/0378-5173(96)04486-9

135. Stankus DP, Lohse SE, Hutchison JE, Nason JA. Interactions between natural organic matter and gold nanoparticles stabilized with different organic capping agents. Environ Sci Technol. 2011;45(8):3238-3244. doi:10.1021/es102603p

136. Jain PK, Lee KS, El-Sayed IH, El-Sayed MA. Calculated absorption and scattering properties of gold nanoparticles of different size, shape, and composition: applications in biological imaging and biomedicine. J Phys Chem B. 2006;110(14):7238-7248. doi:10.1021/jp057170o

137. Eustis S, El-Sayed MA. Why gold nanoparticles are more precious than pretty gold: noble metal surface plasmon resonance and its enhancement of the radiative and nonradiative properties of nanocrystals of different shapes. Chem Soc Rev. 2006;35 (3):209-217. doi:10.1039/b514191e

138. Link S, El-sayed MA. Size and temperature dependence of the plasmon absorption of colloidal gold nanoparticles. J Phys Chem B. 1999;103(21):4212-4217. doi:10.1021/jp984796o

139. Mie G. BeitrMge XU Optik triiber Medden, spexiell 7colloidaler Metallosurcgem; von Gustav Mie. Ann Phys. 1908;330 (3):377-445. doi:10.1002/andp.19083300302

140. Templeton AC, Pietron JJ, Murray RW, Mulvaney P. Solvent refractive index and core charge influences on the surface plasmon absorbance of alkanethiolate monolayer-protected gold clusters. J Phys Chem B. 2000;104(3):564-570. doi:10.1021/ jp991889c 
141. Toderas F, Baia M, Maniu D. Tuning the plasmon resonances of gold nanoparticles by controlling their size and shape. J Optoelectron Adv Mater. 2008;10(9).

142. Kelly KL, Coronado E, Zhao LL, Schatz GC. The optical properties of metal nanoparticles: the influence of size, shape, and dielectric environment. $J$ Phys Chem B. 2003;107(3):668-677. doi:10.1021/jp026731y

143. Su KH, Wei QH, Zhang X, Mock JJ, Smith DR, Schultz S. Interparticle coupling effects on plasmon resonances of nanogold particles. Nano Lett. 2003;3(8):1087-1090. doi:10.1021/n1034197f

144. Sapsford KE, Berti L, Medintz IL. Materials for fluorescence resonance energy transfer analysis: beyond traditional donor-acceptor combinations. Angew Chem Int Ed. 2006;45 (28):4562-4588. doi:10.1002/anie.200503873

145. Oh E, Hong MY, Lee D, Nam SH, Yoon HC, Kim HS. Inhibition assay of biomolecules based on fluorescence resonance energy transfer (FRET) between quantum dots and gold nanoparticles. $J$ Am Chem Soc. 2005;127(10):3270-3271. doi:10.1021/ ja0433323

146. Bigioni TP, Whetten RL, Dag Ö. Near-infrared luminescence from small gold nanocrystals. $J$ Phys Chem B. 2000;104 (30):6983-6986. doi:10.1021/jp993867w

147. Thomas KG, Kamat PV. Chromophore-functionalized gold nanoparticles. Acc Chem Res. 2003;36(12):888-898. doi:10.1021/ar030030h

148. Huang X, Jain PK, El-Sayed IH, El-Sayed MA. Gold nanoparticles: interesting optical properties and recent applications in cancer diagnostics and therapy. Nanomedicine. 2007;2(5):681-693. doi:10.2217/17435889.2.5.681

149. Kumar SS, Kwak K, Lee D. Electrochemical sensing using quantum-sized gold nanoparticles. Anal Chem. 2011;83 (9):3244-3247. doi:10.1021/ac200384w

150. Tseng RJ, Huang J, Ouyang J, Kaner RB. Polyaniline nanofiber/ gold nanoparticle nonvolatile memory. Nano Lett. 2005;5(6):1-4. doi:10.1021/n10505871

151. Lee S, Yoon S, Shin H, Joo W. Hierarchical organization of Au nanoparticles in a poly (vinyl carbazole) matrix for hybrid electronic devices. Nanotechnology. 2008;075606(19):7. doi:10.1088/ 0957-4484/19/7/075606

152. Prakash A, Ouyang J, Lin J, et al. Polymer memory device based on conjugated polymer and gold nanoparticles. J Appl Phys. 2006;100(5):054309. doi:10.1063/1.2337252

153. Zavaleta CL, Smith BR, Walton I, et al. Multiplexed imaging of surface enhanced Raman scattering nanotags in living mice using noninvasive Raman spectroscopy. Proc Natl Acad Sci. 2009;106 (32):13511-13516. doi:10.1073/pnas.0813327106

154. Samanta A, Maiti KK, Soh K, et al. Ultrasensitive near-infrared raman reporters for SERS-based in vivo cancer detection. Angew Chem Int Ed. 2011;50(27):6089-6092. doi:10.1002/ anie. 201007841

155. Thuy NTB, Yokogawa R, Yoshimura Y, Fujimoto K, Koyano M, Maenosono S. Surface-enhanced Raman spectroscopy for facile DNA detection using gold nanoparticle aggregates formed via photoligation. Analyst. 2010;135(3):595-602. doi:10.1039/ b919969a

156. Lou T, Wang Y, Li J, Peng H, Xiong H, Chen L. Rapid detection of melamine with 4-mercaptopyridine-modified gold nanoparticles by surface-enhanced Raman scattering. Anal Bioanal Chem. 2011;401(1):333-338. doi:10.1007/s00216-011-5067-3

157. Li X, Wang J, Wang Z, Wang Z. Gold nanoparticle-based colorimetric assay for selective detection of aluminium cation on living cellular surfaces. ChemComm. 2010;46(6):988-990. doi:10.1039/ b920135a

158. Liu G, Mao X, Phillips JA, Xu H, Tan W, Zeng L. Aptamer nanoparticle strip biosensor for sensitive detection of cancer cells. Anal Chem. 2009;81(24):10013-10018. doi:10.1021/ac901889s
159. Kang B, Mackey MA, Chen PC, Oyelere AK, El-sayed IH. Comparative study of photothermolysis of cancer cells with nuclear-targeted or cytoplasm-targeted gold nanospheres: continuous wave or pulsed lasers. J Biomed Opt. 2019;15(5):058002. doi: $10.1117 / 1.3486538$

160. Van de Broek B, Devoogdt N, D'Hollander A. Specific cell targeting with nanobody conjugated branched gold nanoparticles for photothermal therapy. ACS Nano. 2011;5(6):4319-4328. doi: $10.1021 / \mathrm{nn} 1023363$

161. Liang T, Lin H. Supramolecular assembly of H-bonded copolymers/complexes/nanocomposites and fluorescence quenching effects of surface-modified gold nanoparticles on fluorescent copolymers containing pyridyl $\mathrm{H}$-acceptors and acid H-donors. J Mater Chem. 2009;19(27):4753-4763. doi:10.1039/b823450g

162. Imahori BH, Fukuzumi S. Porphyrin monolayer-modified gold clusters as photoactive materials. Adv Mater. 2001;13 (15):1197-1199. doi:10.1002/1521-4095(200108)13:15<1197:: AID-ADMA1197>3.0.CO;2-4

163. Dubertret B, Calame M, Libchaber AJ. Single-mismatch detection using gold-quenched fluorescent oligonucleotides. Nat Biotechnol. 2001;19(4):365-370. doi:10.1038/86762

164. Oh E, Hong M, Lee D, Nam S, Yoon HC, Kim H. Inhibition assay of biomolecules based on fluorescence resonance energy transfer (FRET) between quantum dots and gold nanoparticles. $J \mathrm{Am}$ Chem Soc. 2005;127(10):3270-3271. doi:10.1021/ja0433323

165. Buffat P, Borel J-P. Size effect on the melting temperature of gold particles. Phys Rev A. 1976;13(6):2287-2298. doi:10.1103/ physreva.13.2287

166. Sambles JR. An electron microscope study of evaporating gold particles: the kelvin equation for liquid gold and the lowering of the melting point of solid gold particles. Proc R Soc a Math Phys Eng Sci. 1971;324(1558):339-351. doi:10.1098/rspa.1971.0143

167. Zawrah MF, Khattab RM, Girgis LG, El Daidamony H, Abdel Aziz RE. Stability and electrical conductivity of water-base $\mathrm{Al}_{2}$ $\mathrm{O}_{3}$ nanofluids for different applications. HBRC J. 2016;12 (3):227-234. doi:10.1016/j.hbrcj.2014.12.001

168. Tiwari A, Chugh A, Jin C, Narayan J. Role of self-assembled gold nanodots in improving the electrical and optical characteristics of zinc oxide films. J Nanosci Nanotechnol. 2019;3(5):368-371. doi:10.1166/jnn.2003.217

169. Li N, Zhao P, Astruc D. Anisotropic gold nanoparticles: synthesis, properties, applications, and toxicity. Angew Chem Int Ed. 2014;53:1756-1789. doi:10.1002/anie.201300441

170. Jana NR, Gearheart L, Murphy CJ. Seed-mediated growth approach for shape- controlled synthesis of spheroidal and rod-like gold nanoparticles using a surfactant template. $A d v$ Mater. 2001;13(18):1389-1393. doi:10.1002/1521-4095(200109) 13:18<1389::AID-ADMA1389>3.0.CO;2-F

171. Nikoobakht B, El-sayed MA. Preparation and growth mechanism of gold nanorods (NRs) using seed-mediated growth method. Chem Mater. 2003;15(16):1957-1962. doi:10.1021/cm0207321

172. Skrabalak SE, Chen J, Sun Y, et al. Gold nanocages: synthesis, properties, and applications. Acc Chem Res. 2008;41 (12):1587-1595. doi:10.1021/ar800018v

173. Kim F, Sohn K, Wu J, Huang J. Chemical synthesis of gold nanowires in acidic solutions. $J$ Am Chem Soc. 2008;130 (44):14442-14443. doi:10.1021/ja806759v

174. Wang L, Song Y, Sun L, Guo C, Sun Y, Li Z. Controllable synthesis of gold nanowires. Mater Lett. 2010;62 (2008):4124-4126. doi:10.1016/j.matlet.2008.06.014

175. Shao Y, Jin Y, Dong S. Synthesis of gold nanoplates by aspartate reduction of gold chloride. Chem Commun (Camb). 2004; (9):1104-1105. doi:10.1039/b315732f

176. Ah CS, Yun YJ, Park HJ, Kim W, Ha DH. Size-controlled synthesis of machinable single crystalline gold nanoplates. Chem Mater. 2005;17(22):5558-5561. doi:10.1021/cm051225h 
177. Lee J, Kamada K, Enomoto N, Hojo J. Polyhedral gold nanoplate: high fraction synthesis of two-dimensional nanoparticles through rapid heating process \& DESIGN 2008. Cryst Growth Des. 2008;8(8):2638-2645. doi:10.1021/cg0702075

178. Huang $\mathrm{MH}$, Lin P. Shape-controlled synthesis of polyhedral nanocrystals and their facet-dependent properties. Adv Funct Mater. 2012;22(1):14-24. doi:10.1002/adfm.201101784

179. Singh P, Kim YJ, Wang C, Mathiyalagan R, Yang DC. Microbial synthesis of flower-shaped gold nanoparticles. Artif Cells Nanomed Biotechnol. 2015;(April):1-6. doi:10.3109/21691401.2015.1041640

180. Al-akraa IM, Mohammad AM, El-anadouli BE. Flower-shaped gold nanoparticles: preparation, characterization, and electrocatalytic application. Arab $J$ Chem. 2015;10(6):877-884. doi:10.1016/j.arabjc.2015.05.004

181. Minati L, Benetti F, Chiappini A, Speranza G. One-step synthesis of star-shaped gold nanoparticles. Colloids Surf a Physicochem Eng Asp. 2014;441:623-628. doi:10.1016/j.colsurfa.2013.10.025

182. Yamamoto M, Kashiwagi Y, Sakata T, Mori H, Nakamoto M. Synthesis and morphology of star-shaped gold nanoplates protected by poly(N -vinyl-2-pyrrolidone). Chem Mater. 2005;17 (22):5391-5393. doi:10.1021/cm0515000

183. Das SK, Das AR, Guha AK. Microbial synthesis of multishaped gold nanostructures. Small. 2010;6(9):1012-1021. doi:10.1002/ smll.200902011

184. Nehl CL, Liao H, Hafner JH. Optical properties of star-shaped gold nanoparticles. Nano Lett. 2006;6(4):638-688. doi:10.1021/ n1052409y

185. Foss CA, Gabor L, Stockert JA, Martin CR. Template-synthesized nanoscopic gold particles: optical spectra and the effects of particle size and shape. J Phys Chem. 1994;94(11):2963-2971. doi:10.1021/j100062a037

186. Hu L, Peng Q, Li Y. Selective synthesis of Co3O4 nanocrystal with different shape and crystal. J Am Chem Soc. 2008;130 (48):16136-16137. doi:10.1021/ja806400e

187. Zhang J, Feng C, Deng Y, et al. Shape-controlled synthesis of palladium single-crystalline nanoparticles: the effect of $\mathrm{HCl}$ oxidative etching and facet- dependent catalytic properties. Chem Mater. 2014;26(2):1213-1218. doi:10.1021/cm403591g

188. Shuford KL, Ratner MA, Schatz GC, Shuford KL, Ratner MA, Schatz GC. Multipolar excitation in triangular nanoprisms multipolar excitation in triangular nanoprisms. Int J Chem Phys. 2005;123(11):114713. doi:10.1063/1.2046633

189. Raghavan V, Fan HM, McCarthy EK, et al. Synthesis and characterisation of dual plasmonic gold nanostars as high-performance surface-enhanced Raman spectroscopy substrate. Micro Nano Lett. 2016;11(11):769-774. doi:10.1049/mnl.2016.0095

190. Fong KE, Yung LYL. Localized surface plasmon resonance: a unique property of plasmonic nanoparticles for nucleic acid detection. Nanoscale. 2013;5(24):12043-12071. doi:10.1039/c3nr02257a

191. Link S, El-sayed MA. Optical properties and ultrafast dynamics of metallic nanocrystals. Annu Rev Phys Chem. 2003;54 (1):331-366. doi:10.1146/annurev.physchem.54.011002.103759

192. Melting LP, Dependence P, Mohamed MB, Nikoobakht B, ElSayed MA. Laser photothermal melting and fragmentation of gold nanorods: energy and laser pulse-width dependence. Phys Chem A. 1999;103(9):1165-1170. doi:10.1021/jp983141k

193. Kim M, Lee JH, Nam JM. Plasmonic photothermal nanoparticles for biomedical applications. Adv Sci. 2019;6(17):1900471. doi:10.1002/advs.201900471

194. Hao F, Nehl CL, Hafner JH, Nordlander P. Plasmon resonances of a gold nanostar. Nano Lett. 2007;7(3):729-732. doi:10.1021/ n1062969c

195. Han G, You CC, Kim BJ, et al. Light-regulated release of DNA and its delivery to nuclei by means of photolabile gold nanoparticles. Angew Chem Int Ed. 2006;45(19):3165-3169. doi:10.1002/anie.200600214
196. Hong R, Han G, Fernández JM, Kim B, Forbes NS, Rotello VM. Glutathione-mediated delivery and release using monolayer protected nanoparticle carriers. J Am Chem Soc. 2006;128 (4):1078-1079. doi:10.1021/ja056726i

197. Ishii T, Otsuka H, Kataoka K, Nagasaki Y. Preparation of functionally pegylated gold nanoparticles with narrow distribution through autoreduction of auric cation by $\alpha$-biotinyl-PEG- block -[poly(2-( $N, N$-dimethylamino)ethyl methacrylate)]. Langmuir. 2004;20(3):561-564. doi:10.1021/la035653i

198. Scott AW, Garimella V, Calabrese CM, Mirkin CA. Universal biotin-PEG-linked gold nanoparticle probes for the simultaneous detection of nucleic acids and proteins. Bioconjug Chem. 2017;28 (1):203-211. doi:10.1021/acs.bioconjchem.6b00529

199. Takae S, Akiyama Y, Otsuka H, Nakamura T, Nagasaki Y, Kataoka K. Ligand density effect on biorecognition by PEGylated gold nanoparticles: regulated interaction of RCA120 lectin with lactose installed to the distal end of tethered PEG strands gold surface. Biomacromolecules. 2005;6(2):818-824. doi:10.1021/bm049427e

200. Shenoy D, Fu W, Li J, et al. Surface functionalization of gold nanoparticles using hetero-bifunctional poly(ethylene glycol) spacer for intracellular tracking and delivery. Int J Nanomedicine. 2006;1(1):51-57. doi:10.2147/nano.2006.1.1.51

201. Zhang G, Yang Z, Lu W, et al. Influence of anchoring ligands and particle size on the colloidal stability and in vivo biodistribution of polyethylene glycol-coated gold nanoparticles in tumor-xenografted mice. Biomaterials. 2009;30(10):1928-1936. doi:10.1016/j.biomaterials.2008.12.038

202. Zare D, Khoshnevisan K, Barkhi M, Tahami HV. Fabrication of capped gold nanoparticles by using various amino acids. J Exp Nanosci. 2014;9(9):957-965. doi:10.1080/ 17458080.2012.752582

203. Satnami ML, Chandraker K, Vaishanav SK, Nagwanshi R. Interaction of Thiolated Amino Acids and Peptide Onto the Gold Nanoparticle Surface: Radical Scavenging Activity. Vol. 54. 2015 .

204. Asadishad B, Vosoughi M, Alamzadeh I, Tavakoli A. Synthesis of folate-modified, polyethylene glycol-functionalized gold nanoparticles for targeted drug delivery. J Dispers Sci Technol. 2010;31 (4):492-500. doi:10.1080/01932690903213113

205. Hou Z, Wang Z, Liu R, et al. The effect of phospho-peptide on the stability of gold nanoparticles and drug delivery. J Nanobiotechnology. 2019;17(1):88. doi:10.1186/s12951-0190522-y

206. Ghosh PS, Kim CK, Han G, Forbes NS, Rotello VM. Efficient gene delivery vectors by tuning the surface charge density of amino acid-functionalized gold nanoparticles. ACS Nano. 2008;2 (11):2213-2218. doi:10.1021/nn800507t

207. Lee $\mathrm{SH}$, Bae $\mathrm{KH}$, Kim SH, Lee KR, Park TG. Aminefunctionalized gold nanoparticles as non-cytotoxic and efficient intracellular siRNA delivery carriers. Int J Pharm. 2008;364 (1):94-101. doi:10.1016/j.ijpharm.2008.07.027

208. Kim ST, Chompoosor A, Yeh YC, Agasti SS, Solfiell DJ, Rotello VM. Dendronized gold nanoparticles for siRNA delivery. Small. 2012;8(21):3253-3256. doi:10.1002/ smll.201201141

209. Sun L, Liu D, Wang Z. Functional gold nanoparticle - peptide complexes as cell-targeting agents. Langmuir. 2008;24 (18):10293-10297. doi:10.1021/la8015063

210. Geerts N, Eiser E. DNA-functionalized colloids: physical properties and applications. Soft Matter. 2010;6(19):4647-4660. doi:10.1039/c001603a

211. Katz E, Willner I. Integrated nanoparticle-biomolecule hybrid systems: synthesis, properties, and applications. Angew Chem Int Ed. 2004;43(45):6042-6108. doi:10.1002/ anie. 200400651 
212. Lin C, Liu Y, Yan H. Designer DNA nanoarchitectures. Biochemistry. 2009;48(8):1663-1674. doi:10.1021/bi802324w

213. Alivisatos AP, Johnsson KP, Peng X. Organization of "nanocrystal molecules" using DNA. Nature. 1996;382(6592):609-611. doi:10.1038/382609a0

214. Mirkin CA, Letsinger RL, Mucic RC, Storhoff JJ. A DNA-based method for rationally assembling nanoparticles into macroscopic materials. Nature. 1996;382(6592):607-609. doi:10.1038/382607a0

215. Nykypanchuk D, Maye MM, Van Der Lelie D, Gang O. DNAguided crystallization of colloidal nanoparticles. Nature. 2008;451(7178):549-552. doi:10.1038/nature06560

216. Park SY, Lytton-Jean AKR, Lee B, Weigand S, Schatz GC, Mirkin CA. DNA-programmable nanoparticle crystallization. Nature. 2008;451(7178):553-556. doi:10.1038/nature06508

217. Maye MM, Kumara MT, Nykypanchuk D, Sherman WB, Gang O. Switching binary states of nanoparticle superlattices and dimer clusters by DNA strands. Nat Nanotechnol. 2010;5 (2):116-120. doi:10.1038/nnano.2009.378

218. Pellegrino T, Sperling RA, Alivisatos AP, Parak WJ. Gel electrophoresis of gold-DNA nanoconjugates. J Biomed Biotechnol. 2007;2007:26796. doi:10.1155/2007/26796

219. Chen C, Wang W, Ge J, Zhao XS. Kinetics and thermodynamics of DNA hybridization on gold nanoparticles. Nucleic Acids Res. 2009;37(11):3756-3765. doi:10.1093/nar/gkp230

220. Javier DJ, Nitin N, Levy M, Ellington A, Richards-Kortum R. Aptamer-targeted gold nanoparticles as molecular-specific contrast agents for reflectance imaging. Bioconjug Chem. 2008;19 (6):1309-1312. doi:10.1021/bc8001248

221. Du B, Li Z, Cheng Y. Homogeneous immunoassay based on aggregation of antibody-functionalized gold nanoparticles coupled with light scattering detection. Talanta. 2008;75 (4):959-964. doi:10.1016/j.talanta.2007.12.048

222. Di Pasqua AJ, Mishler RE, Ship YL, Dabrowiak JC, Asefa T. Preparation of antibody-conjugated gold nanoparticles. Mater Lett. 2009;63(21):1876-1879. doi:10.1016/j.matlet.2009.05.070

223. Luo XL, Xu JJ, Du Y, Chen HY. A glucose biosensor based on chitosan-glucose oxidase-gold nanoparticles biocomposite formed by one-step electrodeposition. Anal Biochem. 2004;334 (2):284-289. doi:10.1016/j.ab.2004.07.005

224. Selvaraj V, Alagar M. Analytical detection and biological assay of antileukemic drug 5-fluorouracil using gold nanoparticles as probe. Int $J$ Pharm. 2007;337(1-2):275-281. doi:10.1016/j. ijpharm.2006.12.027

225. Thiruppathi R, Mishra S, Ganapathy M, Padmanabhan P, Gulyás B. Nanoparticle functionalization and its potentials for molecular imaging. Adv Sci. 2017;4(3):1600279. doi:10.1002/ advs.201600279

226. Avgoustakis K. Pegylated poly(lactide) and poly(lactide-coglycolide) nanoparticles: preparation, properties and possible applications in drug delivery. Curr Drug Deliv. 2005;1 (4):321-333. doi:10.2174/1567201043334605

227. Alexis F, Pridgen E, Molnar LK, Farokhzad OC. Factors affecting the clearance and biodistribution of polymeric nanoparticles. $\mathrm{Mol}$ Pharm. 2008;5:505-515. doi:10.1021/mp800051m

228. Caliceti P, Veronese FM. Pharmacokinetic and biodistribution properties of poly(ethylene glycol)-protein conjugates. Adv Drug Deliv Rev. 2003;55(10):1261-1277. doi:10.1016/S0169-409X(03) 00108-X

229. Knop K, Hoogenboom R, Fischer D, Schubert US. Poly(ethylene glycol) in drug delivery: pros and cons as well as potential alternatives. Angew Chem Int Ed. 2010;49(36):6288-6308. doi:10.1002/anie.200902672

230. Hostetler MJ, Templeton AC, Murray RW. Dynamics of place-exchange reactions on monolayer-protected gold cluster molecules. Langmuir. 1999;15(11):3782-3789. doi:10.1021/ la981598f
231. Zare D, Akbarzadeh A, Bararpour N. Synthesis and functionalization of gold nanoparticles by using of poly functional amino acids. Int J Nanosci Nanotechnol. 2010;6(4):223-230.

232. Ding Y, Jiang Z, Saha K. Gold nanoparticles for nucleic acid delivery. Mol Ther. 2014;22(6):1075-1083. doi:10.1038/ mt.2014.30

233. Bao QY, Geng DD, Xue JW, et al. Glutathione-mediated drug release from tiopronin-conjugated gold nanoparticles for acute liver injury therapy. Int $J$ Pharm. 2013;446(1-2):112-118. doi:10.1016/j.ijpharm.2013.01.073

234. Madhusudhan A, Reddy GB, Venkatesham M, et al. Efficient ph dependent drug delivery to target cancer cells by gold nanoparticles capped with carboxymethyl chitosan. Int J Mol Sci. 2014;15 (5):8216-8234. doi:10.3390/ijms15058216

235. Cheng Y, Doane TL, Chuang CH, Ziady A, Burda C. Near infrared light-triggered drug generation and release from gold nanoparticle carriers for photodynamic therapy. Small. 2014;10 (9):1799-1804. doi:10.1002/smll.201303329

236. Vasir J, Reddy M, Labhasetwar V. Nanosystems in drug targeting: opportunities and challenges. Curr Nanosci. 2006;1(1):47-64. doi: $10.2174 / 1573413052953110$

237. Hu G, Guo M, Xu J, et al. Nanoparticles targeting macrophages as potential clinical therapeutic agents against cancer and inflammation. Front Immunol. 2019;10(AUG). doi:10.3389/ fimmu.2019.01998

238. Li JL, Wang L, Liu XY, et al. In vitro cancer cell imaging and therapy using transferrin-conjugated gold nanoparticles. Cancer Lett. 2009;274(2):319-326. doi:10.1016/j.canlet.2008.09.024

239. Saha B, Bhattacharya J, Mukherjee A, et al. In vitro structural and functional evaluation of gold nanoparticles conjugated antibiotics. Nanoscale Res Lett. 2007;2(12):614-622. doi:10.1007/s11671007-9104-2

240. Farooq MU, Novosad V, Rozhkova EA, et al. Gold nanoparticles-enabled efficient dual delivery of anticancer therapeutics to HeLa cells. Sci Rep. 2018;8(1):1-12. doi:10.1038/ s41598-018-21331-y

241. Kommareddy S, Amiji M. Poly(ethylene glycol)-modified thiolated gelatin nanoparticles for glutathione-responsive intracellular DNA delivery. Nanomedicine. 2007;3(1):32-42. doi:10.1016/j. nano.2006.11.005

242. Niidome T, Yamagata M, Okamoto Y, et al. PEG-modified gold nanorods with a stealth character for in vivo applications. J Control Release. 2006;114(3):343-347. doi:10.1016/j.jconrel.2006.06.017

243. Niidome T, Akiyama Y, Shimoda K, et al. In vivo monitoring of intravenously injected gold nanorods using near-infrared light. Small. 2008;4(7):1001-1007. doi:10.1002/smll.200700438

244. Bhattacharya R, Patra CR, Earl A, et al. Attaching folic acid on gold nanoparticles using noncovalent interaction via different polyethylene glycol backbones and targeting of cancer cells. Nanomedicine. 2007;3(3):224-238. doi:10.1016/j. nano.2007.07.001

245. Takahashi H, Niidome T, Kawano T, Yamada S, Niidome Y. Surface modification of gold nanorods using layer-by-layer technique for cellular uptake. J Nanopart Res. 2008;10(1):221-228. doi:10.1007/s11051-007-9227-5

246. Gu YJ, Cheng J, Lin CC, Lam YW, Cheng SH, Wong WT. Nuclear penetration of surface functionalized gold nanoparticles. Toxicol Appl Pharmacol. 2009;237(2):196-204. doi:10.1016/j. taap.2009.03.009

247. Gibson JD, Khanal BP, Zubarev ER. Paclitaxel-functionalized gold nanoparticles. $J$ Am Chem Soc. 2007;129 (37):11653-11661. doi:10.1021/ja075181k

248. Fischer NO, McIntosh CM, Simard JM, Rotello VM. Inhibition of chymotrypsin through surface binding using nanoparticle-based receptors. Proc Natl Acad Sci U S A. 2002;99(8):5018-5023. doi:10.1073/pnas.082644099 
249. Srivastava S, Verma A, Frankamp BL, Rotello VM. Controlled assembly of protein-nanoparticle composites through protein surface recognition. Adv Mater. 2005;17(5):617-621. doi:10.1002/ adma.200400776

250. Hauck TS, Ghazani AA, Chan WCW. Assessing the effect of surface chemistry on gold nanorod uptake, toxicity, and gene expression in mammalian cells. Small. 2008;4(1):153-159. doi:10.1002/smll.200700217

251. Gole A, Murphy CJ. Polyelectrolyte-coated gold nanorods: synthesis, characterization and immobilization. Chem Mater. 2005;17 (6):1325-1330. doi:10.1021/cm048297d

252. Goodman CM, McCusker CD, Yilmaz T, Rotello VM. Toxicity of gold nanoparticles functionalized with cationic and anionic side chains. Bioconjug Chem. 2004;15(4):897-900. doi:10.1021/ bc049951i

253. Arvizo R, Bhattacharya R, Mukherjee P. Gold nanoparticles: opportunities and challenges in nanomedicine. Expert Opin Drug Deliv. 2010;7(6):753-763. doi:10.1517/17425241003777010

254. Singh P, Pandit S, Mokkapati VRSS, Garg A, Ravikumar V, Mijakovic I. Gold nanoparticles in diagnostics and therapeutics for human cancer. Int J Mol Sci. 2018;19(7):1979. doi:10.3390/ ijms 19071979

255. Miller AD. Human gene therapy comes of age. Nature. 1992;357 (6378):455-460. doi:10.1038/357455a0

256. Yeh $\mathrm{P}$, Perricaudet $M$. Advances in adenoviral vectors: from genetic engineering to their biology. FASEB J. 1997;11 (8):615-623. doi:10.1096/fasebj.11.8.9240963

257. Check E. A tragic setback. Nature. 2002;420(6912):116-118. doi:10.1038/420116a

258. Wiethoff CM, Middaugh CR. Barriers to nonviral gene delivery. J Pharm Sci. 2003;92(2):203-217. doi:10.1002/jps.10286

259. Thomas M, Klibanov AM. Non-viral gene therapy: polycation-mediated DNA delivery. Appl Microbiol Biotechnol. 2003;62(1):27-34. doi:10.1007/s00253-003-1321-8

260. Kim EY, Schulz R, Swantek P, Kunstman K, Malim MH, Wolinsky SM. Gold nanoparticle-mediated gene delivery induces widespread changes in the expression of innate immunity genes. Gene Ther. 2012;19(3):347-353. doi:10.1038/gt.2011.95

261. Rosi NL, Giljohann DA, Thaxton CS, Lytton-Jean AKR, Han MS, Mirkin CA. Oligonucleotide-modified gold nanoparticles for infracellular gene regulation. Science. 2006;312 (5776):1027-1030. doi:10.1126/science.1125559

262. Seferos DS, Prigodich AE, Giljohann DA, Patel PC, Mirkin CA. Polyvalent DNA nanoparticle conjugates stabilize nucleic acids Nano Lett. 2009;9(1):308-311. doi:10.1021/n1802958f

263. Hao L, Patel PC, Alhasan AH, Giljohann DA, Mirkin CA. Nucleic acid-gold nanoparticle conjugates as mimics of microRNA. Small. 2011;7(22):3158-3162. doi:10.1002/smll.201101018

264. Sandhu KK, McIntosh CM, Simard JM, Smith SW, Rotello VM Gold nanoparticle-mediated transfection of mammalian cells. Bioconjug Chem. 2002;13(1):3-6. doi:10.1021/bc015545c

265. Zhao X, Huang Q, Jin Y. Gold nanorod delivery of LSD1 siRNA induces human mesenchymal stem cell differentiation. Mater Sci Eng C. 2015;54:142-149. doi:10.1016/j.msec.2015.05.013

266. Verma A, Simard JM, Worrall JWE, Rotello VM. Tunable reactivation of nanoparticle-inhibited $\beta$-galactosidase by glutathione at intracellular concentrations. J Am Chem Soc. 2004;126 (43):13987-13991. doi:10.1021/ja046572r

267. Bhumkar DR, Joshi HM, Sastry M, Pokharkar VB. Chitosan reduced gold nanoparticles as novel carriers for transmucosal delivery of insulin. Pharm Res. 2007;24(8):1415-1426. doi:10.1007/s11095-007-9257-9

268. Schäffler M, Sousa F, Wenk A, et al. Blood protein coating of gold nanoparticles as potential tool for organ targeting. Biomaterials. 2014;35(10):3455-3466. doi:10.1016/j biomaterials.2013.12.100
269. Gao W, Chan JM, Farokhzad OC. PH-responsive nanoparticles for drug delivery. Mol Pharm. 2010;7(6):1913-1920. doi:10.1021/mp100253e

270. Vaupel P. Tumor microenvironmental physiology and its implications for radiation oncology. Semin Radiat Oncol. 2004;14 (3):198-206. doi:10.1016/j.semradonc.2004.04.008

271. Murphy RF, Powers S, Cantor CR. Endosome pH measured in single cells by dual fluorescence flow cytometry: rapid acidification of insulin to $\mathrm{pH}$ 6. J Cell Biol. 1984;98(5):1757-1762. doi:10.1083/jcb.98.5.1757

272. Bae Y, Fukushima S, Harada A, Kataoka K. Design of environment-sensitive supramolecular assemblies for intracellular drug delivery: polymeric micelles that are responsive to intracellular pH change. Angew Chem Int Ed. 2003;42(38):4640-4643. doi:10.1002/anie.200250653

273. Aryal S, Grailer JJ, Pilla S, Steeber DA, Gong S. Doxorubicin conjugated gold nanoparticles as water-soluble and $\mathrm{pH}$-responsive anticancer drug nanocarriers. J Mater Chem. 2009;19 (42):7879-7884. doi:10.1039/b914071a

274. Wang F, Wang YC, Dou S, Xiong MH, Sun TM, Wang J. Doxorubicin-tethered responsive gold nanoparticles facilitate intracellular drug delivery for overcoming multidrug resistance in cancer cells. ACS Nano. 2011;5(5):3679-3692. doi:10.1021/ $\mathrm{nn} 200007 \mathrm{z}$

275. Anderson ME. Glutathione: an overview of biosynthesis and modulation. Chem Biol Interact. 1998;111-112:1-14. doi:10.1016/S0009-2797(97)00146-4

276. Sies H. Glutathione and its role in cellular functions. Free Radic Biol Med. 1999;27(9-10):916-921. doi:10.1016/s0891-5849(99) 00177-x

277. Jones DP, Carlson JL, Mody VC, Cai J, Lynn MJ, Sternberg P. Redox state of glutathione in human plasma. Free Radic Biol Med. 2000;28(4):625-635. doi:10.1016/S0891-5849(99)00275-0

278. Jones DP, Carlson JL, Samiec PS, et al. Glutathione measurement in human plasma. Evaluation of sample collection, storage and derivatization conditions for analysis of dansyl derivatives by HPLC. Clin Chim Acta. 1998;275(2):175-184. doi:10.1016/ S0009-8981(98)00089-8

279. Saito G, Swanson JA, Lee KD. Drug delivery strategy utilizing conjugation via reversible disulfide linkages: role and site of cellular reducing activities. Adv Drug Deliv Rev. 2003;55 (2):199-215. doi:10.1016/S0169-409X(02)00179-5

280. Shen WC, Ryser HJ, LaManna L. Disulfide spacer between methotrexate and poly(D-lysine). A probe for exploring the reductive process in endocytosis. J Biol Chem. 1985;260 (20):10905-10908.

281. Harris N, Ford MJ, Cortie MB. Optimization of plasmonic heating by gold nanospheres and nanoshells. $J$ Phys Chem B. 2006;110(22):10701-10707. doi:10.1021/jp0606208

282. Sean Norman R, Stone JW, Gole A, Murphy CJ, Sabo-Attwood TL. Targeted photothermal lysis of the pathogenic bacteria, pseudomonas aeruginosa, with gold nanorods. Nano Lett. 2008;8 (1):302-306. doi:10.1021/n10727056

283. Wang S, Chen K-J, Wu T-H, et al. Photothermal effects of supramolecularly assembled gold nanoparticles for the targeted treatment of cancer cells. Angew Chem Int Ed. 2010;49 (22):3777-3781. doi:10.1002/anie.201000062

284. Lu W, Singh AK, Khan SA, Senapati D, Yu H, Ray PC. Gold nano-popcorn-based targeted diagnosis, nanotherapy treatment, and in situ monitoring of photothermal therapy response of prostate cancer cells using surface-enhanced raman spectroscopy. $\mathrm{J} \mathrm{Am}$ Chem Soc. 2010;132(51):18103-18114. doi:10.1021/ja104924b

285. Zharov VP, Mercer KE, Galitovskaya EN, Smeltzer MS. Photothermal nanotherapeutics and nanodiagnostics for selective killing of bacteria targeted with gold nanoparticles. Biophys $J$. 2006;90(2):619-627. doi:10.1529/biophysj.105.061895 
286. Sershen SR, Westcott SL, Halas NJ, West JL. Temperaturesensitive polymer-nanoshell composites for photothermally modulated drug delivery. J Biomed Mater Res. 2000;51 (3):293-298. doi:10.1002/1097-4636(20000905)51:3<293::AIDJBM1 $>3.0 . \mathrm{CO} ; 2-\mathrm{T}$

287. Sreejivungsa K, Suchaichit N, Moosophon P, Chompoosor A. Light-regulated release of entrapped drugs from photoresponsive gold nanoparticles. J Nanomater. 2016;2016:1-7. doi:10.1155/ 2016/4964693

288. Agasti SS, Chompoosor A, You CC, Ghosh P, Kim CK, Rotello VM. Photoregulated release of caged anticancer drugs from gold nanoparticles. $J$ Am Chem Soc. 2009;131 (16):5728-5729. doi:10.1021/ja900591t

289. Wang D, Xu Z, Yu H, et al. Treatment of metastatic breast cancer by combination of chemotherapy and photothermal ablation using doxorubicin-loaded DNA wrapped gold nanorods. Biomaterials. 2014;35(29):8374-8384. doi:10.1016/j.biomaterials.2014.05.094

290. O'Neal DP, Hirsch LR, Halas NJ, Payne JD, West JL. Photothermal tumor ablation in mice using near infrared-absorbing nanoparticles. Cancer Lett. 2004;209(2):171-176. doi:10.1016/j. canlet.2004.02.004

291. Loo C, Lin A, Hirsch L, et al. Nanoshell-enabled photonics-based imaging and therapy of cancer. Technol Cancer Res Treat. 2004;3 (1):33-40. doi:10.1177/153303460400300104

292. Kawano T, Niidome Y, Mori T, Katayama Y, Niidome T. PNIPAM gel-coated gold nanorods for targeted delivery responding to a near-infrared laser. Bioconjug Chem. 2009;20 (2):209-212. doi: 10.1021/bc800480k

293. Shiotani A, Mori T, Niidome T, Niidome Y, Katayama Y. Stable incorporation of gold nanorods into $\mathrm{n}$-isopropylacrylamide hydrogels and their rapid shrinkage induced by near-infrared laser irradiation. Langmuir. 2007;23(7):4012-4018. doi:10.1021/ la0627967

294. Ipe BI, Mahima S, Thomas KG. Light-induced modulation of self-assembly on spiropyran-capped gold nanoparticles: a potential system for the controlled release of amino acid derivatives. $J$ Am Chem Soc. 2003;125(24):7174-7175. doi:10.1021/ja0341182

295. Weishaupt KR, Gomer CJ, Dougherty TJ. Identification of singlet oxygen as the cytotoxic agent in photo inactivation of a murine tumor. Cancer Res. 1976;36(7).

296. Hone DC, Walker PI, Evans-Gowing R, et al. Generation of cytotoxic singlet oxygen via phthalocyanine-stabilized gold nanoparticles: a potential delivery vehicle for photodynamic therapy. Langmuir. 2002;18(8):2985-2987. doi:10.1021/ la0256230

297. Mocellin S, Bronte V, Nitti D. Nitric oxide, a double edged sword in cancer biology: searching for therapeutic opportunities. Med Res Rev. 2007;27(3):317-352. doi:10.1002/med.20092

298. Polizzi MA, Stasko NA, Schoenfisch MH. Water-soluble nitric oxide-releasing gold nanoparticles. Langmuir. 2007;23 (9):4938-4943. doi:10.1021/la0633841

299. Yang Q, Wang S, Fan P, et al. pH-Responsive carrier system based on carboxylic acid modified mesoporous silica and polyelectrolyte for drug delivery. Chem Mater. 2005;17 (24):5999-6003. doi:10.1021/cm051198v

300. Mellman I, Fuchs R, Helenius A. Acidification of the endocytic and exocytic pathways. Annu Rev Biochem. 1986;55(1):663-700. doi:10.1146/annurev.bi.55.070186.003311

301. Engin K, Leeper DB, Cater JR, Thistlethwaite AJ, Tupchong L, Mcfarlane JD. Extracellular ph distribution in human tumours. Int $J$ Hyperth. 1995;11(2):211-216. doi:10.3109/02656739509022457

302. de la Rica R, Aili D, Stevens MM. Enzyme-responsive nanoparticles for drug release and diagnostics. Adv Drug Deliv Rev. 2012;64(11):967-978. doi:10.1016/j.addr.2012.01.002
303. Andresen TL, Thompson DH, Kaasgaard T. Enzyme-triggered nanomedicine: drug release strategies in cancer therapy (invited review). Mol Membr Biol. 2010;27(7):353-363. doi:10.3109/ 09687688.2010.515950

304. Hwu JR, Lin YS, Josephrajan T, et al. Targeted paclitaxel by conjugation to iron oxide and gold nanoparticles. $\mathrm{J} \mathrm{Am} \mathrm{Chem}$ Soc. 2009;131(1):66-68. doi:10.1021/ja804947u

305. Barar J, Omidi Y. Dysregulated $\mathrm{pH}$ in tumor microenvironment checkmates cancer therapy. BioImpacts. 2013;3(4):149-162. doi:10.5681/bi.2013.036

306. Asgharzadeh MR, Barar J, Pourseif MM, et al. Molecular machineries of $\mathrm{pH}$ dysregulation in tumor microenvironment: potential targets for cancer therapy. BioImpacts. 2017;7(2):115-133. doi:10.15171/bi.2017.15

307. Bernkop-Schnürch A. Strategies to overcome the polycation dilemma in drug delivery. Adv Drug Deliv Rev. 2018;136-137:62-72. doi:10.1016/j.addr.2018.07.017

308. Ai X, Mu J, Xing B. Recent advances of light-mediated theranostics. Theranostics. 2016;6(13):2439-2457. doi:10.7150/ thno. 16088

309. Han G, Ghosh P, Rotello VM. Functionalized gold nanoparticles for drug delivery. Nanomedicine. 2007;2(1):113-123. doi:10.2217/17435889.2.1.113

310. Ulijn RV. Enzyme-responsive materials: a new class of smart biomaterials. J Mater Chem. 2006;16(23):2217-2225. doi:10.1039/b601776m

311. Li J, Li Q, Ma X, et al. Biosynthesis of gold nanoparticles by the extreme bacterium deinococcus radiodurans and an evaluation of their antibacterial properties. Int $J$ Nanomedicine. 2016;11:5931-5944. doi:10.2147/IJN.S119618

312. Narayanan KB, Sakthivel N. Biological synthesis of metal nanoparticles by microbes. Adv Colloid Interface Sci. 2010;156(1-2):1-13. doi:10.1016/j.cis.2010.02.001

313. Park Y, Hong YN, Weyers A, Kim YS, Linhardt RJ. Polysaccharides and phytochemicals: a natural reservoir for the green synthesis of gold and silver nanoparticles. IET Nanobiotechnol. 2011;5(3):69. doi:10.1049/iet-nbt.2010.0033

314. Ahmad A, Senapati S, Khan MI, Kumar R, Sastry M. Extra-/ intracellular biosynthesis of gold nanoparticles by an alkalotolerant fungus, Trichothecium sp. J Biomed Nanotechnol. 2006;1 (1):47-53. doi:10.1166/jbn.2005.012

315. Chauhan A, Zubair S, Tufail S, et al. Fungus-mediated biological synthesis of gold nanoparticles: potential in detection of liver cancer. Int J Nanomedicine. 2011;6:2305-2319.

316. Mishra A, Tripathy SK, Wahab R, et al. Microbial synthesis of gold nanoparticles using the fungus penicillium brevicompactum and their cytotoxic effects against mouse mayo blast cancer C 2C 12 cells. Appl Microbiol Biotechnol. 2011;92(3):617-630. doi:10.1007/s00253-011-3556-0

317. Parial D, Patra HK, Dasgupta AKR, Pal R. Screening of different algae for green synthesis of gold nanoparticles screening of different algae for green synthesis of gold nanoparticles. Eur J Phycol. 2012;0262(1):22-29. doi:10.1080/ 09670262.2011.653406

318. Senapati S, Syed A, Moeez S, Kumar A, Ahmad A. Intracellular synthesis of gold nanoparticles using alga tetraselmis kochinensis. Mater Lett. 2012;79:116-118. doi:10.1016/j. matlet.2012.04.009

319. Ogi T, Saitoh N, Nomura T, Konishi Y. Room-temperature synthesis of gold nanoparticles and nanoplates using Shewanella algae cell extract. J Nanopart Res. 2010;12(7):2531-2539. doi:10.1007/ s11051-009-9822-8

320. Song JY, Jang HK, Kim BS. Biological synthesis of gold nanoparticles using magnolia kobus and diopyros kaki leaf extracts. Process Biochem. 2009;44(10):1133-1138. doi:10.1016/j. procbio.2009.06.005 
321. Sharma NC, Sahi SV, Nath S, Parsons JG, Gardea-Torresdey JL, Tarasankar P. Synthesis of plant-mediated gold nanoparticles and catalytic role of biomatrix-embedded nanomaterials. Environ Sci Technol. 2007;41(14):5137-5142. doi:10.1021/es062929a

322. Narayanan KB, Sakthivel N. Coriander leaf mediated biosynthesis of gold nanoparticles. Mater Lett. 2008;62(30):4588-4590. doi:10.1016/j.matlet.2008.08.044

323. Dubey SP, Lahtinen M, Sillanpää M. Tansy fruit mediated greener synthesis of silver and gold nanoparticles. Process Biochem. 2010;45(7):1065-1071. doi:10.1016/j.procbio.2010.03.024

324. Jayaseelan C, Ramkumar R, Rahuman AA, Perumal P. Green synthesis of gold nanoparticles using seed aqueous extract of abelmoschus esculentus and its antifungal activity. Ind Crops Prod. 2013;45:423-429. doi:10.1016/j.indcrop.2012.12.019

325. Lipka J, Semmler-Behnke M, Sperling RA, et al. Biodistribution of PEG-modified gold nanoparticles following intratracheal instillation and intravenous injection. Biomaterials. 2010;31 (25):6574-6581. doi:10.1016/j.biomaterials.2010.05.009

326. Cho WS, Cho M, Jeong J, et al. Size-dependent tissue kinetics of PEG-coated gold nanoparticles. Toxicol Appl Pharmacol. 2010;245(1):116-123. doi:10.1016/j.taap.2010.02.013

327. Khalil H, Mahajan D, Rafailovich M, Gelfer M, Pandya K. Synthesis of zerovalent nanophase metal particles stabilized with poly(ethylene glycol). Langmuir. 2004;20(16):6896-6903. doi:10.1021/la0497402

328. Tkachenko AG, Xie H, Liu Y, et al. Cellular trajectories of peptide-modified gold particle complexes: comparison of nuclear localization signals and peptide transduction domains. Bioconjug Chem. 2004;15(3):482-490. doi:10.1021/bc034189q

329. Bastús NG, Sánchez-Tilló E, Pujals S, et al. Peptides conjugated to gold nanoparticles induce macrophage activation. Mol Immunol. 2009;46(4):743-748. doi:10.1016/j.molimm.2008.08.277
330. Rayavarapu RG, Petersen W, Ungureanu C, Post JN, Van Leeuwen TG, Manohar S. Synthesis and bioconjugation of gold nanoparticles as potential molecular probes for light-based imaging techniques. Int $J$ Biomed Imaging. 2007;2007:1-10. doi:10.1155/2007/29817

331. Surujpaul PP, Gutiérrez-Wing C, Ocampo-García B, et al. Gold nanoparticles conjugated to [Tyr3]octreotide peptide. Biophys Chem. 2008;138(3):83-90. doi:10.1016/j.bpc.2008.09.005

332. Javier DJ, Castellanos-Gonzalez A, Weigum SE, White AC, Richards-Kortum R. Oligonucleotide-gold nanoparticle networks for detection of cryptosporidium parvum heat shock protein 70 mRNA. J Clin Microbiol. 2009;47(12):4060-4066. doi:10.1128/ JCM.00807-09

333. Rink JS, McMahon KM, Chen X, Mirkin CA, Thaxton CS, Kaufman DB. Transfection of pancreatic islets using polyvalent DNA-functionalized gold nanoparticles. Surgery. 2010;148 (2):335-345. doi:10.1016/j.surg.2010.05.013

334. Kim JH, Jang HH, Ryou SM, et al. A functionalized gold nanoparticles-assisted universal carrier for antisense DNA. ChemComm. 2010;46(23):4151-4153. doi:10.1039/c0cc00103a

335. Lee JS, Green JJ, Love KT, Sunshine J, Langer R, Anderson DG. Gold, poly( $\beta$-amino ester) nanoparticles for small interfering RNA delivery. Nano Lett. 2009;9(6):2402-2406. doi:10.1021/ n19009793

336. Giljohann DA, Seferos DS, Prigodich AE, Patel PC, Mirkin CA. Gene regulation with polyvalent siRNA-nanoparticle conjugates. J Am Chem Soc. 2009;131(6):2072-2073. doi:10.1021/ja808719p

337. Akinyelu J, Singh M. Folate-tagged chitosan-functionalized gold nanoparticles for enhanced delivery of 5-fluorouracil to cancer cells. Appl Nanosci. 2019;9(1):7-17. doi:10.1007/s13204-0180896-4
International Journal of Nanomedicine

\section{Publish your work in this journal}

The International Journal of Nanomedicine is an international, peerreviewed journal focusing on the application of nanotechnology in diagnostics, therapeutics, and drug delivery systems throughout the biomedical field. This journal is indexed on PubMed Central, MedLine, CAS, SciSearch ${ }^{\mathbb{R}}$, Current Contents ${ }^{\mathbb{B}} /$ Clinical Medicine, $^{2}$

\section{Dovepress}

Journal Citation Reports/Science Edition, EMBase, Scopus and the Elsevier Bibliographic databases. The manuscript management system is completely online and includes a very quick and fair peer-review system, which is all easy to use. Visit http://www.dovepress.com/ testimonials.php to read real quotes from published authors. 